\title{
DEVELOPMENT OF A CANDLE FILTER FAILURE SAFEGUARD DEVICE FINAL REPORT
}

Report Period Start Date: September 20, 1999

Report Period End Date: June 20, 2002

\begin{abstract}
G. J. BRUCK, E. E. SMELTZER, Z. N. SANJANA, SWPC, PITTSBURGH, PA
\end{abstract}

June 6, 2002

DOE Award No. DE-AC26-99FT40199 


\section{DISCLAIMER}

"This report was prepared as an account of work sponsored by an agency of the United States

Government. Neither the United States Government nor any agency thereof, nor any of their employees, makes any warranty, express or implied, or assumes any legal liability or responsibility for the accuracy, completeness, or usefulness of any information, apparatus, product, or process

disclosed, or represents that its use would not infringe privately owned rights. Reference herein to any specific commercial product, process, or service by trade name, trademark, manufacturer, or otherwise does not necessarily constitute or imply its endorsement, recommendation, or favoring by the United States Government or any agency thereof. The views and opinions of authors expressed herein do not necessarily state or reflect those of the United States Government or any agency thereof." 


\title{
DEVELOPMENT OF A CANDLE FILTER FAILURE SAFEGUARD DEVICE FINAL REPORT
}

\begin{abstract}
Development, testing and optimization of advanced metal and ceramic, barrier and fiber safeguard devices (SGDs) is described. Metal barrier devices are found prone to manufacturing defects and premature blinding. Fiber devices are found to be satisfactory if fine fibers are used. Durable alloys are identified for both oxidation and gasification conditions.

Ceramic honeycomb SGDs were found to perform as excellent barrier devices. Optimization has shown such devices to be durable. Field testing of ceramic honeycomb SGDs from two different manufacturers is being pursued.
\end{abstract}




\section{TABLE OF CONTENTS}

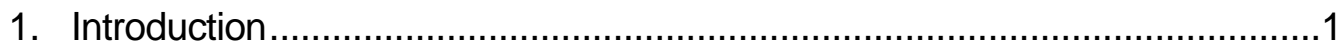

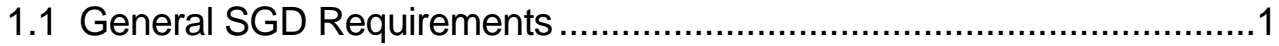

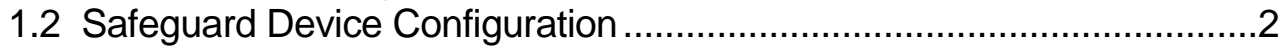

1.3 Active vs. Passive SGD .................................................................

1.4 SGD Pressure Drop and Gas Flow Capacity ......................................

1.5 Particle Removal and Response Time................................................

1.6 SGD Fixturing and Gasket Needs ………………………………...

1.7 Required SGD Life and Gas Environment...........................................

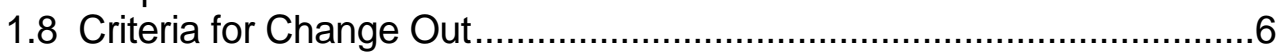

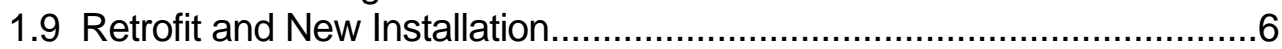

1.10 Maximum DP Criterion for SGD Screening ……………………......

1.11 Cross Flow Barrier SGD ...............................................................

1.11.1 Detailed Design of Cross Flow Barrier ….................................7

1.11.2 Mechanism/Principle of Operation of Cross Flow Barrier ............7

1.11.3 Projected Performance of Cross Flow Barrier and PermeabilityScreening Results ..................................................

1.12 Inverted Metal Filter Barrier SGD ………......................................10

1.12.1 Detailed Design of Inverted Metal Filter Barrier..........................10

1.12.2 Mechanism/Principle of Operation of Inverted Metal Filter Barrier.......................................................................10

1.12.3 Projected Performance of Inverted Metal Filter Barrier and Permeability Screening Results...............................................10

1.13 Nested Fiber Impaction SGD ……..............................................10

1.13.1 Detailed Design of Nested Fiber SGD …………....................10

1.13.2 Mechanism/Principle of Operation of Nested Fiber SGD ............10

1.13.3 Permeability Screening Results and Performance of Nested Fiber SGD .......................................................................11

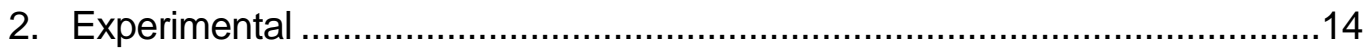

2.1 NETL Equipment and Modifications ...................................................14

2.2 STC Equipment and Modifications.......................................................14

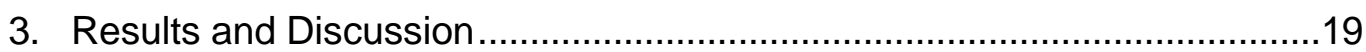

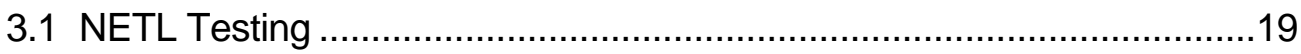

3.1.1 Experimental Approach........................................................19

3.1.2 Sample Procurement..............................................................20

3.1.3 NETL Tests 1 and $3-316$ SS and SiC Honeycomb Barrier.........20

3.1.4 NETL Test 2 - 316 SS Inverted Filter Barrier ...............................22

3.1.5 NETL Tests 4 and 5 - Coarse and Fine Fiber SGDs...................24

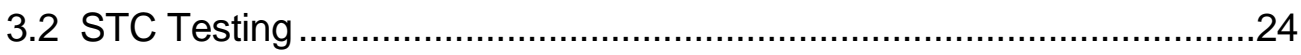

3.2.1 Experimental Approach.........................................................24

3.2.2 STC Test 1 - 316 SS Honeycomb Barrier …………………......25

3.2.3 STC Test 2 - SiC Honeycomb Barrier ......................................27

3.2.4 STC Tests 3, 4, and 5 - Coarse 310 Stainless Steel, Fine Alloy 214, And Fine FeCrAlY Fiber.....................................30

3.2.5 STC Test 6 - Optimization - Four Silicon Carbide Honeycomb SGDs...............................................................

3.2.6 STC Test 7 - Optimization - Three Silicon Carbide 


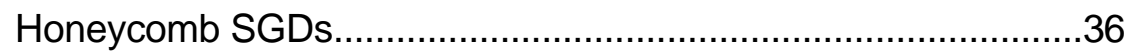

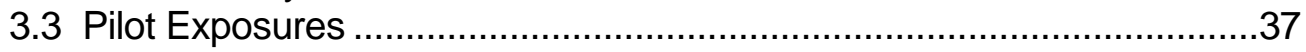

3.3.1 Introduction and Material Selection ............................................37

3.3.2 Equipment Arrangement and Description of Exposure ..................37

3.3.3 Results of Examination for 310 Fiber - Unexposed and Oxidizing ............................................................................. 41

3.3.4 Results of Examination for 230 Fiber - Unexposed and

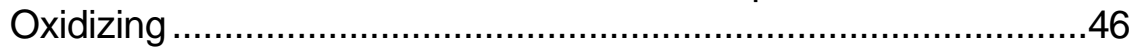

3.3.5 Results of Examination for 214 Fiber - Unexposed and Oxidizing .............................................................................51

3.3.6 Results of Examination for FeCrAlY Fiber - Unexposed and Oxidizing ...........................................................................

3.3.7 Results of Examination for 310 Fiber - Unexposed and

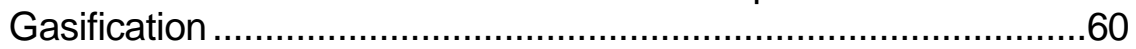

3.3.8 Results of Examination for 160 Fiber - Unexposed and

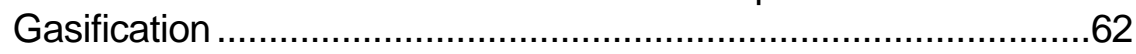

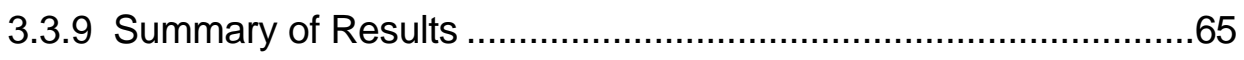

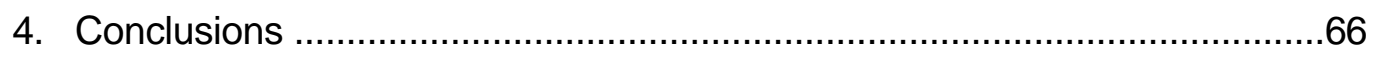

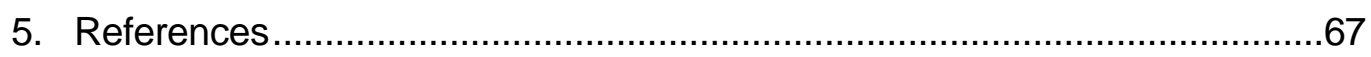




\section{LIST OF TABLES}

Table 1.1-1 - SGD Technical and Application Requirements .............................

Table 1.5-1 - Summary of Turbine Tolerance to Particle Deposition ...................4

Table 1.11.3-1 - Permeability of Specific Surface SiC Honeycomb ..................9

Table 1.13.3-1 - Permeability of Failsafes Using Wire Pieces and SCS Standard..........................................................................11

Table 3.1.1-1 - NETL Test Arrangements, Conditions and Exposures ..............19

Table 3.1.2-1 - Summary of Flow Resistance...................................................20

Table 3.1.3-1 - 316 SS and SiC SGDs Exposed at NETL...............................21

Table 3.1.4-1 - Inverted Filter SGD Exposed at NETL ......................................23

Table 3.2.1-1 - STC Test Arrangements, Conditions and Exposures ................25

Table 3.2.2-1 - Differential Pressure Comparison for 316 SS Honeycomb

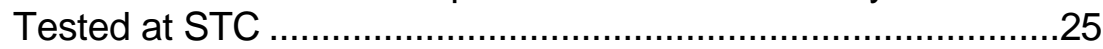

Table 3.2.3-1 - Differential Pressure Comparison for SiC Honeycomb

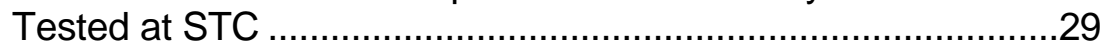

Table 3.3.1-1 - Materials for Oxidation Exposure ..............................................37

Table 3.3.1-2 - Materials for Gasification Exposure ..........................................37

Table 3.3.2-1 - Fibers and Fiber Geometry for Oxidation Exposure....................38

Table 3.3.2-2 - Positions, SGD IDs and Fiber Descriptions for Gasification

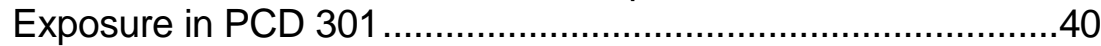

Table 3.3.2-3 - Hours at Temperature in the PCD at Wilsonville........................40

Table 3.3.9-1 - Summary of Oxidation Results................................................65

Table 3.3.9-2 - Summary of Gasification Results .............................................65 


\section{LIST OF FIGURES}

Figure 1.2-1 - Representation of Siemens Westinghouse Approach.................3

Figure 1.6-1 - Current Siemens Westinghouse SGD and Candle Fixturing.......5

Figure 1.11.2-1 - First Subscale SiC Cross Flow Prototype ............................8

Figure 1.11.3-1 - Permeability of Specific Surface SiC Honeycomb for Failsafe - 10/99 9

Figure 1.13.3-1 - Permeability of Failsafes Using Wire Pieces and SCS Standard.

Figure 1.13.3-2 - Comparison of Standard Fine Mesh and Nested Fiber Safeguard Device Performance.

Figure 2.1-1 - Modified NETL Hardware for Honeycomb SGD Testing ...............15

Figure 2.1-2 - Modified NETL Hardware for Inverted Filter SGD Testing .............16

Figure 2.1.3 - Modified NETL Hardware for Fiber SGD Testing.........................17

Figure 2.2-2 - Modified STC Hardware for Honeycomb Barrier SGDs...............18

Figure 3.1.2-1 - Plexiglas Fixture for Gasket Evaluation ...................................21

Figure 3.1.3-1 - Type 316 Stainless Honeycomb SGC after NETL Test............22

Figure 3.1.3-2 - SiC Honeycomb Unit after NETL Exposure ............................23

Figure 3.2.2-1 - Outlet Dust Concentration During Dust Feed for 316 SS

Honeycomb Cross-Flow Safeguard Device...........................26

Figure 3.2.2-2 - 316 SS Honeycomb SGD after STC Testing .........................27

Figure 3.2.3-1 - Flowtube DP During First 6 Dust Feed Cycles for SiC Honeycomb Cross-Flow Safeguard Device...........................28

Figure 3.2.3-2 - SiC Honeycomb SGD after STC Testing ................................29

Figure 3.2.4-1 - Flowtube DP During First 5 Dust Feed Cycles for Coarse 310 SS Fiber Safeguard Device....

Figure 3.2.5-1 - Cross Section of Specific Surface SGD Showing Integral Channel Plugs. .32

Figure 3.2.5-2 - Ceramic Silicon Carbide Honeycomb SGDs for Optimization Testing .32

Figure 3.2.5-3 - Specific Surface New Material. 33

Figure 3.2.5-4 - Specific Surface Fully Recrystallized ....................................33

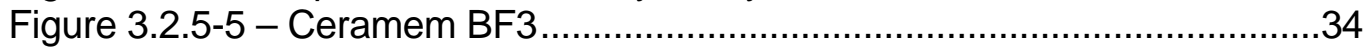

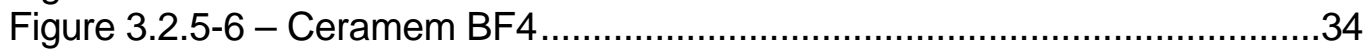

Figure 3.2.5-7 - Plugged Inlet End of Ceramem Unit BF4 ...............................35

Figure 3.2.5-8 - Clean Outlet End of Plugged Ceramem Unit BF4 ....................36

Figure 3.3.2-1 - Modules for Oxidizing Exposure .............................................38

Figure 3.3.2-2 - SGDs for Gasification Exposure ...........................................39

Figure 3.3.3-1 - SEM of Unexposed Alloy 310 Fiber Cross Section ....................41

Figure 3.3.3-2 - SEM of Unexposed Alloy 310 Fiber Cross Section ....................41

Figure 3.3.3-3 - Surface (spot 1), Matrix (spot 2) and Precipitates

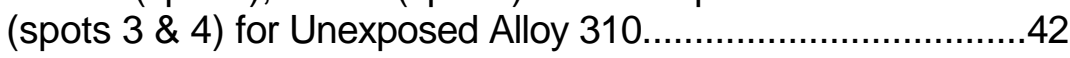

Figure 3.3.3-4 - EDAX Analysis of Matrix and Precipitate in Unexposed

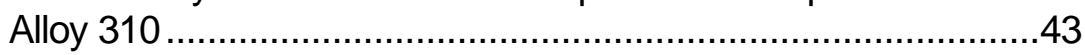

Figure 3.3.3-5 - SEM of Exposed Alloy 310 Fiber Cross Section ......................44

Figure 3.3.3-6 - SEM of Exposed Alloy 310 Fiber Cross Section ........................44

Figure 3.3.3-7 - Surface Oxide (spot 1), and Internal but Connected

Oxides (spots 2, and 3) and Subsurface Oxides (spot 4)

for Exposed Alloy 310 Fiber

Figure 3.3.3-8 - EDAX Analysis of Exposed Alloy 310 Fiber 
Figure 3.3.4-1 - SEM of Unexposed Alloy 230 Fiber Cross Sections .................46

Figure 3.3.4-2 - SEM of Unexposed Alloy 230 Fiber Cross Sections .................46

Figure 3.3.4-3 - Matrix (area 1) and Precipitate (spot 2) for Unexposed Alloy 230 .....

Figure 3.3.4-4 - EDAX Analysis of Matrix and Precipitate in Unexposed Alloy 230.

Figure 3.3.4-5 - SEM of Exposed Alloy 230 Fiber Cross Sections

Figure 3.3.4-6 - SEM of Exposed Alloy 230 Fiber Cross Section

Figure 3.3.4-7 - Surface Oxide (spots 1 and 2), Matrix (spot 3), Internal Oxide (spot 4) and Precipitate (spot 5) for Exposed Alloy 230 Fiber

Figure 3.3.4-8 - EDAX Analysis of Exposed Alloy 230 Fiber....

Figure 3.3.5-1 - SEM of Unexposed Alloy 214 Fiber Cross Section ....................51

Figure 3.3.5-2 - SEM of Unexposed Alloy 214 Fiber Cross Section ....................51

Figure 3.3.5-3 - Matrix, Near Surface (spot 1) and Matrix - Subsurface

(spot 2) for Unexposed Alloy 214 .......................................52

Figure 3.3.5-4 - EDAX Analysis of Matrix in Unexposed Alloy 214 .....................52

Figure 3.3.5-5 - SEM of Exposed Alloy 214 Fiber Cross Section .........................53

Figure 3.3.5-6 - SEM of Exposed Alloy 214 Fiber Cross Section ...........................53

Figure 3.3.5-7 - Surface Oxide (spots 1 and 2), Precipitate (spot 3) and Matrix (spots 4 and 5) for Exposed Alloy 214 Fiber ...................54

Figure 3.3.5-8 - EDAX Analysis of Exposed Alloy 214 Fiber...............................55

Figure 3.3.6-1 - SEM of Unexposed FeCrAIY Alloy Fiber Cross Section.............56

Figure 3.3.6-2 - SEM of Unexposed FeCrAIY Alloy Fiber Cross Section.............56

Figure 3.3.6-3 - EDAX Analysis of Matrix in Unexposed FeCrAl Alloy..................57

Figure 3.3.6-4 - SEM of Exposed FeCrAIY Alloy Fiber Cross Section.................57

Figure 3.3.6-5 - SEM of Exposed FeCrAIY Alloy Fiber Cross Section.................58

Figure 3.3.6-6 - Surface Oxide (spot 1), Internal Oxide (spot 2) and Matrix (spots 3 and 4) for Exposed FeCrAlY Alloy Fiber...........58

Figure 3.3.6-7 - EDAX Analysis of Exposed FeCrAIY Alloy Fiber ........................59

Figure 3.3.7-1 - SEM of Unexposed Alloy 310 Fiber Cross Section ....................60

Figure 3.3.7-2 - SEM of Unexposed Alloy 310 Fiber Cross Sections .................60

Figure 3.3.7-3 - SEM of Gasification Exposed Alloy 310 Fiber Cross

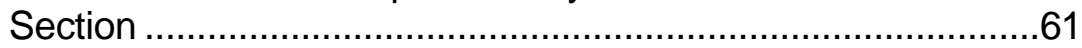

Figure 3.3.7-4 - EDAX Analysis of Exposed Alloy 310 Fiber ............................61

Figure 3.3.8-1 - SEM of Unexposed Alloy 160 Fiber Cross Section ....................62

Figure 3.3.8-2 - SEM of Unexposed Alloy 160 Fiber Cross Section ...................62

Figure 3.3.8-3 - EDAX Analysis of Unexposed Alloy 160 .................................63

Figure 3.3.8-4 - SEM of Gasification Exposed Alloy 160 Fiber Cross Section ......................................................................63

Figure 3.3.8-5 - SEM of Gasification Exposed Alloy 160 Fiber Cross Section .........................................................................64

Figure 3.3.8-6 - EDAX Analysis of Exposed Alloy 160 Fiber..............................64 


\section{INTRODUCTION}

The candle filter failure safeguard device (SGD) development included conceptual design and screening of advanced concepts, proof-of-concept testing utilizing in-house and DOE/FETC bench scale test facilities, pilot plant testing, and deployment and demonstration of the developed SGD. All elements of the program and plan were structured to meet a 21 -month program schedule.

In the current program, Siemens Westinghouse developed a passive compact SGD, designed and configured as an independent component, which was located at the outlet of each candle element. This approach is preferred since:

- It provides maximum protection to all downstream components, including other operating, intact candle elements.

- It is maintainable, replaceable, and leads to the lowest cost alternative.

The following two SGD concept approaches were evaluated by initial screening and bench-scale testing:

- A unique, low-cost Nested Metal Fiber design.

- A high-performance, barrier device fabricated as a ceramic or metal cross flow and as an inverted miniature array of metal candles.

Siemens Westinghouse worked with Specific Surface, Ceramem and Mott Corporation to design and supply the barrier SGD concepts.

\subsection{General SGD Requirements}

Siemens Westinghouse is developing Hot Gas Filter (HGF) Systems for commercial, advanced power generation systems. The corporation has supplied systems into various pilot plant test and demonstration programs - e.g., SCS (PSDF) and SPPC (Pinon Pine). Advanced, filter safeguard devices are needed in these and future HGF systems to ensure plant availability and to meet the stringent requirements of today's advanced gas turbine engines. Siemens Westinghouse conducted this 21-month technical program to develop an advanced SGD, capable of meeting all application requirements and the deployment of this technology into all existing and new HGF systems.

This program utilized the lessons learned from our ongoing operating and test experience to identify specific technical and application requirements. Table 1.1-1 identifies the key SGD requirements and outlines how they were evaluated in our program. 


\section{Table 1.1-1 - SGD Technical and Application Requirements}

Over 15,000 hours of HGF test experience has helped to identify and focus our SGD development requirements. Our program was structured to address the key technology and market driver issues.

\begin{tabular}{|l|l|l|}
\hline $\begin{array}{l}\text { Technical and Application } \\
\text { Requirements }\end{array}$ & \multicolumn{1}{|c|}{$\begin{array}{c}\text { Selected Approach or } \\
\text { Parameter Values }\end{array}$} & \multicolumn{1}{|c|}{$\begin{array}{c}\text { How Addressed in SGD } \\
\text { Program }\end{array}$} \\
\hline Device Configuration & $\begin{array}{l}\text { Per Candle as Preferred } \\
\text { Solution }\end{array}$ & Not Varied, See Below \\
\hline Active vs. Passive & $\begin{array}{l}\text { Passive as Preferred } \\
\text { Solution }\end{array}$ & Not Varied, See Below \\
\hline $\begin{array}{l}\text { Pressure Drop and Gas } \\
\text { Flow Capacity }\end{array}$ & $\begin{array}{l}20 \% \text { of HGF Maximum DP } \\
10 \text { to } 100 \text { acfm }\end{array}$ & Bench-Scale Testing \\
\hline $\begin{array}{l}\text { Particle Removal and } \\
\text { Response Time (Maintained } \\
\text { Over Repeated Cleaning } \\
\text { Cycles) }\end{array}$ & $<0.5$ ppmw leak & Bench-Scale Testing \\
\hline Fixturing and Gaskets & $\begin{array}{l}\text { Reliable, Stable and No } \\
\text { Leaks }\end{array}$ & $\begin{array}{l}\text { Bench-Scale Testing and Pilot } \\
\text { Plant Exposure }\end{array}$ \\
\hline $\begin{array}{l}\text { Effective Operating Life and } \\
\text { Gas Environment }\end{array}$ & $\begin{array}{l}>3 \text { years } \\
\text { Reducing } 1200^{\circ} \mathrm{F} \text { (IGCC) } \\
\text { Oxidizing, 1600 }{ }^{\circ} \mathrm{F} \text { (APCFB) }\end{array}$ & $\begin{array}{l}\text { Material Exposure in Operating } \\
\text { Pilot Plants (PSDF) and } \\
\text { laboratory furnace }\end{array}$ \\
\hline Change-Out & $\begin{array}{l}\text { Quick, No Extension of } \\
\text { Maintenance Period }\end{array}$ & Pilot Plant Experience \\
\hline $\begin{array}{l}\text { Retrofit/New Installations } \\
\text { (Reusable) }\end{array}$ & $\begin{array}{l}\text { Meet Physical Constraints } \\
\text { 3" long and 2.65" OD } \\
\text { (Retrofit) } \\
\text { <12" long and 2.65" OD } \\
\text { (New) }\end{array}$ & $\begin{array}{l}\text { Design Phase, Demonstrated in } \\
\text { Pilot Plant Testing }\end{array}$ \\
& \multicolumn{2}{|c|}{} \\
\hline
\end{tabular}

\subsection{Safeguard Device Configuration}

Figure 1.2-1 illustrates the general SGD configuration. The Siemens Westinghouse approach was to configure the SGD as an independent component located at the outlet of each filter element. This isolates a damaged or degraded filter element, or an element with leaking seals, from all downstream hardware and from the other properly functioning filter elements.

An alternative configuration is to place a backup hot gas filter system in series with the primary hot gas filter system to provide protection for the gas turbine, and other downstream equipment, from primary filter system particulate leaks. Such a backup is not preferred because it will not prevent the internal components within the primary hot gas filter unit from being contaminated by particulate, leading to, for example, blinding of the clean-side of the undamaged filter elements. Occurrence of such "back side" blinding could in fact cause earlier shutdown (loss of availability) and unnecessary costs to replace an even larger number of otherwise undamaged candle elements. The 
backup hot gas filter configuration is also expected to result in greater total system pressure drop and cost than the use of individual SGDs.

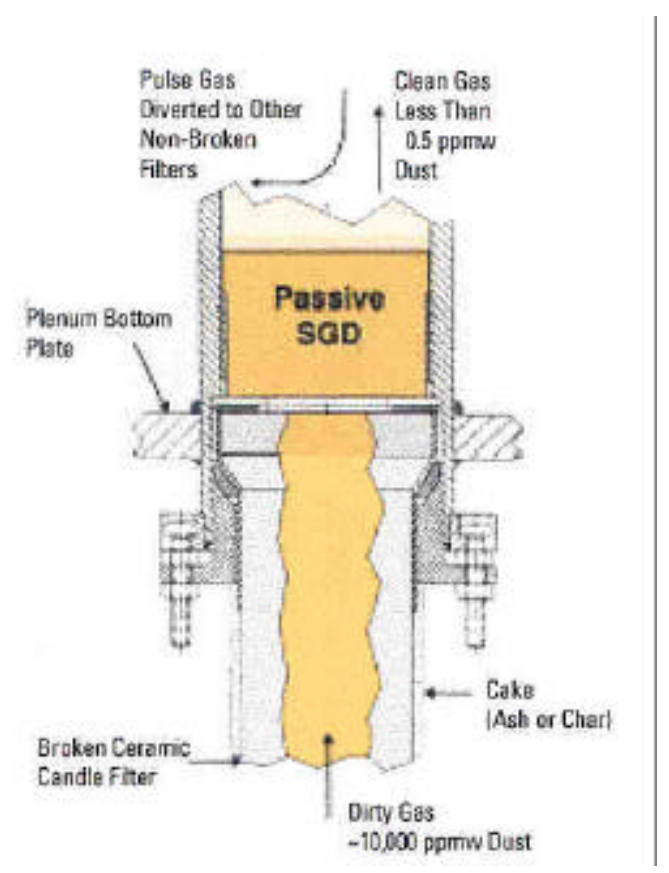

Figure 1.2-1 - Representation of Siemens Westinghouse Approach. As an independent component located at the outlet of each candle, the SGD provides maximum protection to all downstream components and is easily maintained.

\subsection{Active vs. Passive SGD}

Siemens Westinghouse chose a passive SGD approach, limiting the penetration of particulate by inherent phenomena that requires no leak detection or external device activation. A barrier filter SGD is an example of a passive SGD. The SGD could also be an active device, requiring some sort of leak detection, or leak triggering phenomena to automatically activate the SGD particulate penetration control. A valve activated by detecting a sudden increase in gas flow through the SGD is an example of an active SGD. Active devices such as valves will require grouping a relatively large number of candle elements per valve set. When activated, this will result in the removal from service of undamaged candle elements, resulting in higher operating pressure drops, more frequent cleaning, and the need to shut down sooner. Also, undamaged candle elements in the activated grouping will suffer back-side blinding and will need to be replaced. The passive SGD is also favored because of greater reliability, expected less complex design and lower cost, and the possibility of active SGD being triggered in error.

\subsection{SGD Pressure Drop and Gas Flow Capacity}

In general, the clean SGD should handle the maximum gas flow from a single ceramic filter element with an acceptable SGD pressure drop. Hot gas filter systems are being 
designed with operating face velocities ranging from 3 to $10 \mathrm{ft} / \mathrm{min}$, depending on IGCC or APCFB applications. The SGD under normal operation must therefore handle volumetric gas flows from 10 to 30 acfm for current 1.5-meter candles and to 100 acfm for future 3meter candles without significant pressure drop penalty. The higher the normal, clean pressure drops of the SGD, the greater is the penalty to the ceramic filter system (higher baseline system pressure drop, higher pulse cleaning frequency). Based on our system studies, the SGD pressure drop should be less than about $20 \%$ of the total hot gas filter system baseline pressure drop.

SGD pressure drop is a key parameter in our design specification and was measured in the bench scale test program. Cold flow permeability tests (covering 10 to $100 \mathrm{acfm}$ ) were conducted on each device, for screening evaluation. Hot flow testing confirmed operating pressure drop both before and after activation. This data was complemented by directly measuring how the gas flow through the SGD changes once activated.

\subsection{Particle Removal and Response Time}

SWPC has made detailed estimates of gas turbine performance degradation due to particle erosion and deposition. In IGCC and Advanced-PFBC, the gas turbine performance will degrade most significantly from the effects of particles that penetrate the hot gas filter system and deposit on the first and second stage vanes and blades. This dominance of deposition is due to the high firing temperatures of the gas turbine in these two advanced power generation systems. In PFBC, with its low turbine inlet temperature, the turbine power might degrade both from the particle erosion and deposition, depending on the size distribution of the particles that penetrates the hot gas filter system. Particles greater than 5-10 $\mu \mathrm{m}$ in diameter are most likely to cause airfoil erosion, whereas, in PFBC, deposition is dominated by particles less than $2 \mu \mathrm{m}$. According to SWPC estimates of particle deposition damage, a large leak from the hot gas filter system of $100 \mathrm{ppmw}$, with $25 \%$ of the particles being greater than $5 \mu \mathrm{m}$ in diameter, would degrade the gas turbine power $10 \%$, requiring shut down of the turbine for water wash in 40-80 hours in IGCC, and in about 200 hours in PFBC. A smaller filter leak of 5 ppmw, with $25 \%$ of the particles being greater than $5 \mu \mathrm{m}$ in diameter, will require turbine water wash in 600-1600 hours in IGCC, and in about 2,300 hours in PFBC. Particle penetration of 0.5 ppmw can be tolerated for $6,000-16,000$ hours before water wash is required in these applications.

Table 1.5-1 summarizes results of turbine tolerance modeling and shows predicted operating times between water wash frequency needed to remove deposited particulate. An SGD capable of limiting particle leakage to $<0.5$ ppmw will be needed to achieve highest system availability, commensurate with annual maintenance outage.

Table 1.5-1 - Summary of Turbine Tolerance to Particle Deposition

\begin{tabular}{|l|l|l|l|l|}
\hline $\begin{array}{c}\text { Hot Gas Filter } \\
\text { Leak }\end{array}$ & \multicolumn{1}{c|}{ IGCC } & \multicolumn{1}{c|}{ PFBC } & \multicolumn{1}{c|}{ APCFB } & SGD Technology \\
\hline $\begin{array}{l}1000 \text { ppmw } \\
25 \%>5 \text { micron }\end{array}$ & 80 hours & 200 hours & 80 hours & No SGD \\
\hline $\begin{array}{l}5 \text { ppmw } \\
25 \%>5 \text { micron }\end{array}$ & 1600 hours & 2300 hours & 1600 hours & Today's SGD \\
\hline
\end{tabular}




\begin{tabular}{|l|l|l|l|l|}
\hline $\begin{array}{l}0.5 \text { ppmw } \\
25 \%>5 \text { micron }\end{array}$ & $>16,000$ hours & $>16,000$ hours & $>16,000$ hours & Future SGD \\
\hline
\end{tabular}


Our advanced SGD concepts were selected to achieve the goal of $>16,000$ hours cleaning interval. Our bench-scale test program was designed to quantify SGD performance during both the initial "plugging" transient and then over extended pulsecleaning cycles. SGD performance was evaluated under two distinct failure criteria; simulating "nominal" candle element failures (10\% or less) and simulating "catastrophic" damage ( $>30 \%$ failed elements). The "nominal" criteria would represent what might be expected during early candle material development (infant mortality) or perhaps the twosigma end of a normal life distribution curve as the candle elements age. The "catastrophic" criteria correspond to an unplanned process upset that might occur during initial start-up and operator training. Both "nominal" and "catastrophic" failure scenarios were evaluated using existing Siemens Westinghouse high-temperature high-pressure (HTHP) filter test facilities in Pittsburgh. In a parallel activity, the DOE/FETC three-candle facility was utilized to initially screen various SGDs.

\subsection{SGD Fixturing and Gasket Needs}

Primary concerns with such fixturing and gasketing include:

- Long-term functional stability of the ring gasket between safeguard device and metal hardware - especially during back-pulse cleaning of the filter.

- Positional stability of the top donut gasket between filter and safeguard device also of special concern during back-pulse cleaning.

The current Siemens Westinghouse configuration of a safeguard device and candle fixturing is showing Figure 1.6-1. Two gaskets represent primary seals - first, a ring gasket seal (e.g., Fiberfrax) between the bottom metal ring of the safeguard device and the counterbore metal seat of the filter element holder, and second, a top donut gasket (e.g., Nextel fabric with (MM) mat filler) between the top flange of the ceramic or metal filter and the bottom metal ring of the safeguard device. A sleeve and bottom donut are used as a cushion or interface between the bottom metal clamp and the underside of the top flange of the filter. The sleeve and bottom donut are not, however, utilized as dust seals.

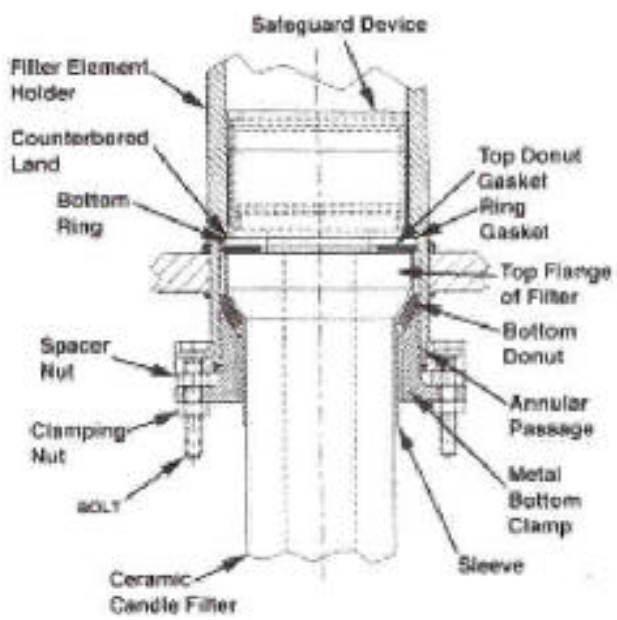

Figure 1.6-1 - Current Siemens Westinghouse SGD and Candle Fixturing 
Our field test experience has identified necessary improvements to SGD fixturing and gaskets that will enable more reliable and effective seals. This includes eliminating the Fiberfrax ring and replacing it with a more robust Nextel gasket. The effectiveness of the SGD fixturing and gaskets were addressed in our bench-scale test program and were evaluated as part of the pilot plant materials exposure activities.

\subsection{Required SGD Life and Gas Environment}

The SGD life should exceed, or at least equal, the normal, expected life of the ceramic or metal filter elements, which is three years.

Operating in either reducing or oxidizing hot gas environments, the SGD may degrade due to corrosion, thermal shock and fatigue, and mechanical stresses and wear from pulse cleaning. In addition, submicron and aerosol particles potentially passing through the filter element could adversely impact SGD flow permeability. SGD units were included at the SCS Power System Development Facility (PSDF) to acquire reducing gas exposure and in a STC laboratory furnace to acquire oxidizing gas exposure, to gain an understanding of these potential issues. Additional exposures were planned at Pinon Pine. Units were provided, however operation at Pinon was discontinued. This test experience allows exposure to both oxidizing and reducing gas streams.

\subsection{Criteria for Change Out}

When ceramic filter elements are removed from service by the SGD, the hot gas filter system's face velocity, pressure drop, and pulse-cleaning frequency will rise until a practical limit is reached (excessive gas pressure drop or temperature drop, excessive pulse gas consumption, or pulse frequency exceeding pulse system capabilities). At this limit, the hot gas filter system must be shut down and the defective ceramic filter elements and gaskets replaced. In a typical IGCC system, $20 \%$ of the filter elements may be removed from service before the plant must be shut down, and in a typical PFBC system, $10 \%$ may be removed from service. Proper design must permit such filter maintenance to take place during a scheduled maintenance period. By keeping the SGD as a compact, self-contained unit that is positioned above a candle element, it can be easily accessed and changed when the failed candle element is replaced. This has been demonstrated with our current SGD in field application. The development of an advanced SGD retained this key maintenance feature.

\subsection{Retrofit and New Installation}

Safeguard improvements under development by Siemens Westinghouse were designed, where practical, to retrofit into currently existing Siemens Westinghouse filter support hardware. The design of the SGD for an existing hot gas filter system must accommodate the available space and sealing capabilities of the existing filter element support configuration. A new hot gas filter system can be designed with features to optimize the installation and performance of the SGD, including larger sizes (longer lengths) to accommodate retrofit.

In the Base Program new SGDs were designed to fit into operating HGF field units for material exposure purposes. 


\subsection{Maximum DP Criterion for SGD Screening}

If PFBC and IGCC are both considered to be applications of equal interest, and if a single safeguard device design is to be developed for all applications, then the maximum pressure drop across the safeguard device should be based on PFBC applications. This is because PFBC has lower acceptable filter system pressure drop than IGCC applications, and PFBC is expected to operate with a greater gas volumetric flow per safeguard device than for IGCC.

The maximum PFBC filter system pressure drop in PFBC applications is normally specified to be about 5 psi, or lower, which is about $2.5 \%$ of the absolute gas inlet pressure to the filter vessel. At this maximum, or "trigger" pressure drop the "average" pressure drop across the filter vessel would be about 4 psi. The filter vessel pressure drop represents a direct efficiency penalty to the PFBC power plant and an increased cost-of-electricity factor, so it is important to keep it at an acceptable level. While arbitrary, a maximum safeguard device pressure drop contribution of $20 \%$ of the filter vessel maximum pressure drop would seem to be reasonable. This criterion results in a maximum acceptable safeguard device pressure drop of about $1 \mathrm{psi}$, which corresponds to about $25 \%$ of the average filter vessel pressure drop. This maximum should correspond to the maximum volumetric flow expected through a standard $1.5-\mathrm{m}$ candle in PFBC and, based on a 10-ft/min-face velocity, the corresponding volumetric flow would be about $30 \mathrm{acfm}$. This criterion functioned to identify if a safeguard device was in the range of acceptability or if it required design modifications to approach acceptable pressure drop performance.

Vendor tests of the safeguard device and our own initial characterization tests were in air at room temperature and atmospheric pressure. Assuming that the safeguard device pressure drop is controlled by viscous losses, with inertial losses being negligible, the maximum pressure drop should be given by the ratio of the gas viscosity of air at room temperature (about $1.24 \times 10-5 \mathrm{lb} / \mathrm{ft}-\mathrm{s}$ ) to that a PFBC combustion gases at $843^{\circ} \mathrm{C}$ $\left(1550^{\circ} \mathrm{F}\right)$ (about $\left.3 \times 10-5 \mathrm{lb} / \mathrm{ft}-\mathrm{s}\right)$, or

$$
\mathrm{DP}(\max )=28(1.24 / 3)=12 \mathrm{iwg} \text { at an airflow of } 30 \mathrm{scfm}
$$

Additional tests were performed (by the vendor and by STC) over a wide range of gas flows, to check on the inertial losses characteristic of the safeguard device. Inertial losses would result in higher safeguard device pressure drop in the actual, pressurized application than expected by the simple atmospheric pressure testing.

\subsection{Cross Flow Barrier SGD}

\subsubsection{Detailed Design of Cross Flow Barrier}

Design details are SWPC proprietary. This section and Figure B-1 are found in the Proprietary Appendix B of the Topical Report, Task 1, Conceptual Design.

\subsubsection{Mechanism/Principle of Operation of Cross Flow Barrier}

The cross flow, honeycomb structure (see Figure1.11.2-1) was made of porous metal or ceramic that is permeable for gas but impermeable for particulates. Adjacent channels 
are alternately sealed at opposing ends to create the cross flow path. In the unactivated condition, sufficient surface area and material permeability are required for low pressure drop. In the event of filter element or gasket failure, particulate would plug the upstream channels. Back pulsing may partially dislodge channels, but since it is a barrier device, leakage of particulate to the clean side would not occur.

\subsubsection{Projected Performance of Cross Flow Barrier and Permeability Screening Results}

An initial study was made to develop a SGD design that would project a performance of 1 psi differential pressure (20 percent of the filter vessel maximum pressure drop) at $1550^{\circ} \mathrm{F}, 150 \mathrm{psig}$, and 10 feet per minute face velocity (30 acfm volumetric flow). The design assumed material of $2.13 \times 10^{-12}$ square foot channel wall flow resistance (5 to 10 percent of candle filter flow resistance). A geometry that would satisfy these requirements and fit inside of the $25 / 8$ inch diameter envelope of current fail-safes, would have $2 \mathrm{~mm}$ by $2 \mathrm{~mm}$ channels of $1 \mathrm{~mm}$ wall thickness and 6 inch length. The unit would have a filter area of 1.9 square feet.

While Specific Surface expressed difficulty in recrystallizing the structure, they were able to provide the first subscale prototype made of unrecrystallized silicon carbide. (See Figure 1.11.2-1) The unit measured 2 inches in diameter by 2 inches in length with $4 \mathrm{~mm}$ by $4 \mathrm{~mm}$ channels and $1 \mathrm{~mm}$ wall thickness. The resulting filter area of this first unit was 0.26 square feet.

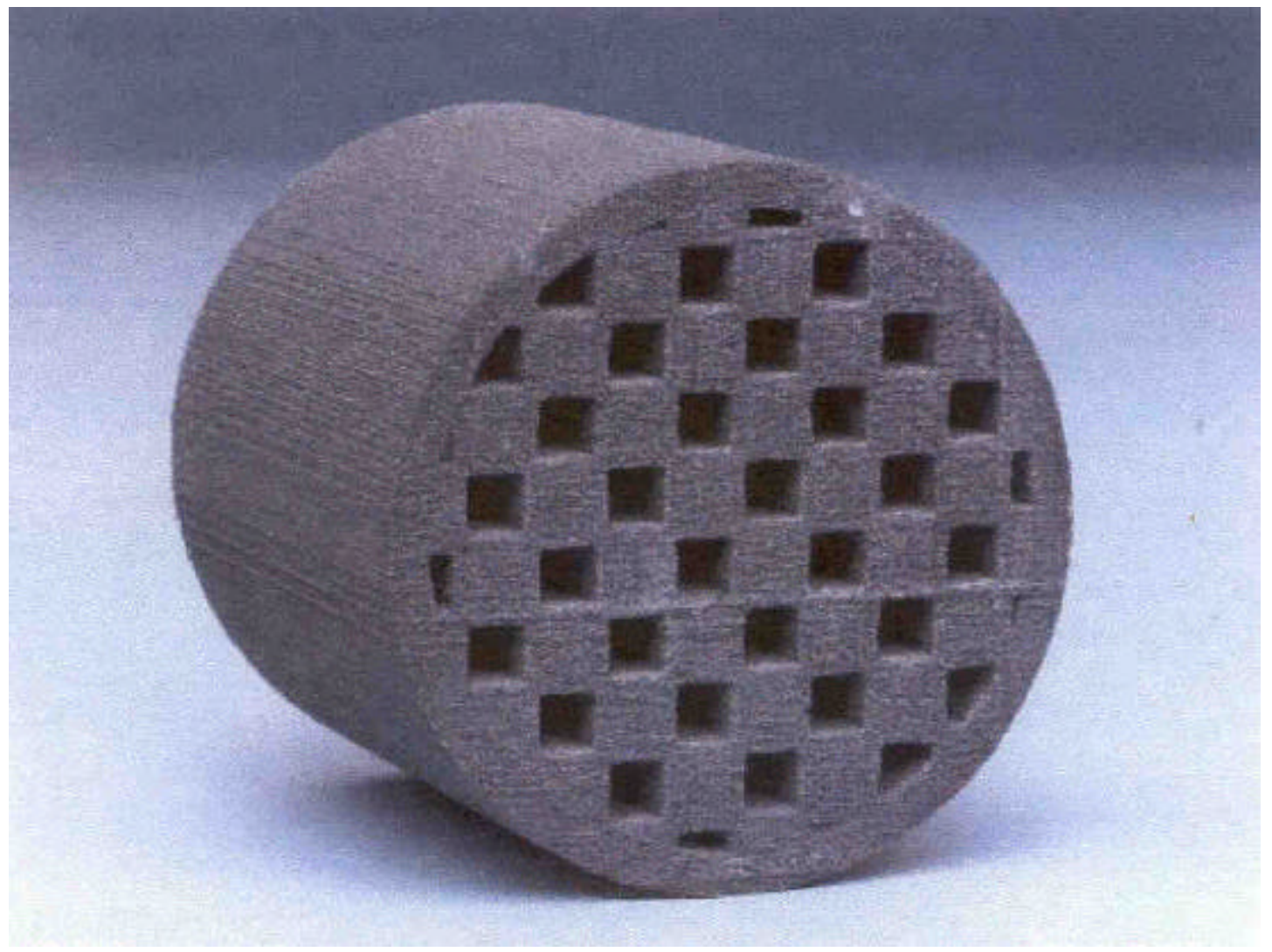

Figure 1.11.2-1 - First Subscale SiC Cross Flow Prototype 
Results of permeability testing are shown in Table 1.11.3-1 and Figure 1.11.3-1. These results indicate that the unit would have close to the targeted flow capability and differential pressure if scaled up in area by a factor of 5 (25/8 inch diameter by 6 inch length with $4 \mathrm{~mm}$ by $4 \mathrm{~mm}$ channels). The unit would have a filter area of 1.1 square feet.

Specific Surface provided four honeycomb units of the aforementioned geometry and performance specification made of type 316 stainless steel.

Table 1.11.3-1 - Permeability of Specific Surface SiC Honeycomb

\begin{tabular}{|c|c|c|c|c|c|c|}
\hline Ident. & $\begin{array}{l}\text { Flow } \\
\text { Scfm }\end{array}$ & $\begin{array}{l}\text { Pressure } \\
\text { Psig }\end{array}$ & $\begin{array}{c}\text { Element } \\
\text { Velocity } \\
\text { Fpm }\end{array}$ & $\begin{array}{c}\text { Full } \\
\text { Candle } \\
\text { Velocity } \\
\text { Fpm }\end{array}$ & $\begin{array}{c}\text { Delta P } \\
\text { Iwc }\end{array}$ & $\begin{array}{c}\text { Delta P } \\
@ 843^{\circ} \mathrm{C} \\
\left(1550^{\circ} \mathrm{F}\right) \\
\text { iwc }\end{array}$ \\
\hline Honeycomb & 3.57 & 0.0 & 13.72 & 1.27 & 3.5 & 6.8 \\
\hline $2.005 " \mathrm{OD}$ & 6.99 & 1.0 & 27.77 & 2.58 & 7.3 & 14.2 \\
\hline 2.019"| & 10.24 & 2.1 & 42.10 & 3.91 & 12.0 & 23.4 \\
\hline \multirow[t]{4}{*}{$.26 \mathrm{ft}^{2}$ area } & 13.45 & 3.3 & 57.24 & 5.32 & 18.3 & 35.6 \\
\hline & 16.80 & 5.1 & 75.00 & 6.96 & 26.0 & 50.6 \\
\hline & 20.15 & 7.7 & 95.68 & 8.88 & 35.0 & 68.2 \\
\hline & 23.77 & 11.5 & 122.03 & 11.33 & 47.0 & 91.5 \\
\hline
\end{tabular}

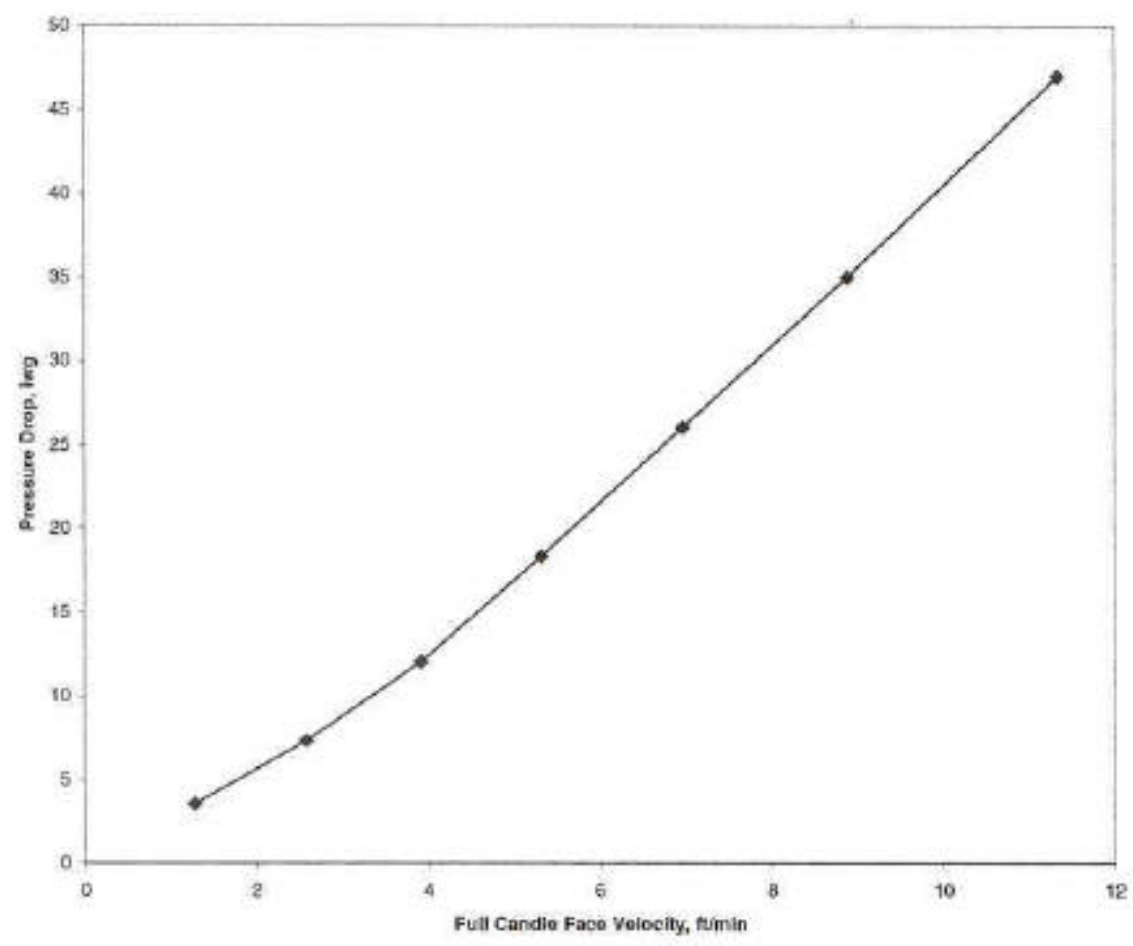

Figure 1.11.3-1 - Permeability of Specific Surface SiC Honeycomb for Failsafe - 10/99 


\subsection{Inverted Metal Filter Barrier SGD}

\subsubsection{Detailed Design of Inverted Metal Filter Barrier}

Design details are SWPC proprietary. This section and Figure B-2 are found in the Proprietary Appendix B of the Topical Report, Task 1, Conceptual Design.

\subsubsection{Mechanism/Principle of Operation of Inverted Metal Filter Barrier}

Design details are SWPC proprietary. This section is found in the Proprietary Appendix B of the Topical Report, Task 1, Conceptual Design.

\subsubsection{Projected Performance of Inverted Metal Filter Barrier and Permeability Screening Results}

A subscale inverted metal filter barrier prototype was permeability tested at STC. This seven unit array of short, thick walled elements was found to have too high a flow resistance by a factor of two.

The manufacturer (Mott) performed bench scale tests on various tube materials that they produce. Testing of $3 / 8$ " diameter 10 micron pore size material (extrapolated to an array of 31 units) did not satisfy pressure drop (<1 psi) and flow criteria $(15-20 \mathrm{acfm})$ at $843^{\circ} \mathrm{C}$ $\left(1550^{\circ} \mathrm{F}\right)$ and $150 \mathrm{psig}$. Flow extrapolated to only 3 acfm for these conditions.

Bench testing of thin wall (1/16") tubes provided an acceptable extrapolation if nine tubes were used of seven inch length. Two prototypes of this geometry made of $316 \mathrm{~L}$ stainless steel were ordered for permeability evaluation at STC. This was not the ultimate material of choice, but these units provided an important step in our iterative testing.

\subsection{Nested Fiber Impaction SGD}

\subsubsection{Detailed Design of Nested Fiber SGD}

Design details are SWPC proprietary. This section and Figure B-3 are found in the Proprietary Appendix B of the Topical Report, Task 1, Conceptual Design.

\subsubsection{Mechanism/Principle of Operation of Nested Fiber SGD}

Unlike the barrier SGDs the nested fiber SGD may be termed an impaction device. In impaction-type SGDs, a bed or layer of impact targets, or obstructions - such as a bed of fibers, pellets, or set of screens - having relatively large flow passages are used to initiate the accumulation of particulate primarily by particulate impaction and sticking on these flow obstructions. The particle penetration is modeled as a passive impact-type SGD having constant particulate removal efficiency. Particle interception, diffusion gravity, and back-pulse settling, also contribute to particle removal. The pressure drop across the clean impact-type SGD has both viscous and inertial contributions. While this type of SGD can have a considerably lower gas pressure drop than the barrier filter 
SGDs, the penetration of particulate may be initially higher, dropping off only as a significant amount of particulate accumulates within the device, increasing collection efficiency. As the flow resistance across the SGD increases with continued particulate accumulation, the gas flow through the SGD will be considerably reduced.

\subsubsection{Permeability Screening Results and Performance of Nested Fiber SGD}

Preliminary work at Siemens Westinghouse STC showed considerable promise for the nested fiber SGD. Using two different grades of nested fibers (coarse and fine fiber), low differential pressure was demonstrated in cold flow tests. These results are tabulated in Table 1.13.3-1 and plotted in Figure 1.13.3-1. While less flow resistance was evident for the fiber-filled SGDs (compared to standard failsafe), little difference was noted between coarse and fine fiber SGDs.

Results of hot testing of a prototype nested fiber SGD using coarse fibers in oxidizing conditions with dust feed and back pulsing is shown in Figure 1.13.3-2. While the reference standard device allowed up to 800 ppmw before incompletely plugging, the nested fiber SGD allowed only about 8 ppmw before plugging to a level very near to the level of the detectable background.

Fibers of different geometry were procured and SGDs incorporating these fibers were fabricated.

Table 1.13.3-1 - Permeability of Failsafes Using Wire Pieces and SCS Standard

\begin{tabular}{|c|c|c|c|c|c|}
\hline Identification & Flow & Pressur & Velocity & Delta P & Delta P \\
\hline & scfm & psig & fpm & iwd & $\begin{array}{c}@ 843^{\circ} \mathrm{C} \\
\left(1550^{\circ} \mathrm{F}\right) \text { iwc }\end{array}$ \\
\hline \multirow[t]{7}{*}{ Coarse Fiber } & 3.57 & 0.0 & 1.25 & 0.15 & 0.3 \\
\hline & 6.99 & 0.0 & 2.45 & 0.50 & 1.0 \\
\hline & 10.24 & 1.7 & 3.79 & 1.04 & 2.0 \\
\hline & 13.45 & 2.9 & 5.16 & 1.83 & 3.6 \\
\hline & 16.80 & 4.5 & 6.74 & 3.04 & 5.9 \\
\hline & 20.15 & 7.0 & 8.59 & 4.85 & 9.4 \\
\hline & 23.77 & 10.5 & 10.92 & 7.70 & 15.0 \\
\hline \multirow[t]{7}{*}{ Fine Fiber } & 3.57 & 0.0 & 1.25 & 0.20 & 0.4 \\
\hline & 6.99 & 0.0 & 2.45 & 0.50 & 1.0 \\
\hline & 10.24 & 1.9 & 3.82 & 0.95 & 1.9 \\
\hline & 13.45 & 2.9 & 5.16 & 1.60 & 3.1 \\
\hline & 16.80 & 4.5 & 6.74 & 2.52 & 4.9 \\
\hline & 20.15 & 7.0 & 8.59 & 3.95 & 7.7 \\
\hline & 23.77 & 10.5 & 10.92 & 5.80 & 11.3 \\
\hline \multirow[t]{3}{*}{ SCS Std. } & 3.57 & 1.0 & 1.29 & 0.3 & 0.5 \\
\hline & 6.99 & 2.0 & 2.61 & 0.8 & 1.5 \\
\hline & 10.24 & 2.9 & 3.93 & 1.7 & 3.2 \\
\hline
\end{tabular}




\begin{tabular}{|r|r|r|r|r|r|}
\hline & 13.45 & 4.5 & 5.39 & 3.0 & 5.8 \\
\hline & 16.80 & 6.5 & 7.08 & 5.0 & 9.7 \\
\hline & 20.15 & 9.8 & 9.13 & 8.1 & 15.8 \\
\hline & 23.77 & 14.2 & 11.69 & 13.9 & 27.1 \\
\hline
\end{tabular}




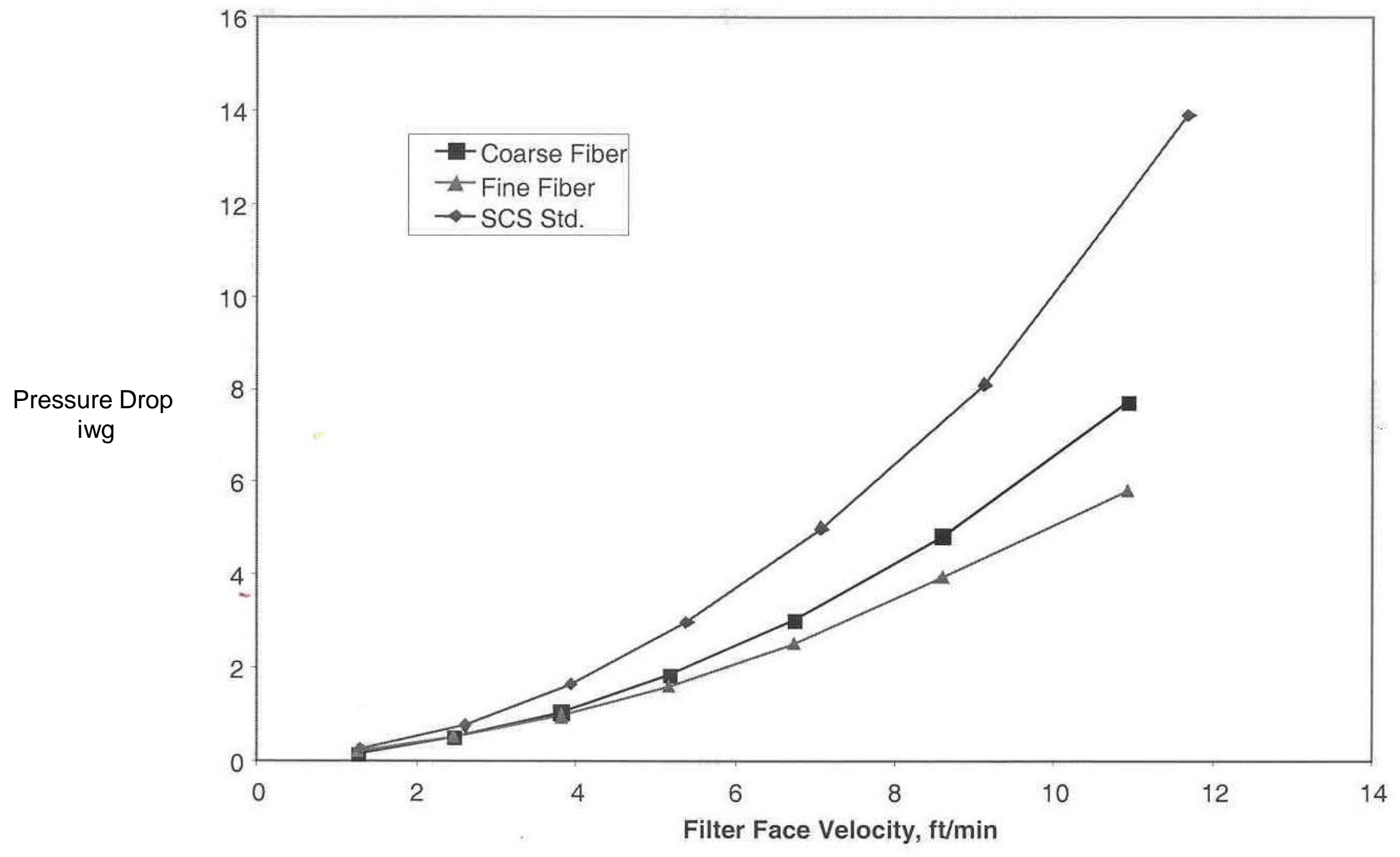

Figure 1.13.3-1 - Permeability of Failsafes Using Wire Pieces and SCS Standard 


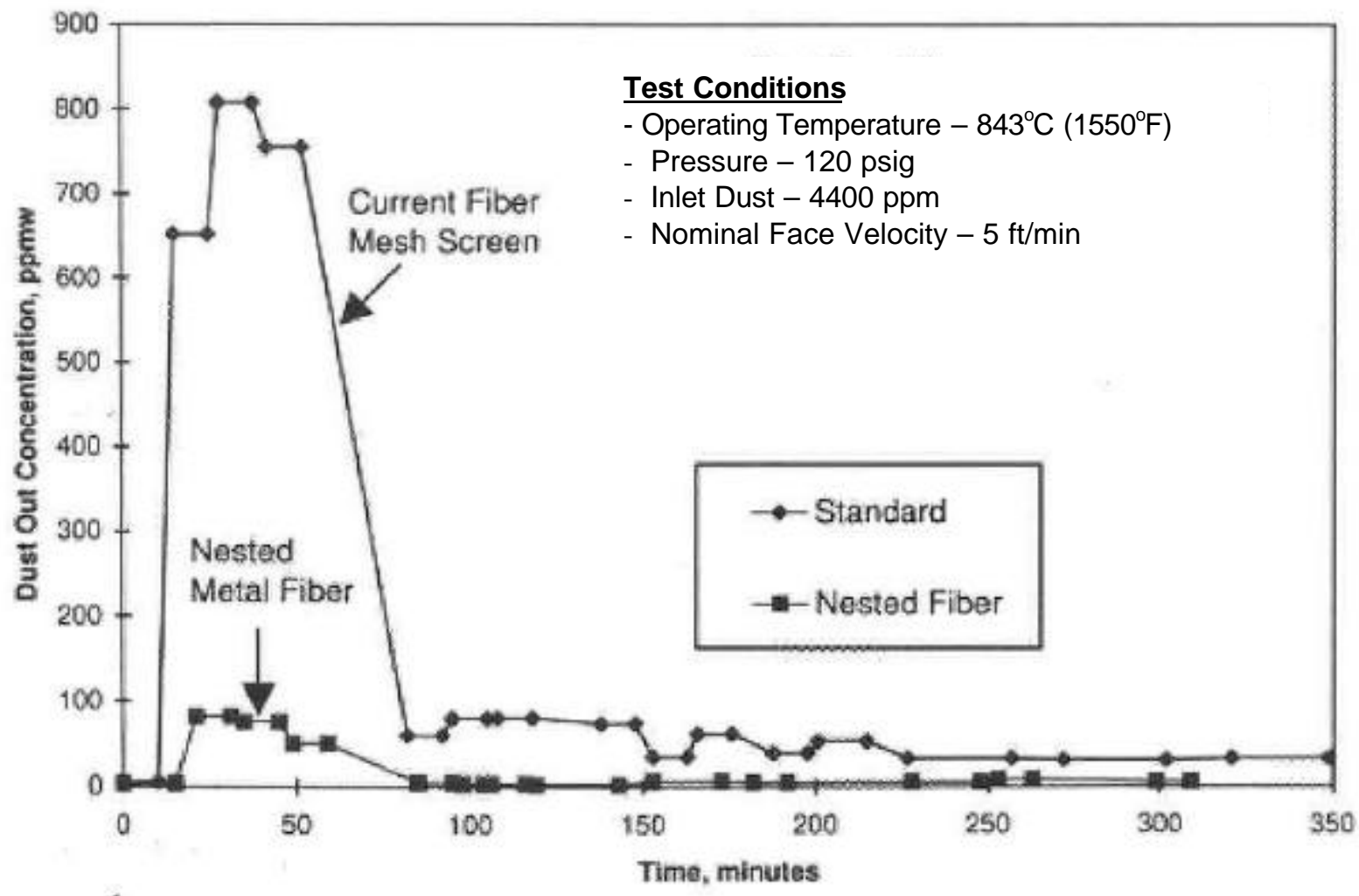

Figure 1.13.3-2 - Comparison of Standard Fine Mesh and Nested Fiber Safeguard Device Performance. A more than 10-fold improvement in performance is achieved with the nested metal fiber SGD concept. 


\section{EXPERIMENTAL}

The experimental method utilized in this program included "bench scale" testing of safeguard devices (SGDs) utilizing the DOE/NETL three candle array hot gas filter test facility and the Siemens Westinghouse 4 and 15 candle plenum hardware. Details of unique equipment modifications and particular arrangements to fixture SGDs for testing follow.

\subsection{NETL Equipment and Modifications}

The three section top plate of the NETL hardware and the surrounding pulse pipe support cylinder were redesigned and refabricated to accommodate two standard failsafes for two candle positions and various special SGDs (fiber, inverted filter and honeycomb) for the third candle position.

Configurations typical of honeycomb, inverted filter and fiber SGD testing are shown in Figures $2.1-1,2.1-2$ and $2.1-3$ respectively. Pulse pipe routing was evidently complicated by the need to interface with existing plumbing and to fit within the existing work envelope, especially the headspace.

Honeycomb SGDs (ref. Fig. 2.1-1) were first prepackaged with donut shaped gaskets at their top and bottom to seal the SGD to the adjoining metal hardware. A regenerator was incorporated in the top of the unit to protect the ceramic honeycomb devices from thermal shock during backpulsing. The bottom of the unit was gasketed to seal against the NETL tubesheet above the test position. The bottom of the unit was fit with a small tube for differential pressure measurement to assess flow. The two alternate filter positions were fit with back pulse tubing and standard failsafe regenerators directly above intact candle filters.

The inverted filter SGD (ref. Fig. 2.1-2) incorporated the array of inverted pencil filters to adjoining hardware with welds rather than gaskets. No regenerator was necessary. The bottom of the unit was then gasketed to seal against the NETL tubesheet with differential pressure tube and alternate filter positions equipped as previously described.

The fiber SGD (ref. Fig. 2.1-3) was also an all welded unit without need for regenerator. The bottom of the unit was again gasketed to seal against the NETL tubesheet with differential pressure tube and alternate filter positions equipped as previously described.

\subsection{STC Equipment and Modifications}

Nested fiber SGDs of standard height were directly retrofitted into existing STC plenum hardware. On the other hand, honeycomb barrier SGDs were of extended height and required extensions to be added to existing hardware.

The overall arrangement is shown in Figure 2.2-1. A cross flow module (Item 02) with internal gasketing and inlet regeneator is shown fixtured between the existing candle array plenum and the lower "filter nut" (Item 04) by way of a "test holder" extension (Item 01 ). A second "primary gasket" (Item 03) was required to seal the module to the extension. 

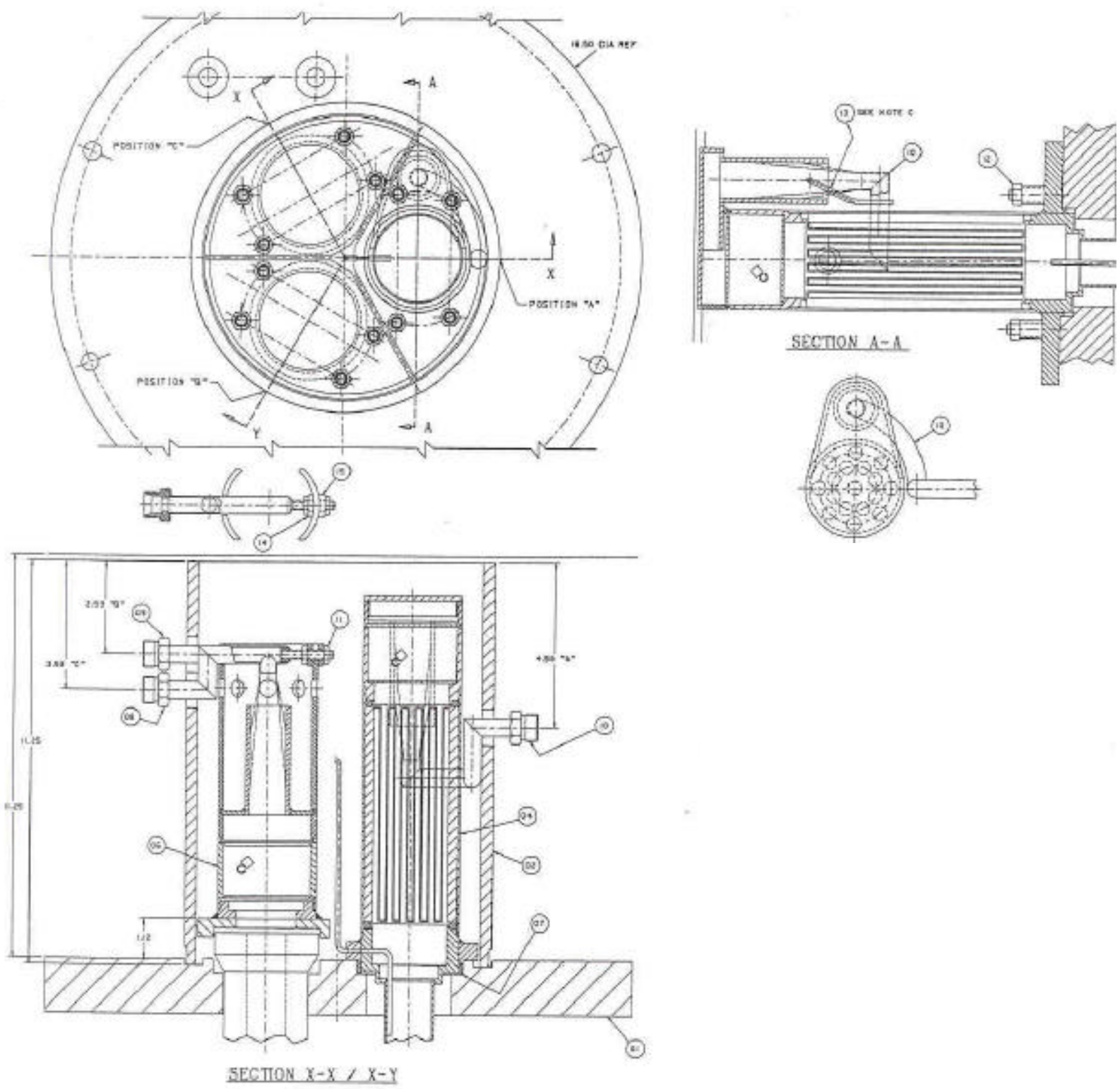

Figure 2.1-1 - Modified NETL Hardware for Honeycomb SGD Testing 


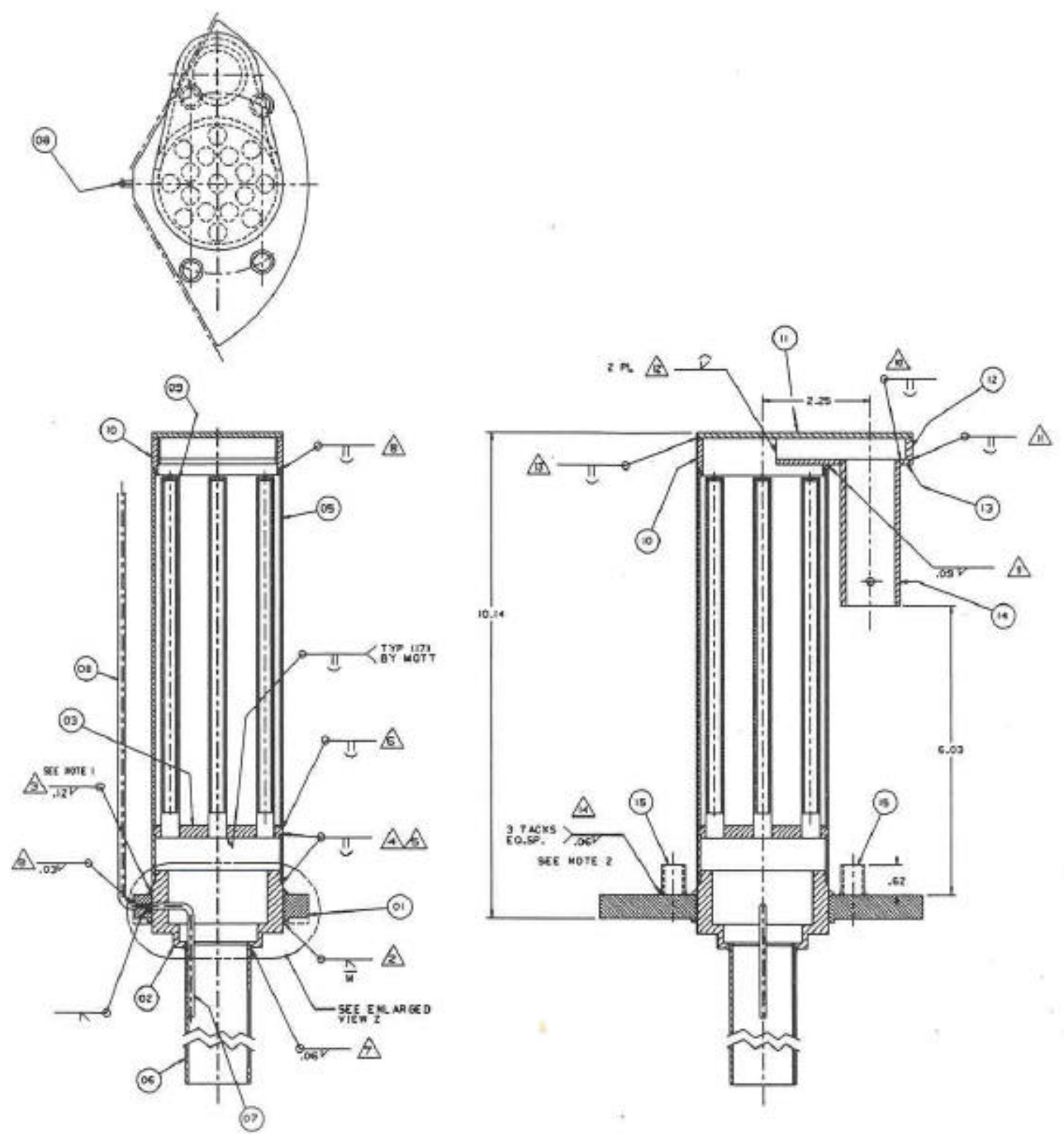

Figure 2.1-2 - Modified NETL Hardware for Inverted Filter SGD Testing 

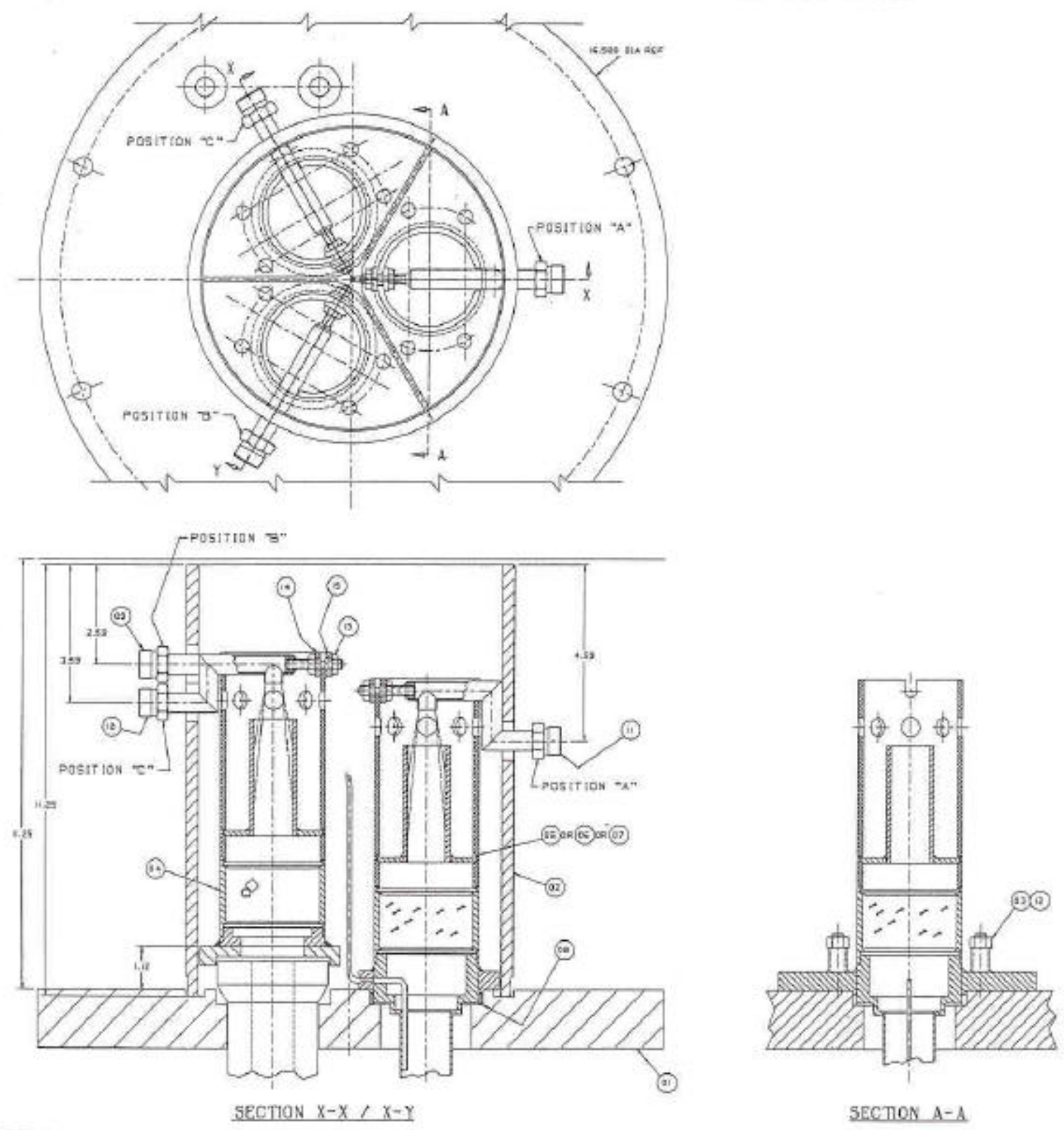

Figure 2.1-3 - Modified NETL Hardware for Fiber SGD Testing 
The top of a broken candle was fixtured as shown (ref. Fig. 2.2-1). A flow tube with differential pressure tap was inserted through the bore of the broken filter. The flow tube was fit with a top flange, which was sandwiched between the top of the candle and the bottom of the adjoining gasket to effect a seal. Differential pressure measurement across the flow tube was utilized to determine flow. The balance of the intact candle filter positions were equipped with standard failsafe devices.

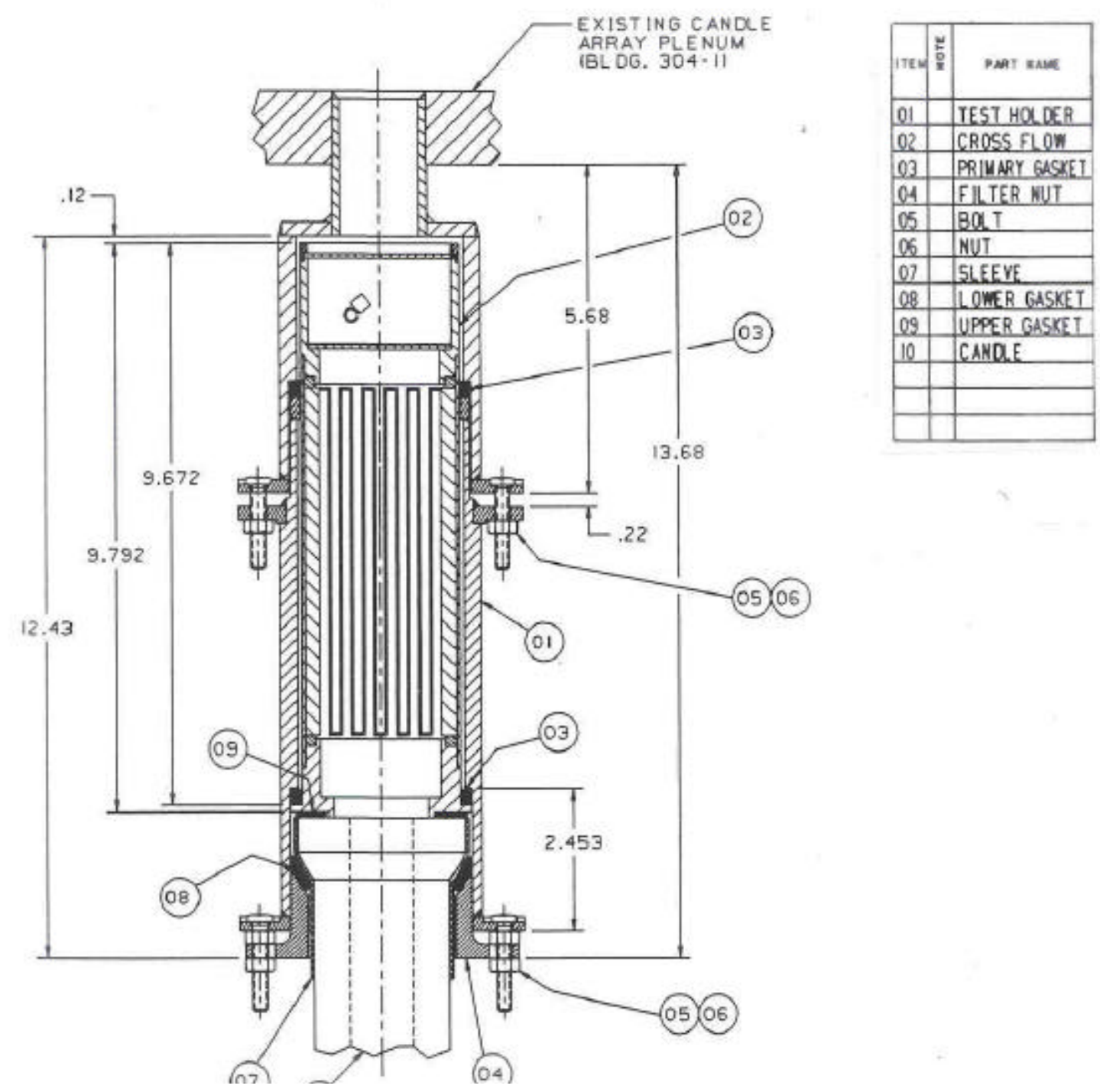

Figure 2.2-1 - Modified STC Hardware for Honeycomb Barrier SGDs 


\section{RESULTS AND DISCUSSION}

\subsection{NETL Testing}

\subsubsection{Experimental Approach}

In the DOE/NETL three-candle array facility, SGD testing was targeted to:

1. Focus on the catastrophic failure scenario, i.e., 33 percent candle failures. Transient performance (time to activate and close down) of the SGD device is considered critical in such circumstances.

2. Qualify fixturing and gasketing of the SGDs. (While this qualification was initially slated for STC 'unactivated' testing, the NETL tests preceded the STC tests.

Therefore, fixturing and gasketing were evaluated from NETL tests.)

Following is a table of test arrangements, conditions and exposures conducted at NETL.

Table 3.1.1-1 - NETL Test Arrangements, Conditions and Exposures

\begin{tabular}{|c|l|c|c|}
\hline Test No. & \multicolumn{1}{|c|}{ SGD Device } & $\begin{array}{c}\text { ConfigurationPI } \\
\text { enums / Candle } \\
\text { Pos. }\end{array}$ & Temp. ${ }^{\circ} \mathrm{C}\left({ }^{\circ} \mathrm{F}\right)$ \\
\hline 1 & 316 SS Honeycomb & $1 / 3$ & $\mathbf{8 1 6 ( 1 5 0 0 )}$ \\
\hline 2 & Inverted Metal Filter & $1 / 3$ & $\mathbf{8 1 6 ( 1 5 0 0 )}$ \\
\hline 3 & SiC Honeycomb & $1 / 3$ & $\mathbf{8 1 6 ( 1 5 0 0 )}$ \\
\hline 4 & Coarse 310 Fiber & $1 / 3$ & $\mathbf{8 1 6 ( 1 5 0 0 )}$ \\
\hline 5 & Fine 214 Fiber & $1 / 3$ & $\mathbf{8 1 6 ( 1 5 0 0 )}$ \\
\hline
\end{tabular}

All NETL tests were conducted at 70 psig with a single plenum, three candle arrangement with two intact candles and with the SGD device fitted to the third candle position. This simulated a 33 percent catastrophic failure during dust feeding.

Attempts were made to measure outlet dust concentration using a laser-based sensor. The resultant data was very scattered and often inconclusive. Attempts were made to measure the speed and extent of flow reduction from pluggage using a flow pipe and pressure taps across the SGD. It was hoped to also measure resistance to unplugging during back pulsing in this manner. As will be described, absence of flow could be detected but high residual dust levels made trending of flow for SGD performance evaluation impossible.

Alternately, performance of SGDs from NETL testing was assessed by post test physical inspection of the units and their gasketing and by permeability evaluation. 


\subsubsection{Sample Procurement}

Other than geometric requirements to fit in the filter holder plenum, the SGDs provided had to meet the pressure drop requirement of $12 \mathrm{iwg}$ at $30 \mathrm{scfm}$ flow. Table 3.1.2-1 summarizes the final pressure drops attained for various SGD designs.

Table 3.1.2-1 - Summary of Flow Resistance

\begin{tabular}{|l|c|}
\hline \multicolumn{1}{|c|}{ SGD Design } & $\begin{array}{c}\text { Pressure Drop (iw g) } \\
\text { (Require 12 max. at 30 scfm) }\end{array}$ \\
\hline $\begin{array}{l}\text { Pinon Standard (reference) } \\
\text { SCS Standard (reference) }\end{array}$ & $\mathbf{7}$ \\
\hline Fine Fiber SGD & $\mathbf{6}$ \\
\hline Coarse Fiber SGD & $\mathbf{8}$ \\
\hline Stainless Honeycomb Bamier SGD & $\mathbf{4}$ \\
\hline SiC Honeycomb Barier SGD & $\mathbf{8}$ \\
\hline $\begin{array}{l}\text { Inverted Filter Barrier SGD - 9 Tube } \\
\text { Inverted Filter Bamier SGD - 17 Tube }\end{array}$ & $\mathbf{2 0}$ \\
& $\mathbf{8}$ \\
\hline
\end{tabular}

Gasketing for the honeycomb SGDs (metal as well as SiC) was evaluated with the help of a series of Plexiglas mockups of the fixturing. This tool is shown in Figure 3.1.2-1.

Honeycomb SGDs were tried with various gaskets. A pocket depth of $3.2 \mathrm{~mm}\left(1 / 8^{\prime \prime}\right)$ was selected. Final gasket geometry was then chosen by fitting a series of Nextel gaskets of various geometry into this pocket. The final gasket selected was $69 \mathrm{~mm}$ (2.73") outside diameter by $51 \mathrm{~mm}\left(2^{\prime \prime}\right)$ inside diameter by $5.1 \mathrm{~mm}\left(0.20^{\prime \prime}\right)$ thick.

\subsubsection{NETL Tests 1 and 3 - 316 SS and SiC Honeycomb Barrier}

A metal honeycomb SGD was the first unit to be exposed to dust laden hot gas at NETL. Higher than expected pressure drops prior to feeding of fines for the barrier SGDs were attributed to residual ash causing early activation. Trending of decreasing flow was, therefore, not possible. Inspection of gasketing following testing confirmed that gaskets and fixturing were effective in preventing any by-pass leakage of fines. Subsequent testing at STC provided additional evidence that residual fines were the probable cause of early SGD activation (i.e. such early activation did not occur at STC with essentially identically gasketed units). 


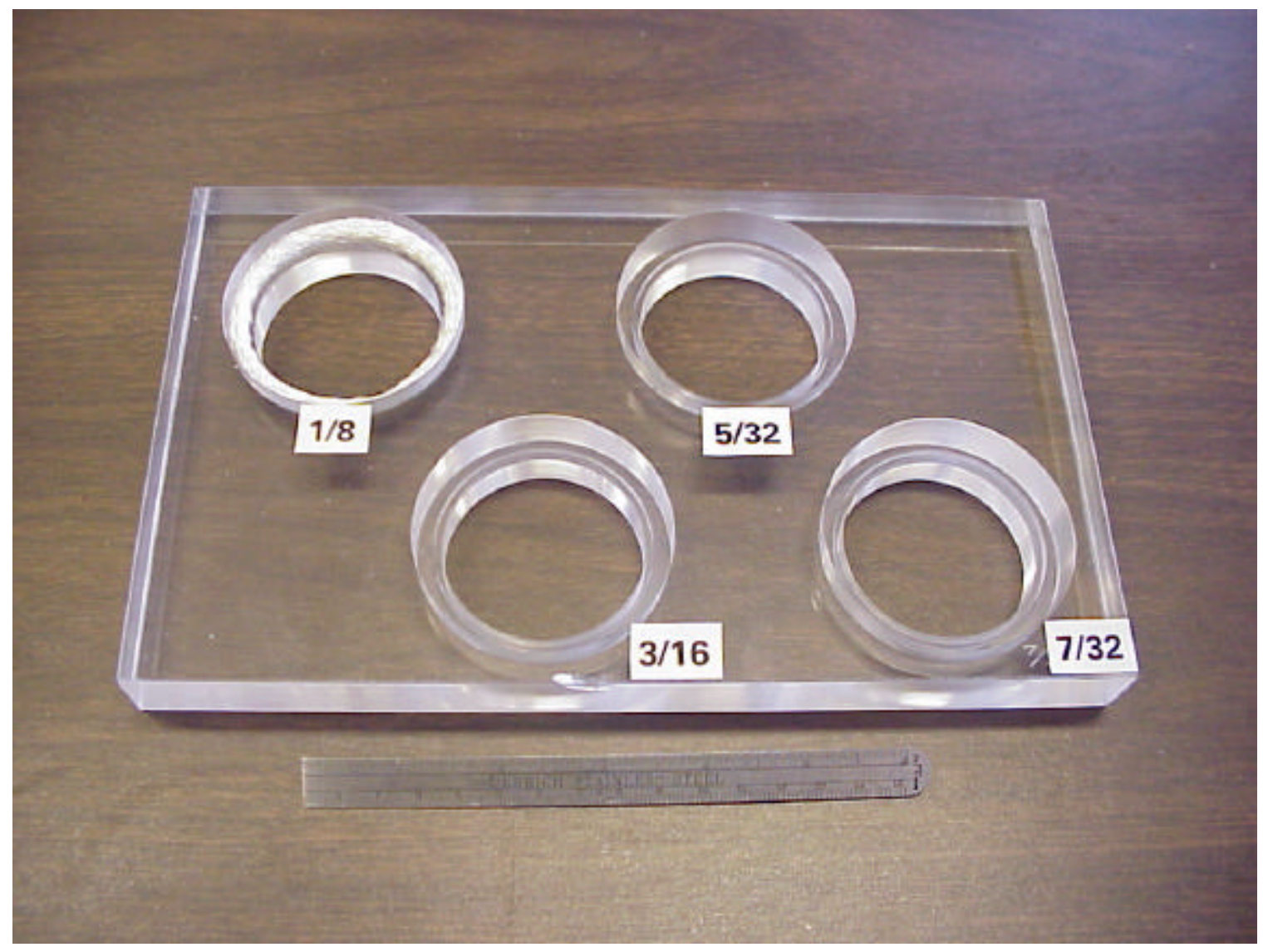

Figure 3.1.2-1 - Plexiglas Fixture for Gasket Evaluation

Pressure drop measurements of the units suggested that they plugged completely and effectively prevented the passage of fines. Table 3.1.3-1 shows differential pressure measurements before and after NETL exposures for the two honeycomb units.

Table 3.1.3-1 - 316 SS and SiC SGDs Exposed at NETL

\begin{tabular}{|l|c|}
\hline \multicolumn{1}{|c|}{ Unit / Condition } & Differential Pressure (iw g @ X scfm) \\
\hline 316 SS / Before Exposure & $\mathbf{9 . 8}$ @ 24.6 \\
\hline 316 SS After Exposure & $\mathbf{1 9 4} @ \mathbf{2 7 . 9}$ \\
\hline SiC / Before Exposure & $\mathbf{8} @ \mathbf{3 1}$ \\
\hline SiC / After Exposure & $\mathbf{6 2 . 4 ~ @ ~ 1 5 ~}$ \\
\hline
\end{tabular}


A photograph of the metal honeycomb SGD tested at NETL is shown in Figure 3.1.3-1. The unit is noted to have broken into two nearly equal halves. A discontinuity occuring during manufacturing is postulated to have caused the fracture.

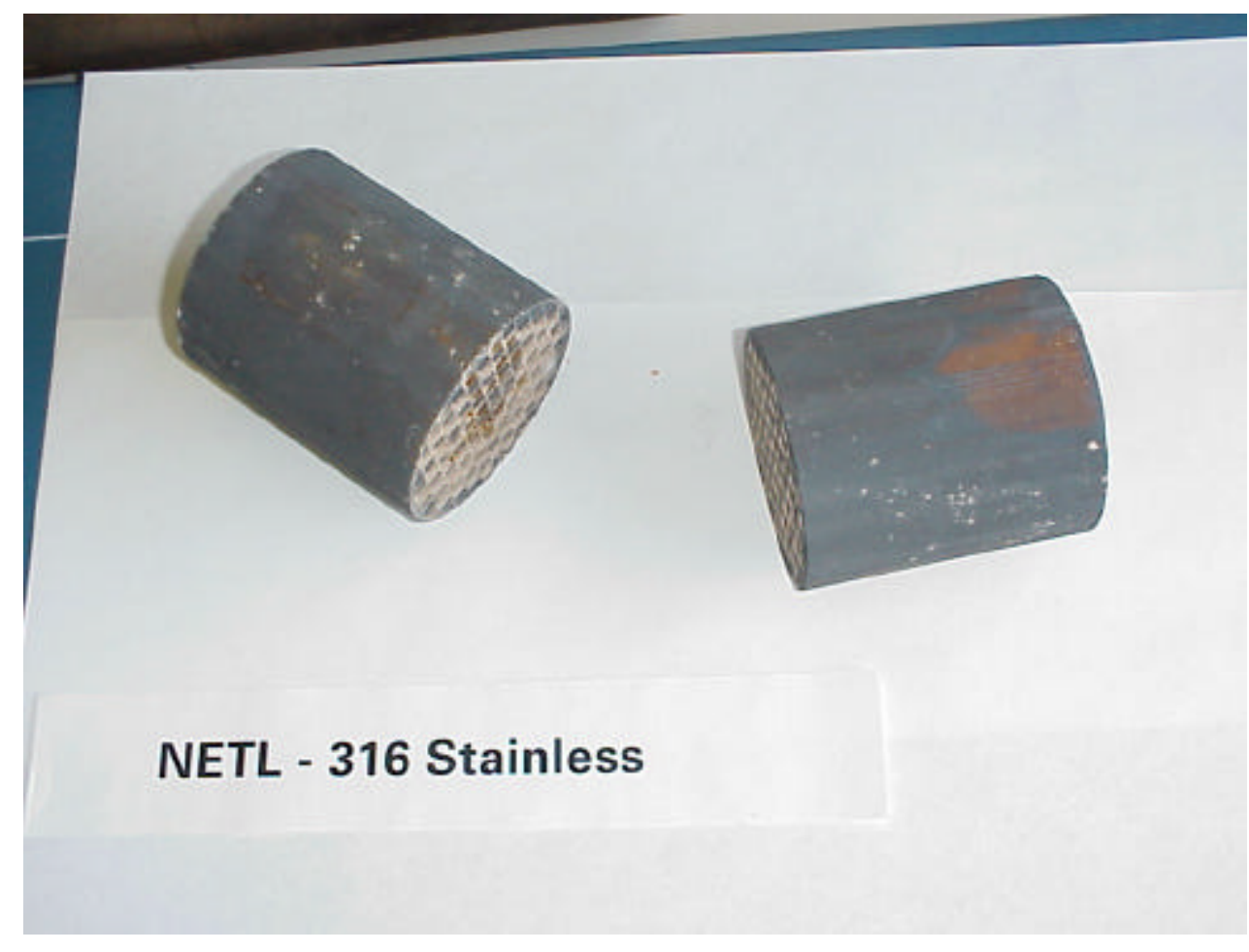

Figure 3.1.3-1 - Type 316 Stainless Honeycomb SGD after NETL Test

A photograph of the SiC honeycomb SGD tested at NETL is shown in Figure 3.1.3-2. Cracking of the unit is noted. The material is evidently fragile for the conditions of exposure.

\subsubsection{NETL Test 2 - 316 SS Inverted Filter Barrier}

The inverted filter SGD tested at NETL showed high-pressure drop upon exposure to flow and prior to feeding of fines. The unit was cut open and found to have one cracked filter tube. The cracking occurred adjacent to the weld joining the tube to the tubesheet. The unit was ultrasonically cleaned in water. A summary of the differential pressures is provided in Table 3.1.4-1. Original permeability was not recovered by the cleaning operation. 


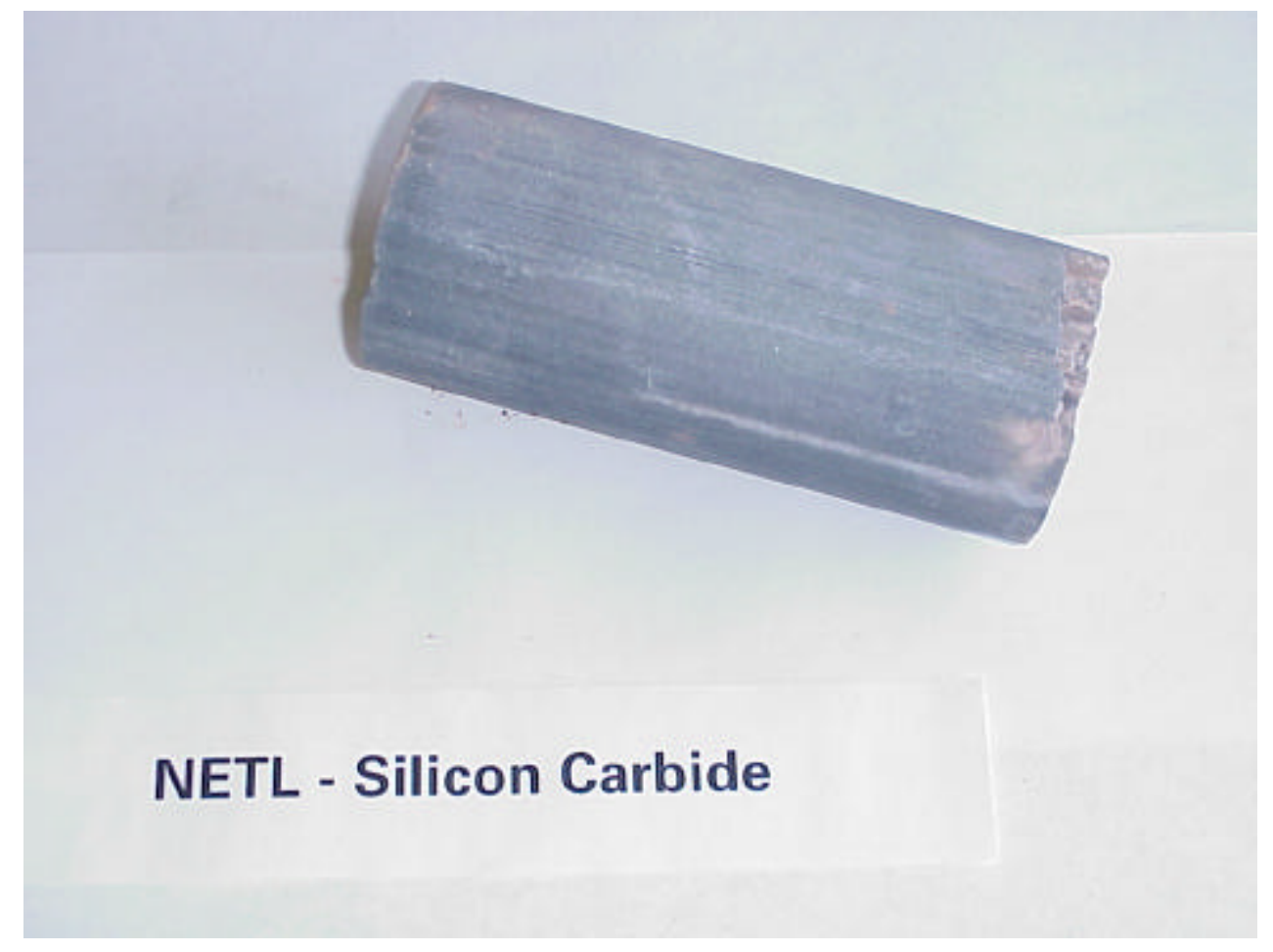

Figure 3.1.3-2 - SiC Honeycomb Unit after NETL Exposure

Table 3.1.4-1 - Inverted Filter SGD Exposed at NETL

\begin{tabular}{|l|c|}
\hline Condition & Differential Pressure (iwg @ X scfm) \\
\hline Before Exposure & $\mathbf{8 . 8} @ \mathbf{3 1 . 1}$ \\
\hline After Exposure & $\mathbf{9 2} @ \mathbf{2 5 . 7}$ \\
\hline After Cleaning & $\mathbf{7 8} @ \mathbf{2 5 . 8}$ \\
\hline
\end{tabular}

Metallographic inspection of the tube indicated that the pores were blinded with material on the interior surface of the tube. Detailed inspection of the structure indicated that fines were absent in the media but that considerable oxidation was present. Such premature blinding evidently limits the usefulness of this SGD design. Cracking adjacent to filter tube welds points to an additional manufacturing issue. 


\subsubsection{NETL Tests 4 and 5 - Coarse and Fine Fiber SGDs}

A coarse fiber (e.g. $\left.0.57 \mathrm{~mm}\left(0.022^{\prime \prime}\right)\right)$ SGD containing short (19 mm (0.75')) type 310 stainless steel fibers was exposed at NETL. Slight passage of fines was detected but could not be quantified. Flow decreased to a low value over a period of approximately twenty minutes. Backpulsing did not cause significant dislodging of fines from the SGD.

A fine alloy 214 fiber (e.g. $\left.0.10 \mathrm{~mm}\left(0.004^{\prime \prime}\right)\right)$ SGD was exposed at NETL. A fairly low flow was noted from the start of testing. Upon feeding of fines very low flow was noted. Very few fines could be detected at the outlet throughout the test.

The qualitative conclusion from coarse and fine fiber testing at NETL is that the fine fiber SGD demonstrated superior control to limit passage of ash fines.

\subsection{STC Testing}

\subsubsection{Experimental Approach}

The scope of STC testing was targeted to take the best advantage of what was leamed from the NETL testing. That is:

1. No further tests of inverted metal filter barier devices were conducted because the NETL testing had shown them to rapidly blind prior to dust feeding.

2. "Normal" operation (no failed candles) testing was not needed because NETL testing had already qualified the fixturing and gasketing of the SGDs.

3. 'Catastrophic" operation tests (high percentage of failed candles) were added to the scope of STC tests because demonstration of performance under such conditions was not confirmed at NETL.

4. "Nominal" operation tests (low percentage of failed candles) were retained in the scope of STC tests.

Following is a table of test arrangements, conditions and exposures conducted at STC.

Outlet dust concentration readings were determined by withdrawing a gas sample, passing it through a filter to collect the dust, measuring the amount of dust gravimetrically (by weight change) and measuring the amount of gas using a dry test meter. Dust concentrations were then reported in parts per million by weight. The speed and extent of flow reduction from pluggage was detemined using a flow pipe and pressure taps across the SGD. Resistance to unplugging during back pulsing was also assessed in this manner. 
Table 3.2.1-1 - STC Test Arrangements, Conditions and Exposures

\begin{tabular}{|c|c|c|c|c|c|c|c|}
\hline Test No. & SGD Device & $\begin{array}{c}\text { Configuration } \\
\text { Plenums / } \\
\text { Candle Pos. }\end{array}$ & $\underset{\left({ }^{0} \mathrm{~F}\right)}{\operatorname{Temp}}{ }^{0} \mathrm{C}$ & $\begin{array}{l}\text { Pressure } \\
\text { psig }\end{array}$ & $\begin{array}{c}\text { Dust Feed } \\
\text { Cycles }\end{array}$ & $\begin{array}{l}\text { Dust Feed } \\
\text { Time (hrs) }\end{array}$ & $\begin{array}{c}\text { No. } \\
\text { Accelerated } \\
\text { Pulses }\end{array}$ \\
\hline 1 & 316 SS Honeycomb & $2 / 4$ & $816(1500)$ & 150 & 15 & 10.6 & 110 \\
\hline 2 & SiC Honeycomb & $2 / 4$ & $816(1500)$ & 150 & 21 & 10.9 & 221 \\
\hline 3 & Coarse 310 Fiber & $1 / 15$ & $816(1500)$ & 88 & 5 & 6.4 & 690 \\
\hline 4 & Fine 214 Fiber & $1 / 15$ & $816(1500)$ & 88 & 9 & 15.3 & 741 \\
\hline 5 & Fine FeCrAlY Fiber & $1 / 15$ & $816(1500)$ & 88 & 11 & 13.6 & 817 \\
\hline 6 & 4 Ceramic Honeycomb & $1 / 13$ & $816(1500)$ & 98 & 21 & 31.4 & $\mathbf{0}$ \\
\hline 7 & 3 Ceramic Honeycomb & $2 / 4$ & 649 (1200) & 132 & 0 & 0 & 1024 \\
\hline
\end{tabular}

\subsubsection{STC Test 1 - 316 SS Honeycomb Barrier}

The first STC test was conducted with a two plenum, four candle arrangement with three intact candles and with the 316 SS honeycomb barrier device fitted to the fourth candle position. This simulated a 25 percent catastrophic failure during dust feeding. Figure 3.2.2-1 shows outlet dust concentration plotted versus time for three dust feeding cycles. After a small detection of dust at startup, dust concentration remained quite low (e.g. 5ppm or less).

The unit was dismantled and examined. Figure 3.2.2-2 shows the honeycomb and regenerator. The unit is noted to have bumed and melted in its interior - even extending into the regenerator section. The postulated cause involves a brief collection of fuel or combustible material, e.g. carbon, on the device resulting in buming. Such brief burning is suspected to occur on startup on the surface of the filter elements.

Permeability was assessed for the metal honeycomb before and after exposure. Table 3.2.2-1 summarizes the differential pressure readings.

\section{Table 3.2.2-1 - Differential Pressure Comparison for 316SS Honeycomb Tested at STC}

\begin{tabular}{|l|c|}
\hline \multicolumn{1}{|c|}{ Condition } & $\begin{array}{c}\text { Differential Pressure } \\
\text { (iwg @ X X scfm) }\end{array}$ \\
\hline Before Exposure & 9.8 @ 24.6 \\
\hline After Exposure & 194 @27.9 \\
\hline
\end{tabular}




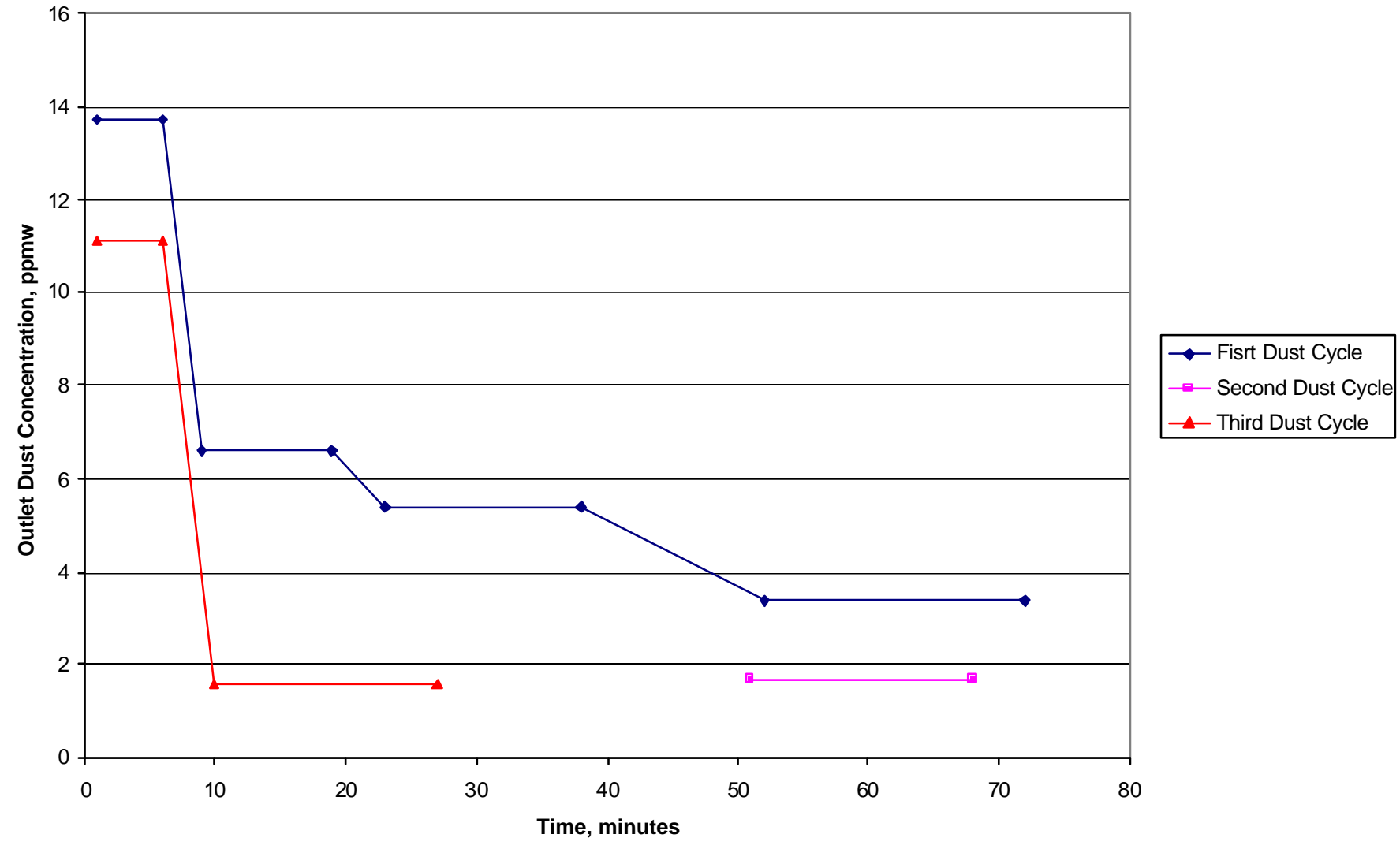

Figure 3.2.2-1 - Outlet Dust Concentration During Dust Feed for 316 SS Honeycomb Cross-Flow Safeguard Device 


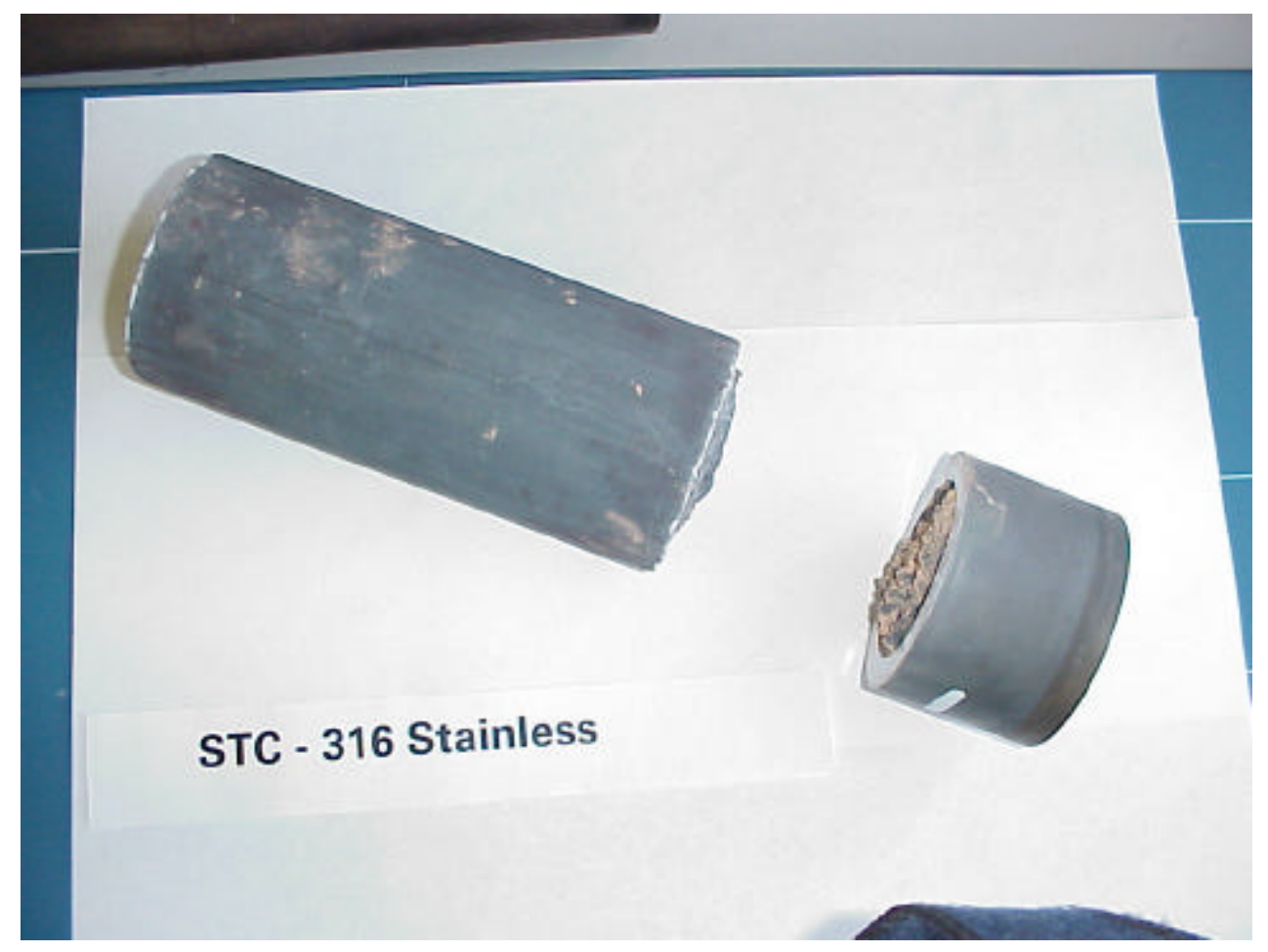

Figure 3.2.2-2 - 316 SS Honeycomb SGD after STC Testing

Conclusion: In light of the fragile structure of the stainless steel honeycomb unit noted in earlier NETL testing and the susceptibility of the unit to burning noted above, additional testing of stainless honeycomb is not advised. It is possible that improved manufacturing and altemate material selection may overcome the limitations noted for such units in this test program.

\subsubsection{STC Test 2 - SiC Honeycomb Barrier}

The second STC test was conducted with a two plenum, four candle arrangement with three intact candles and with the SiC honeycomb barrier device fitted to the fourth candle position. This simulated a 25 percent catastrophic failure during dust feeding. Figure 3.2.3-1 shows flow tube differential pressure as a function of time. Flow decreased rapidly and was virtually stopped in less than 15 minutes. Furthermore, the pluggage was resistant to accelerated back pulsing. Outlet dust concentration remained very low (less than 2 ppmw) 


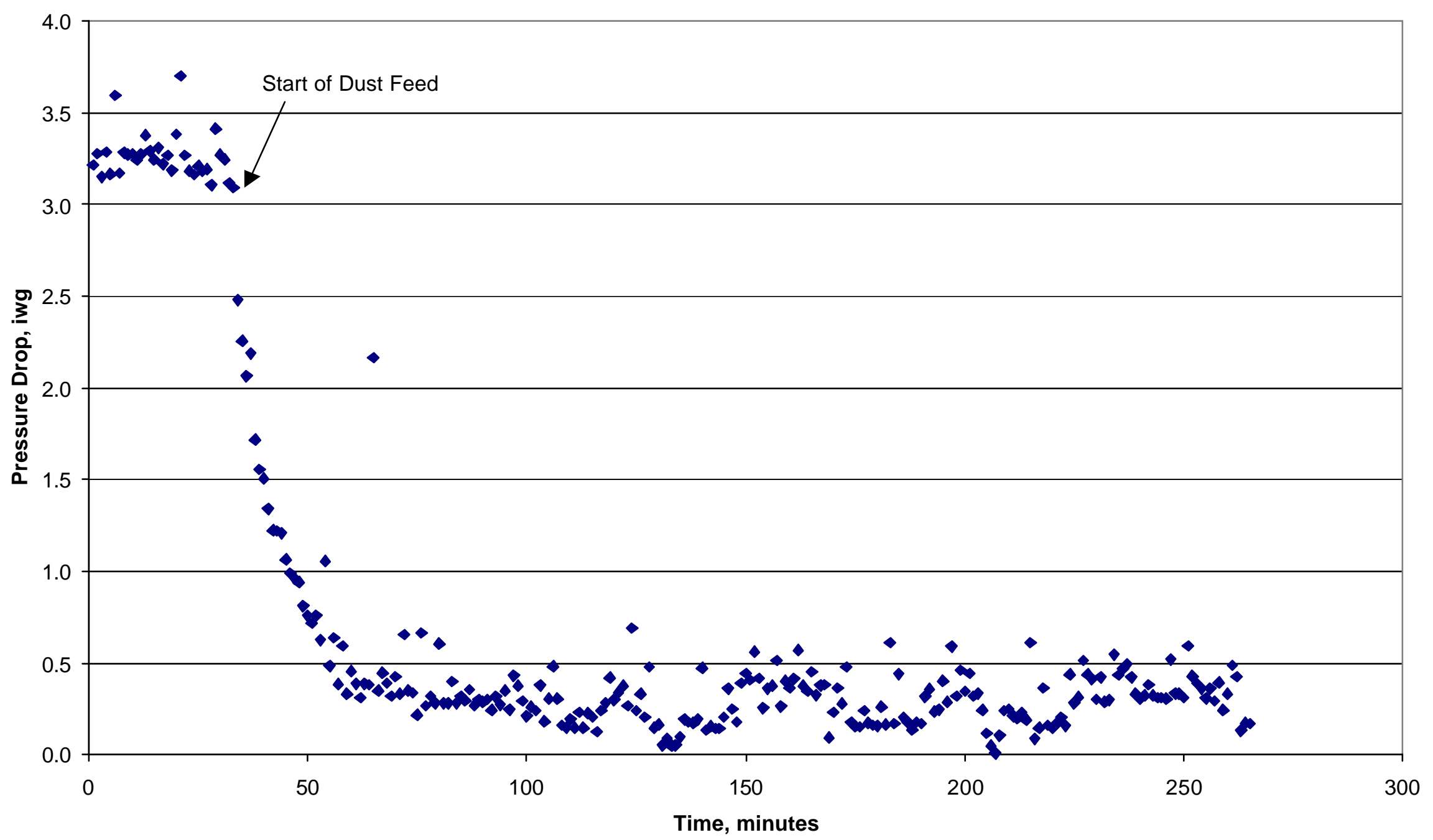

Figure 3.2.3-1 - Flowtube DP During First 6 Dust Feed Cycles for SiC Honeycomb Cross-Flow Safeguard Device 
The unit was dismantled and examined. Figure 3.2.3-2 shows the honeycomb.

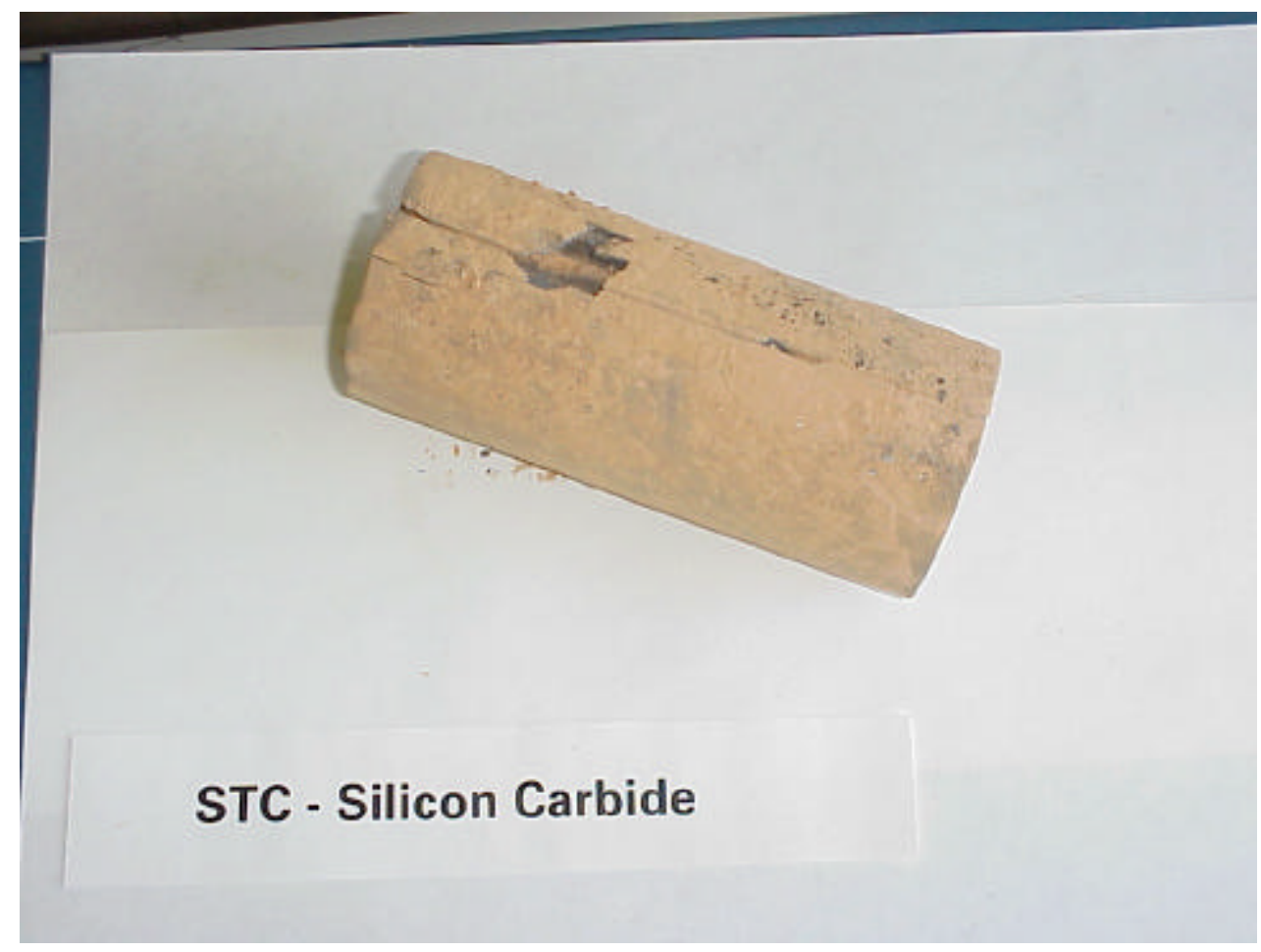

Figure 3.2.3-2 - SiC Honeycomb SGD after STC Testing

The silicon carbide honeycomb showed cracking. The manufacturer reported that the units (including previously tested NETL unit) may have been too brittle for our test exposures because they were only sintered and not recrystallized.

Permeability was assessed for the $\mathrm{SiC}$ honeycomb before and after exposure. Table 3.2.3-1 summarizes the differential pressure readings.

Table 3.2.3-1 - Differential Pressure Comparison for SiC Honeycomb Tested at STC

\begin{tabular}{|c|c|}
\hline Condition & Differential Pressure (iwg @ X scfm) \\
\hline Before Exposure & $12.7 @ 24.6$ \\
\hline After Exposure & $346 @ 9.6$ \\
\hline
\end{tabular}

Conclusion: With positive performance in terms of dust control but with evidence of a less than robust structure, this unit was identified for optimization under Task 6 of this program. The manufacturer was encouraged to provide more rugged units by recrystallizing $\mathrm{SiC}$ and/or by heat treating the sintered $\mathrm{SiC}$ to remove silica bonds between grains and to rebond by vapor deposition of SiC. 


\subsubsection{STC Tests 3, 4, and 5 - Coarse 310 Stainless Steel, Fine Alloy 214, and Fine FeCrAlY Fiber}

The next series of tests at STC involved testing of various alloy (310, 214 and FeCrAlY) fiber SGDs with a single plenum, fifteen candle arrangement. Each test included fourteen intact candles and with the one fiber SGD fitted to the fifteenth candle position. This simulated a seven percent 'nominal' failure during dust feeding. Figure 3.2.4-1 shows flow tube differential pressure as a function of time for the 'coarse' 310 stainless steel fiber SGD. Flow decreased abruptly and was virtually stopped within three minutes. Furthermore, the pluggage was resistant to accelerated back pulsing. Low flow readings during dust feeding were observed for all fiber tests.

While the activated fiber SGDs stopped flow, outlet dust concentrations were not always insignificant. In particular, the coarse fiber device showed readings in the range of 75 to $185 \mathrm{ppmw}$. With repeated cycles of dust feeding, the coarse fiber device continued to display ineffective dust control. On the other hand, both fine fiber devices showed dust control to levels of the order of 6 to 15 ppmw.

This observation is consistent with earlier findings in work by Battelle (ref. US Patent No. 4,976,934 and R. D. Litt) where they concluded that "smaller fibers provided greater particulate capture at constant depth or gas pressure differential".

Conclusion: While fiber devices quickly and effectively block flow, dust continues to permeate through the coarse fiber bed. Fine fiber beds, on the other hand, control dust to relatively low levels. Fiber of $0.10 \mathrm{~mm}\left(0.004^{\prime \prime}\right)$ diameter is effective in preventing dust passage while fiber of $0.57 \mathrm{~mm}(0.022 ")$ is ineffective.

\subsubsection{STC Test 6 - Optimization - Four Silicon Carbide Honeycomb SGDs}

As mentioned, the silicon carbide honeycomb devices demonstrated potential to effectively safeguard against dust penetration and were identified as the prime candidates for optimization testing. The challenge to the manufacturer(s) was to develop a more robust structure that would withstand repeated backpulsing.

Specific Surface developed two new structures for improved thermal shock resistance. The first was essentially a new material structure incorporating non-oxide bonds between particles. The second enhanced thermal conductivity from recrystallizing the silicon carbide at $2450^{\circ} \mathrm{C}\left(4440^{\circ} \mathrm{F}\right)$. The Specific Surface units do not require cement for plugging the altemate channels but are fabricated with plugs integral to their body. A cross section of such a unit is shown in Figure 3.2.5-1.

Ceramem Corporation developed their own silicon carbide honeycomb utillizing two different cements for plugging alternate channels. Units that they provided for testing are shown in Figure 3.2.5-2. 


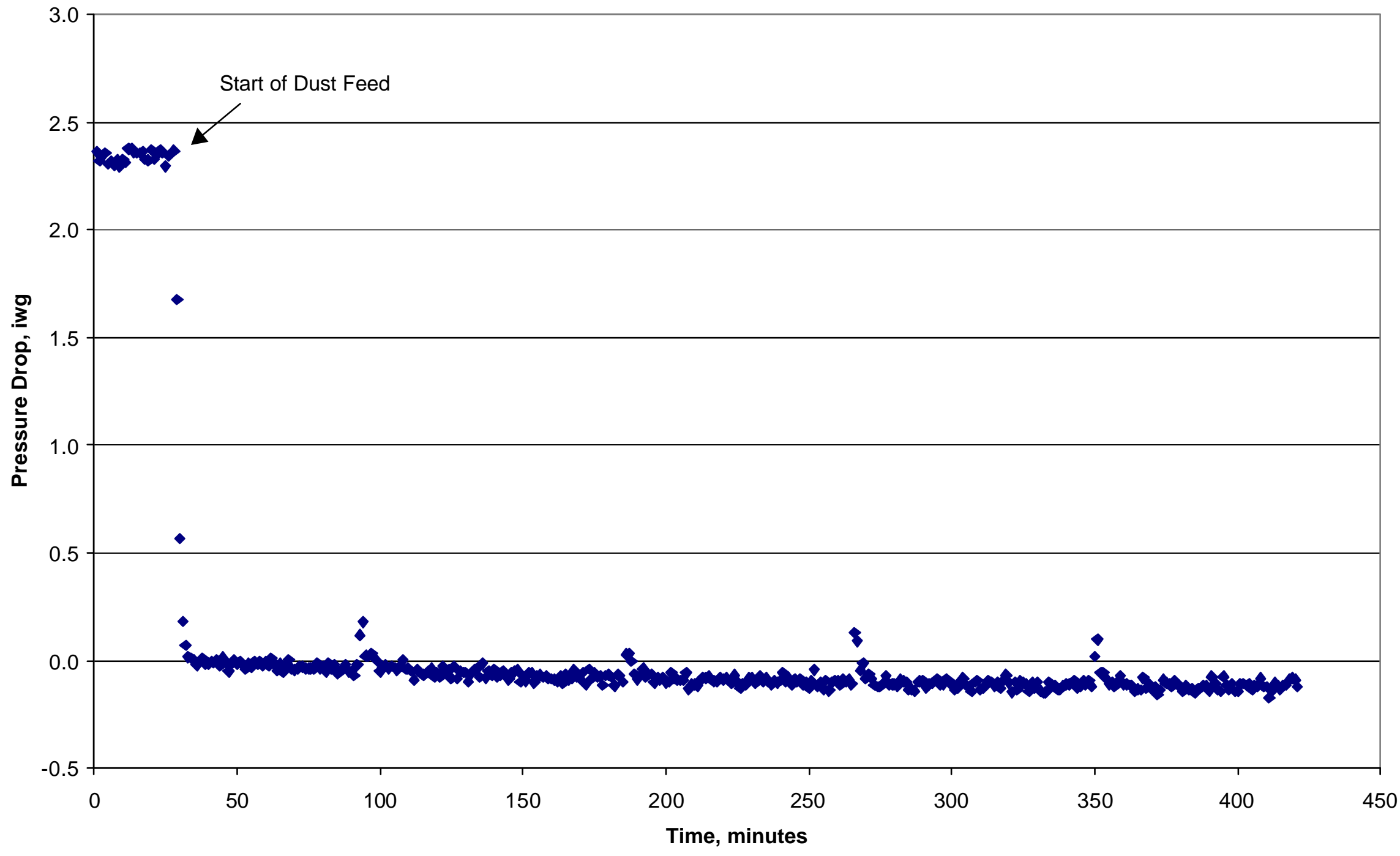

Figure 3.2.4-1 - Flowtube DP During First 5 Dust Feed Cycles for Coarse 310 SS Fiber Safeguard Device 


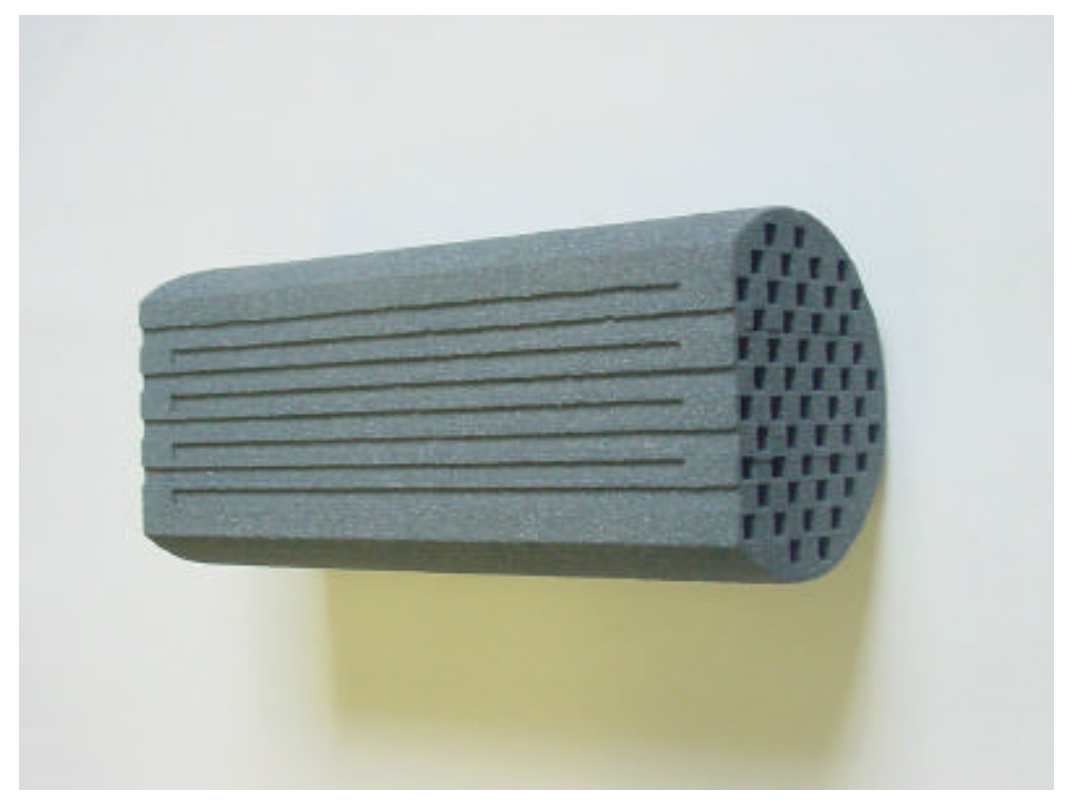

Figure 3.2.5-1 - Cross Section of Specific Surface SGD Showing Integral Channel Plugs

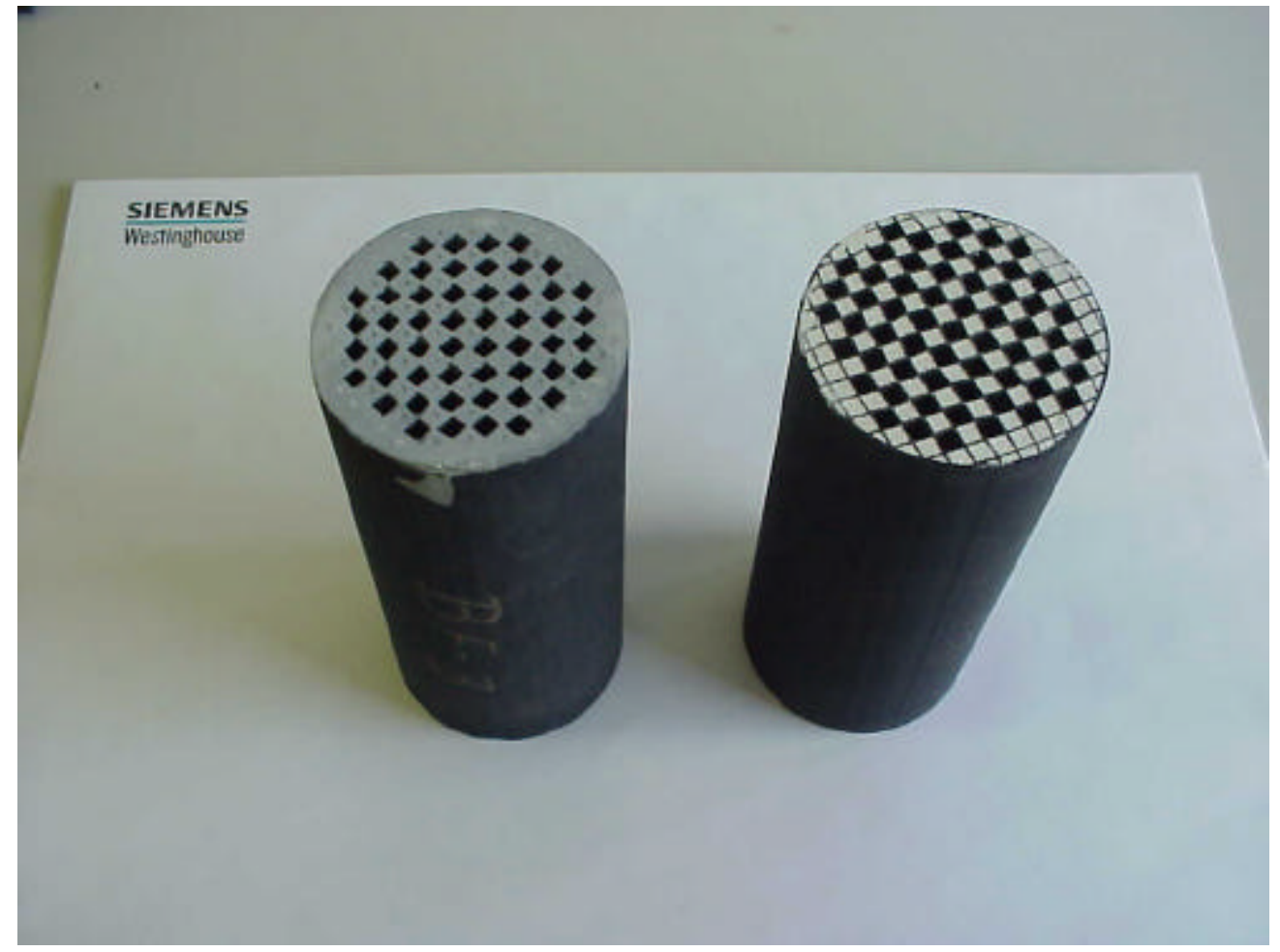

Figure 3.2.5-2 - Ceramem Silicon Carbide Honeycomb SGDs for Optimization Testing 
Two units from Specific Surface Corporation (SSNM - Specific Surface New Material and SSFR Specific Surface Fully Recrystallized) were installed over intact candle filters. Two units from Ceramem were installed - one over an intact candle filter (BF3) and one over a missing candle filter (BF4). Nine additional filter positions were candled with conventional failsafes to simulate an approximate $8 \%$ failure scenario. All honeycomb units were outfitted with Raschig Ring heat exchangers (regenerators).

After approximately 31 hours of exposure to dust and backpulsing (1700\#/hr flow, $1700 \mathrm{gm} / \mathrm{hr}$ ash dust, $816^{\circ} \mathrm{C}\left(1500^{\circ} \mathrm{F}\right), 98 \mathrm{psig}, 20$ pulse cycles) the units were removed from their hardware. All honeycomb units (both from Specific Surface Corporation and from Ceramem Corporation) showed resilience to backpulsing - that is, no damage was noted. Photographs of these units are provided in Figures 3.2.5-3 through 3.2.5-6.

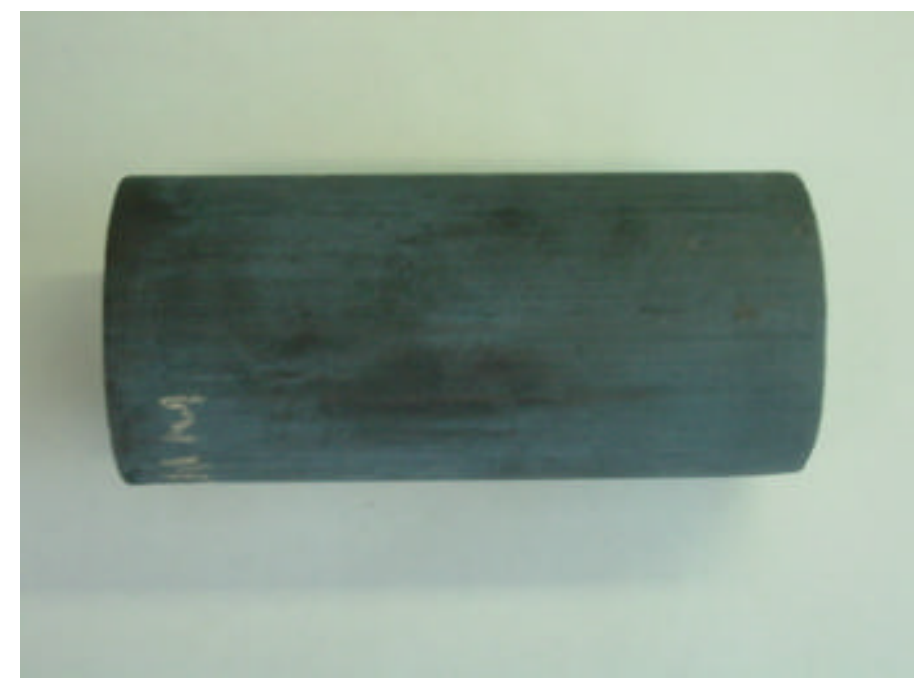

Figure 3.2.5-3 - Specific Surface New Material

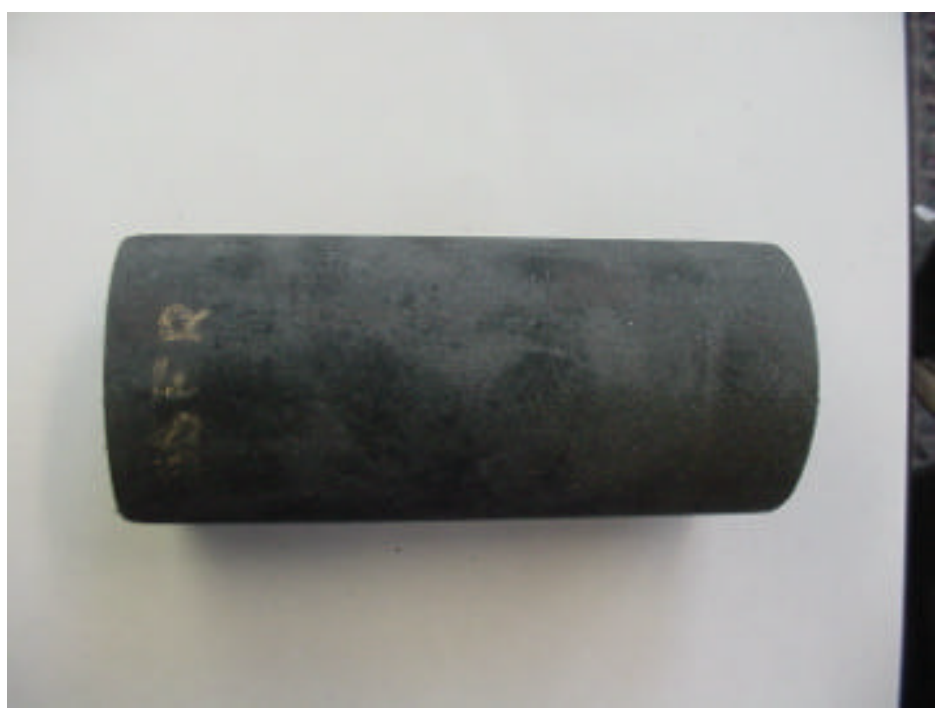

Figure 3.2.5-4 - Specific Surface Fully Recrystallized 


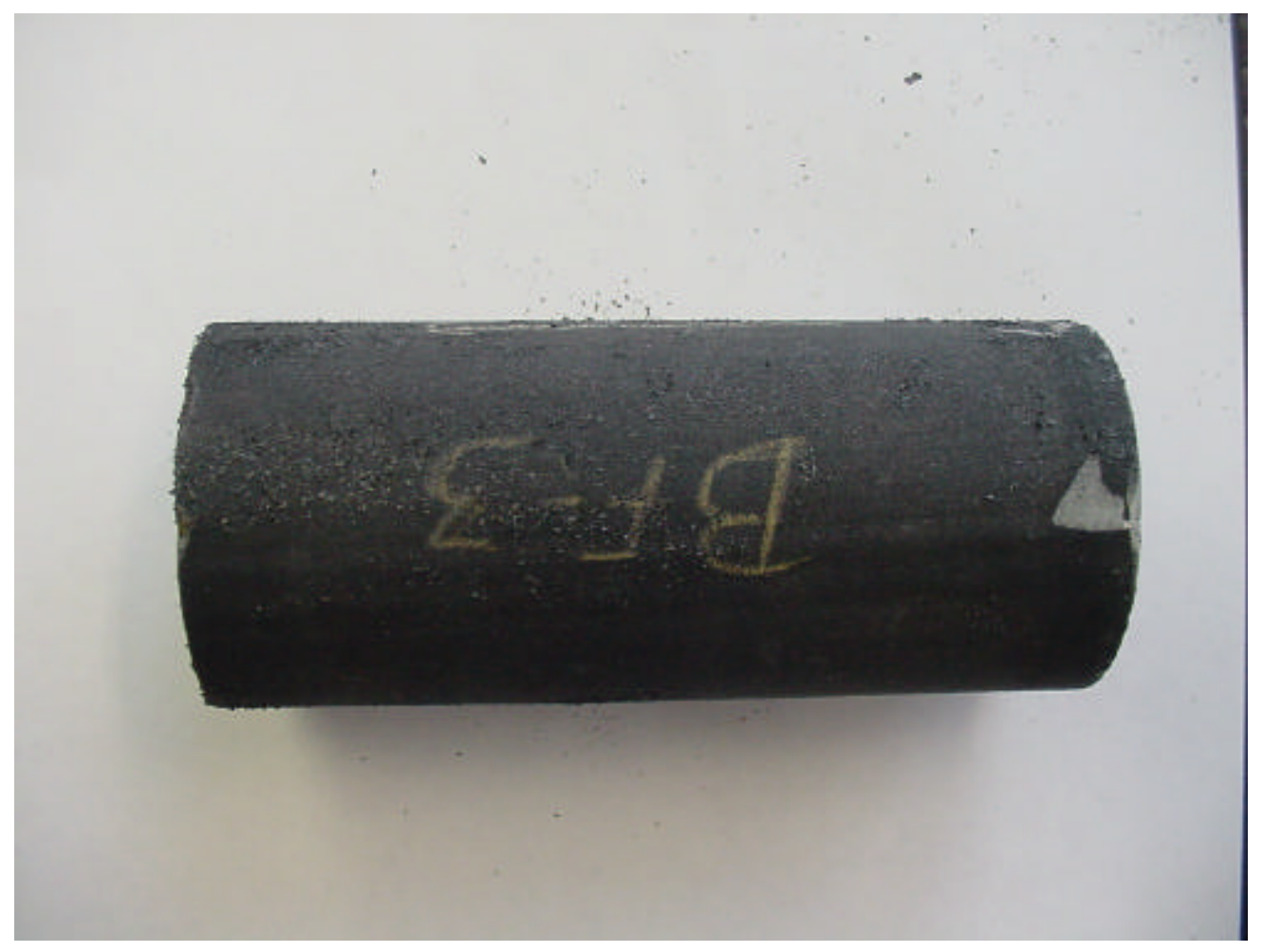

Figure 3.2.5-5 - Ceramem BF3

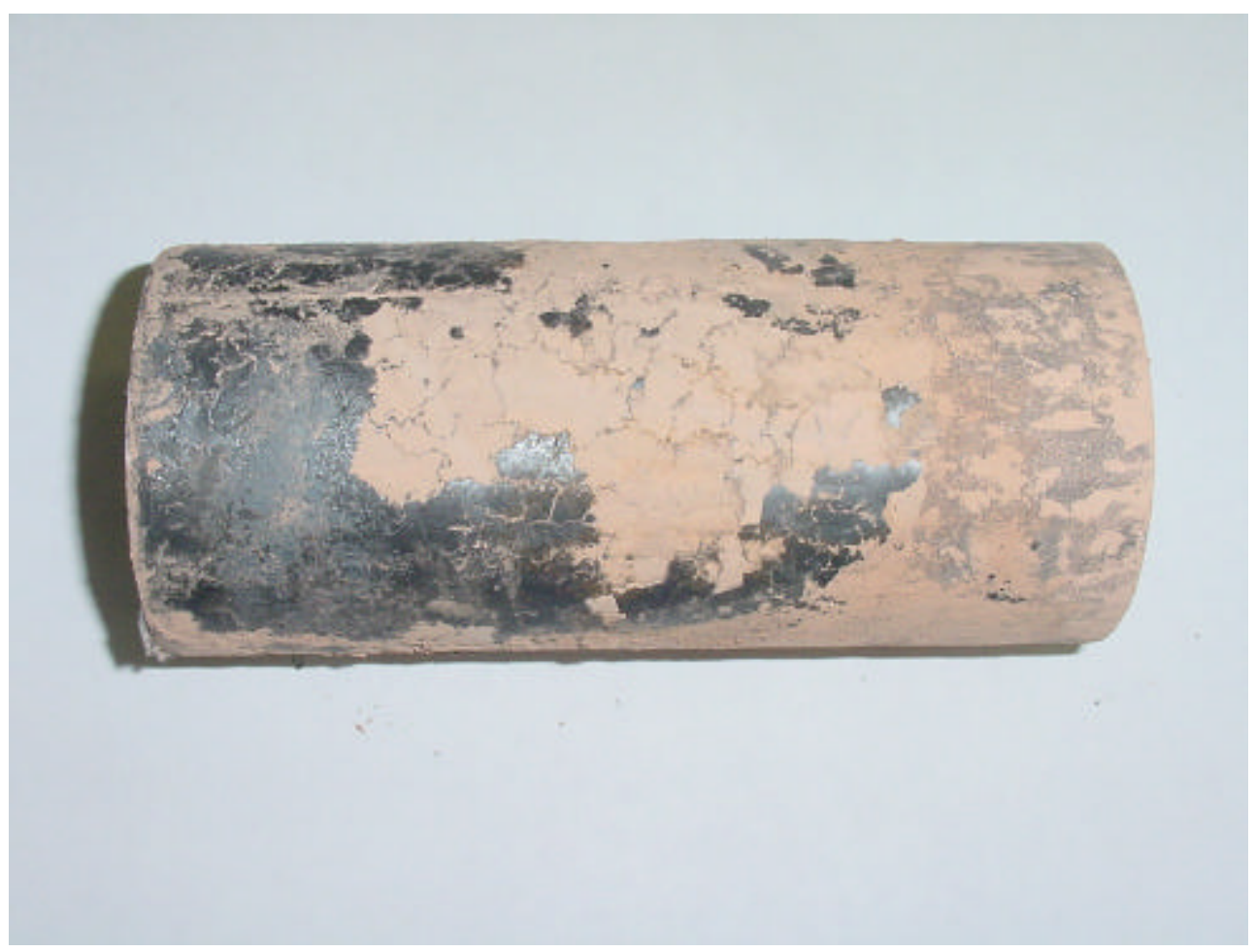

Figure 3.2.5-6 - Ceramem BF4 
Periodic dust sampling of five minute duration showed that the unit from Ceramem (BF4) that was activated (positioned over a missing candle filter) plugged rapidly and completely upon feeding of ash dust. Differential pressure readings over a flow tube leading to the unit showed that the unit did not unplug during backpulsing at any time during the week's worth of testing. Final permeability testing of this unit showed that this honeycomb device remained totally plugged after all testing was complete. A photograph of the plugged inlet end is shown in Figure 3.2.5-7. Figure 3.2.5-6 shows that some dust penetrated along a portion of the body of the unit. The outlet is shown in Figure 3.2.5-8 where it is evident that no dust leakage occurred.

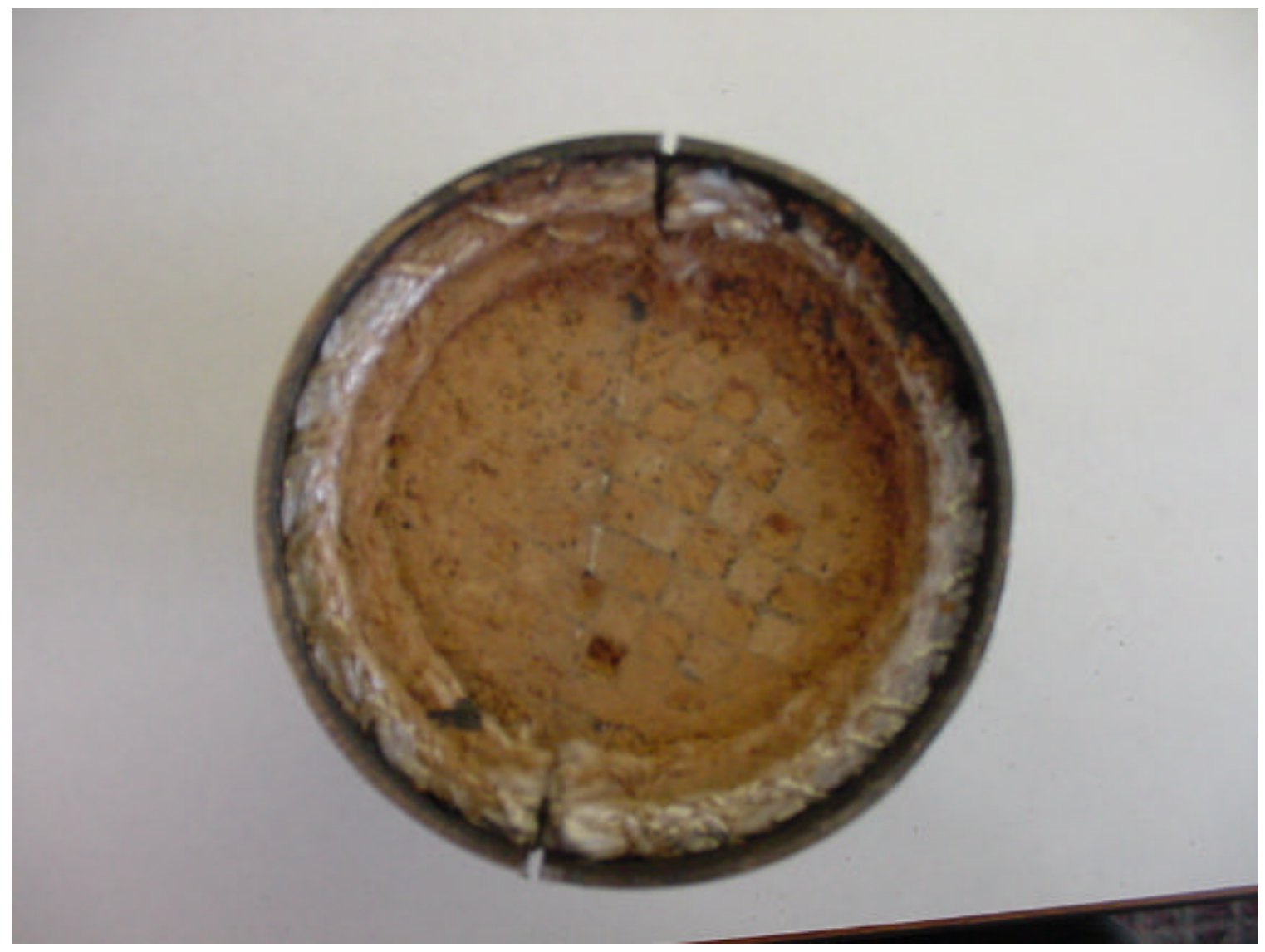

Figure 3.2.5-7 - Plugged Inlet End of Ceramem Unit BF4 


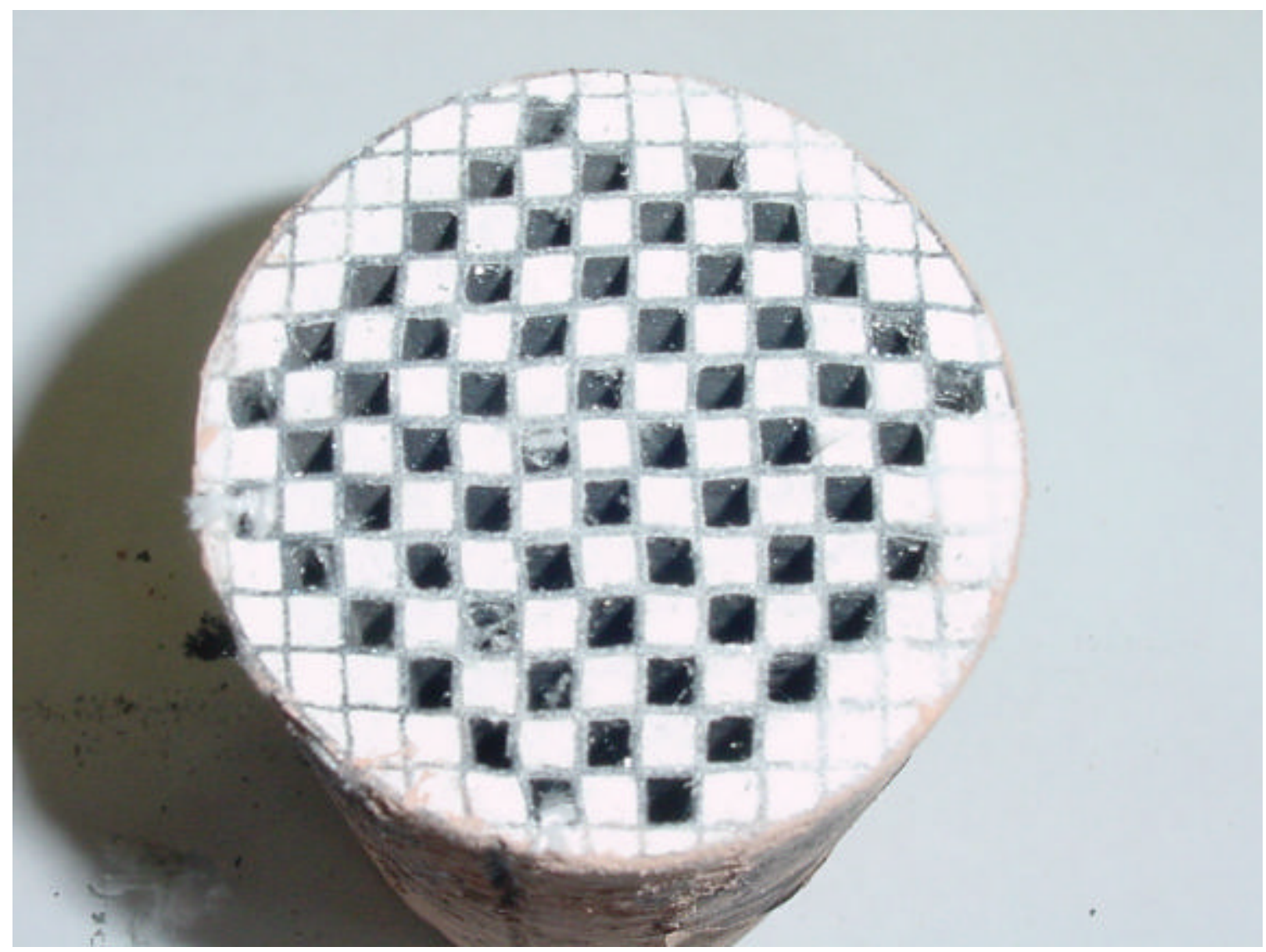

Figure 3.2.5-8 - Clean Outlet End of Plugged Ceramem Unit BF4

\subsubsection{STC Test 7 - Optimization - Three Silicon Carbide Honeycomb SGDs}

The longer tem durability of the silicon carbide units was assessed in this test by accelerated pulsing at $650^{\circ} \mathrm{C}\left(1200^{\circ} \mathrm{F}\right)$. Considering that the test units would include a regenerator to modify the effect of backpulsing, this temperature was selected after discussion with DOECOR and consideration that most near-term applications would be in gasification conditions where temperatures would be limited to $370--480^{\circ} \mathrm{C}\left(700-900^{\circ} \mathrm{F}\right)$. Two units from Specific Surface Corporation (SSNM - Specific Surface New Material and SSFR - Specific Surface Fully Recrystallized) were installed over intact candle filters. One unit from Ceramem (BF3) was installed over an intact candle filter. One additional filter position was candled with a conventional failsafe.

After exposure to 1024 accelerated pulses, the units were disassembled and examined. All three units sustained the exposure without any evidence of damage.

Conclusion: Honeycomb barrier safe guard devices made of silicon carbide from Ceramem and from Specific Surface (fully recrystallized or new material) are durable up to proposed senvice temperatures of $650^{\circ} \mathrm{C}\left(1200^{\circ} \mathrm{F}\right)$. 
Option 1 "Field Testing" should utilize units of this design and manufacture. (Field exposure will be at lower temperatures and without regenerators.) Eight Ceramem units designated 'SiC" and two Specific Surface units of recrystallized SiC designated "RX Silicon" have been prepared for such field evaluation.

\subsection{PILOT EXPOSURES}

\subsubsection{Introduction and Material Selection}

Long term durabilities of various fibers were assessed by pilot exposures. Materials were chosen based on manufacturer's recommendations, corrosion performance reported in the literature, and availability. Alloys chosen for oxidation and gasification exposure are summanized in Tables 3.3.1-1 and 3.3.1-2 respectively.

Table 3.3.1-1 - Materials for Oxidation Exposure

\begin{tabular}{|l|l|l|l|l|l|l|l|l|l|l|l|l|l|l|}
\hline Alloy & UNS No. & Cr & Ni & Mo & W & Si & Mn & Al & C & Fe & La & B & Y & Zr \\
\hline 310 & S31008 & 25 & 20 & & & & 1.6 & & .05 & 52 & & & & \\
\hline 230 & N06230 & 22 & 60 & 1.5 & 14 & .4 & .5 & .3 & .1 & 1 & .02 & .004 & & \\
\hline 214 & N07214 & 16 & 76 & & & & & 4.5 & .04 & 3.5 & & & .005 & .03 \\
\hline FeCrAIY & & & & & & & & & & & & & & \\
\hline
\end{tabular}

Table 3.3.1-2 - Materials for Gasification Exposure

\begin{tabular}{|l|l|l|l|l|l|l|l|l|l|l|l|l|}
\hline Alloy & UNS No. & Cr & Ni & Co & Si & Mn & Al & C & Fe & Y & Zr & Ti \\
\hline 310 & S31008 & 25 & 20 & & & 1.6 & & .05 & 52 & & & \\
\hline 160 & N12160 & 28 & 36 & 30 & 2.8 & .5 & & .05 & 2 & & & .5 \\
\hline $85 \mathrm{H}$ & S30615 & 18.5 & 14.5 & & 3.5 & .8 & 1 & .2 & 61 & & & \\
\hline
\end{tabular}

\subsubsection{Equipment Arrangement and Description of Exposure}

Pilot plant opportunities were not available to expose fibers in oxidizing (PFBC) conditions. Therefore, static laboratory fumace exposure in air was conducted on the four fiber types (310, 230, 214 and FeCrAIY). Two modules were fabricated as shown in Figure 3.3.2-1. Each of the four compartments contained a different fiber type and geometry as summarized in Table 3.3.21. The modules were exposed at $816^{\circ} \mathrm{C}\left(1500^{\circ} \mathrm{F}\right)$ with only two interuptions to room temperature. Exposure was accumulated in such oxidizing conditions totaling approximately 6500 hours. The units were dismantled and the exposed fibers as well as control (unexposed) fibers were prepared for metallographic examination for evidence of hot corrosive attack. 

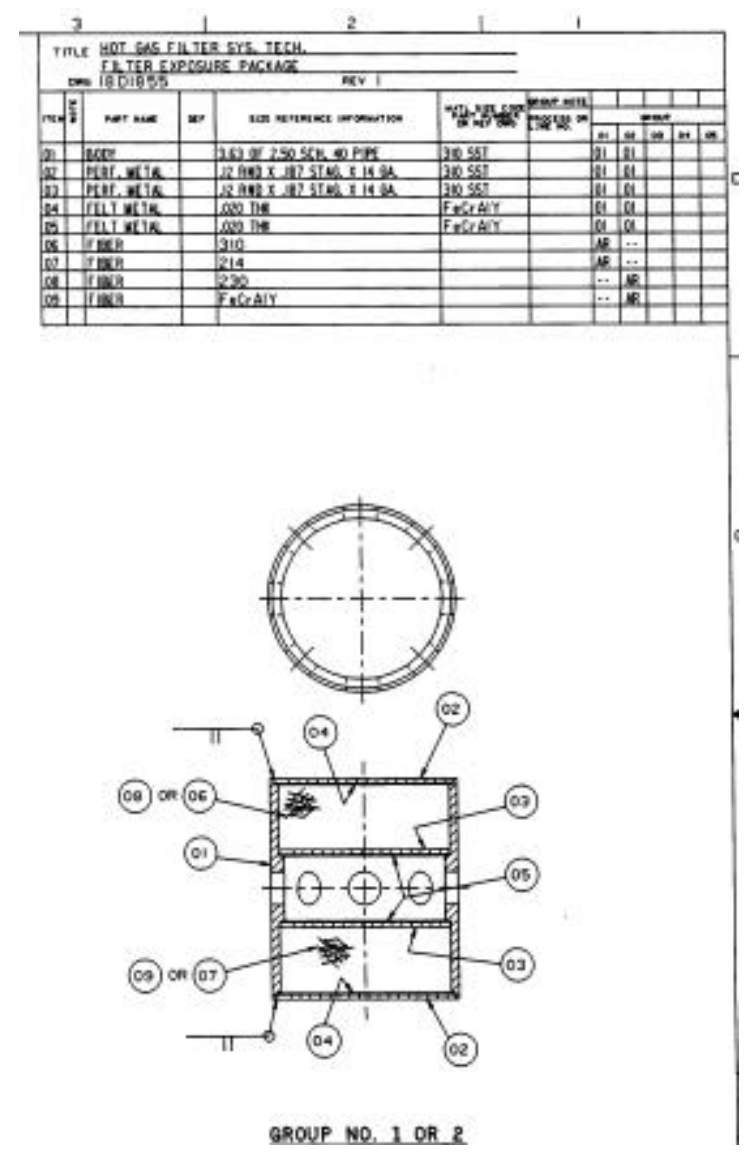

Figure 3.3.2-1 - Modules for Oxidizing Exposure

Table 3.3.2-1 - Fibers and Fiber Geometry for Oxidation Exposure

\begin{tabular}{|c|l|l|}
\hline Alloy & \multicolumn{1}{|c|}{ Diameter } & \multicolumn{1}{|c|}{ Length } \\
\hline 310 & $0.25 \times 0.76 \mathrm{~mm}\left(0.010 \times 0.030^{\prime \prime}\right)$ & $19 \mathrm{~mm}\left(0.75^{\prime \prime}\right)$ \\
\hline 230 & $0.14 \mathrm{~mm}\left(0.0055^{\prime \prime}\right)$ & $6.4 \times 25 \mathrm{~mm}\left(0.25 \times 1^{\prime \prime}\right)$ \\
\hline 214 & $0.10 \mathrm{~mm}\left(0.004^{\prime \prime}\right)$ & $25 \mathrm{~mm}(50 \%)$ and $250 \mathrm{~mm} \mathrm{(50 \% )}$ \\
\hline FeCrAIY & $0.10 \mathrm{~mm}\left(0.004^{\prime \prime}\right)$ & $25 \mathrm{~mm}\left(1^{\prime \prime}\right)$ \\
\hline
\end{tabular}

The opportunity for field exposure in gasification conditions was available in the particulate control device (PCD) 301 at the Power Systems Development Facility (PSDF) in Wilsonville, AL. Ten safe guard devices (SGDs) were fabricated as shown in Figure 3.3.2-2. Each of the SGDs contained a different fiber type and/or geometry as summarized in Table 3.3.2-2. The safe guard devices were exposed to gasification conditions totaling over 1000 hours. The actual number of hours at various temperatures are summarized in Table 3.3.2-3. Two units 
(310 and 160) were removed, dismantled and the exposed fibers as well as control (unexposed) fibers were prepared for metallographic examination for evidence of hot corrosive attack.

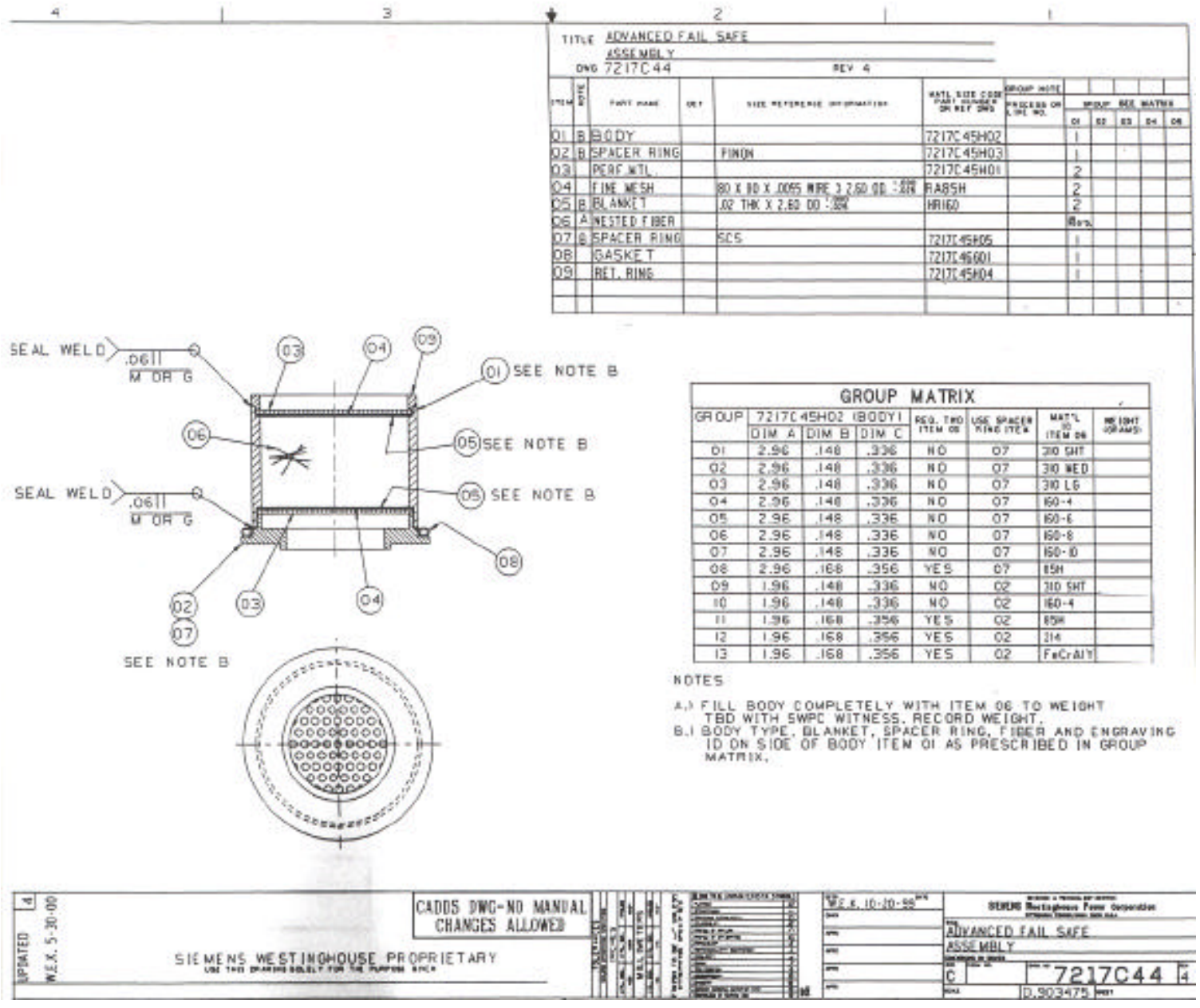

Figure 3.3.2-2 - SGDs for Gasification Exposure 
Table 3.3.2-2 - Positions, SGD IDs and Fiber Descriptions (Weight, Alloy and Size) for Gasification Exposure in PCD 301

\begin{tabular}{|c|c|}
\hline POSITION AND ID & FIBER DESCRIPTION \\
\hline T17 $160-4$ & $120 \mathrm{gm}-160-0.4 \times 25 \mathrm{~mm}$ \\
\hline $\begin{array}{ll}\text { T16 } & 160-6\end{array}$ & $180 \mathrm{gm}-160-0.4 \times 25 \mathrm{~mm}$ \\
\hline $\begin{array}{ll}\text { T15 } & 160-8\end{array}$ & $180 \mathrm{gm}-160-0.4 \times 25 \mathrm{~mm}$ \\
\hline T14 $160-10$ & $180 \mathrm{gm}-160-0.4 \times 25 \mathrm{~mm}$ \\
\hline T13 $85 \mathrm{H}$ & $120 \mathrm{gm}-85 \mathrm{H}-0.14 \times 6.4 \times 25 \mathrm{~mm}$ \\
\hline $\begin{array}{ll}\text { B17 } & 310-S H T\end{array}$ & $240 \mathrm{gm}-310-0.25 \times 0.76 \times 19 \mathrm{~mm}$ \\
\hline B16 310-MED & $169 \mathrm{gm}-310-0.25$ X 25mm \\
\hline B15 310-LG & $139 \mathrm{gm}-310-0.25 \times 0.76 \times 35 \mathrm{~mm}$ \\
\hline B14 $0-6-A$ \#1 & 316 \\
\hline B13 $0-6-A$ \#2 & 316 \\
\hline
\end{tabular}

Table 3.3.2-3 - Hours at Temperature in the PCD at Wilsonville

\begin{tabular}{|l|c|}
\hline Temperature Range ${ }^{\circ} \mathbf{C}\left({ }^{0} \mathrm{~F}\right)$ & Hours in Range \\
\hline $93-149(200-300)$ & 324 \\
\hline $149-204(300-400)$ & 205 \\
\hline $204-260(400-500)$ & 157 \\
\hline $260-316(500-600)$ & 170 \\
\hline $316-371(600-700)$ & 423 \\
\hline $371-427(700-800)$ & 1096 \\
\hline $427-482(800-900)$ & 189 \\
\hline $482-538(900-1000)$ & 150 \\
\hline $538-593(1000-1100)$ & 15 \\
\hline
\end{tabular}




\subsubsection{Results of Examination for 310 Fiber - Unexposed and Oxidizing}

Scanning electron micrographs (SEM) of cross sections of unexposed (new) alloy 310 fibers are shown in Figures 3.3.3-1 and 3.3.3-2. Energy Dispersive X-Ray Analysis (EDAX) of the surface (spot 1),matrix (spot 2) and precipitate (spots $3 \&$ 4) shown in Figure 3.3.3-3 are displayed in Figure 3.3.3-4.

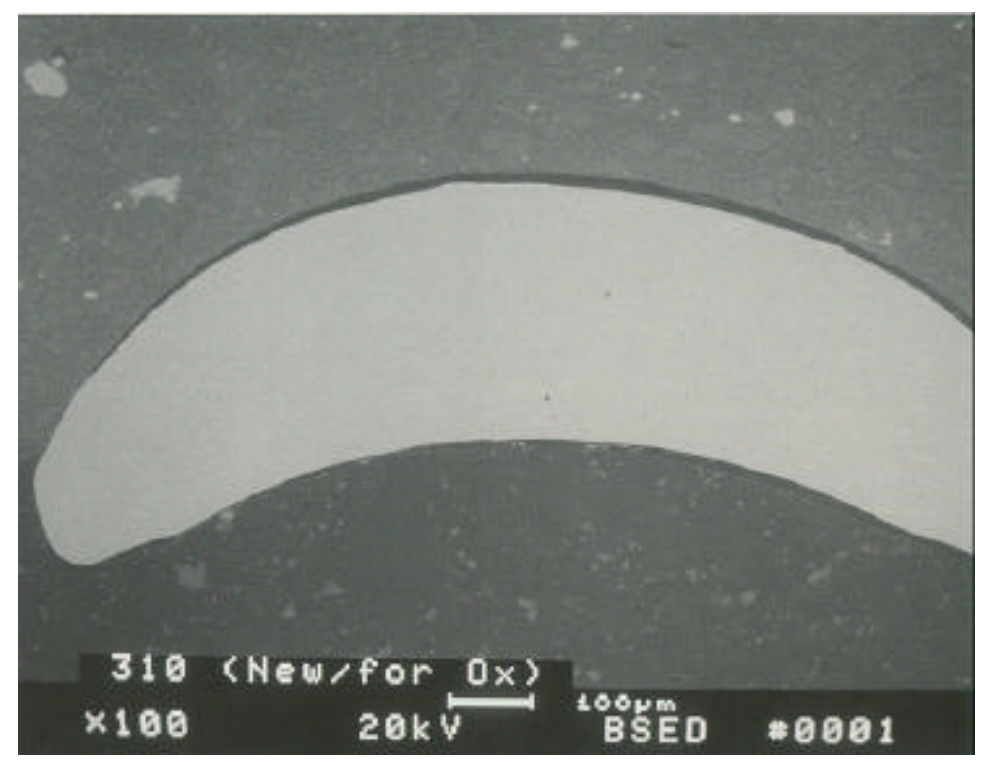

Figure 3.3.3-1 - SEM of Unexposed Alloy 310 Fiber Cross Section

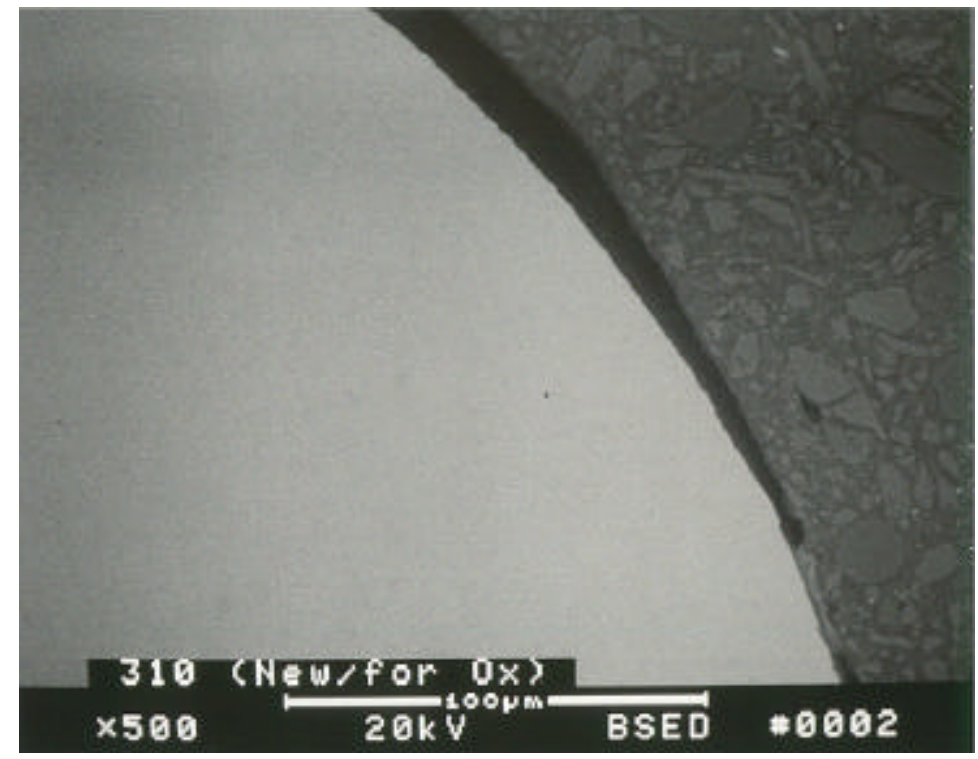

Figure 3.3.3-2 - SEM of Unexposed Alloy 310 Fiber Cross Section 


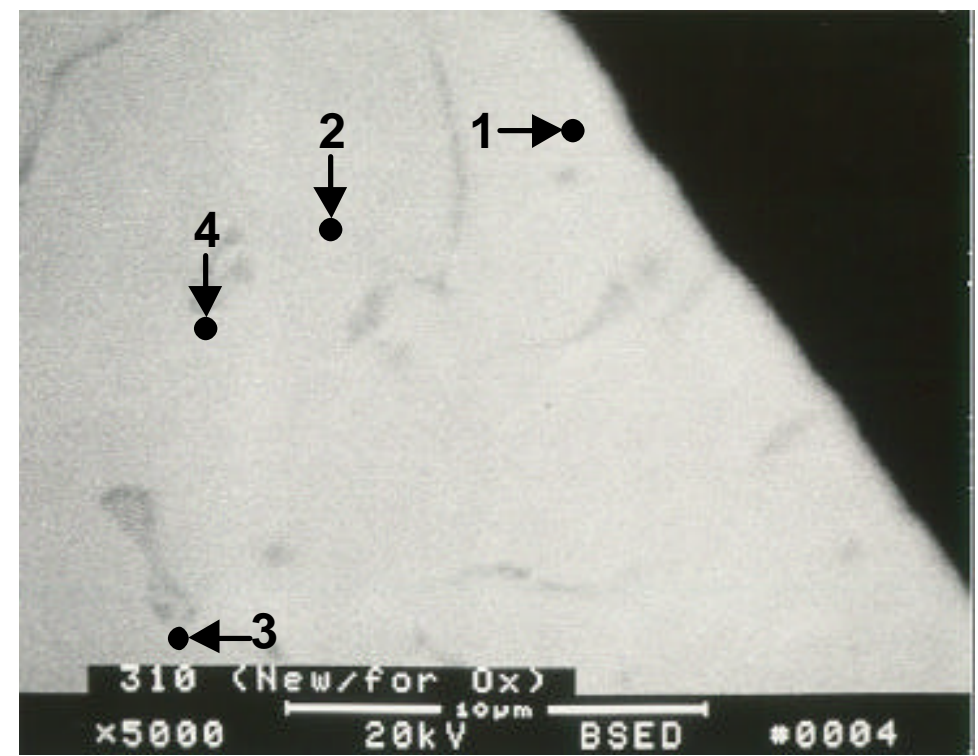

Figure 3.3.3-3 - Surface (spot 1), Matrix (spot 2) and Precipitates (spots $3 \& 4$ ) for
Unexposed Alloy 310

The matrix is typical of the alloy's nominal composition. The surface is somewhat enriched in chromium. The precipitates are evidently highly enriched in chromium. These precipitates are probably carbides which, in a fully austenitic alloy such as 310 stainless, would be of $\mathrm{M}_{23} \mathrm{C}_{6}$ type where $M$ is primarily chromium and/or iron.

Scanning Electron Micrographs of cross sections of alloy 310 wires after static oxidation exposure for 6500 hours at $816^{\circ} \mathrm{C}\left(1500^{\circ} \mathrm{F}\right)$ are shown in Figures 3.3.3-5 and 3.3.3-6. EDAX analysis of various spots shown in Figure 3.3.3-7 are displayed in Figure 3.3.3-8.

The surface oxide (spot 1) and intemal connected oxides (spots 2 and 3 ) are evidently rich in chromium and oxygen. The subsurface oxide is somewhat less rich in chromium and oxygen than the surface oxide but is, in addition, highly enriched in manganese. It is likely that a manganese sulfide happened to be associated with this subsurface oxide. Other candidate internal phases expected to precipitate rapidly (within 200 hours) at $815 \mathrm{C}$ (1500F) include a tetragonal structure called sigma of the general composition $(\mathrm{Fe}, \mathrm{Ni})_{x} \mathrm{Cr}_{\mathrm{y}}$.

The thickness of the surface oxide is of the order of 5 microns. Intemal oxidation of about 30 additional microns extended the total amount of metal affected to approximately 35 microns. Recognizing that the wire is of the order of 500 microns ( 0.02 inches) in 'diameter', about 14 percent of the fiber 'diameter' and 26 percent of the fiber material have been affected by oxidation attack.

If we assume metal loss to be approximately equal to the thickness of the surface oxide, average metal affected may be defined as the surface oxide thickness plus one half of the internal oxidation. Average metal affected is then approximately 20 microns (0.001 inches). Our result of 20 microns average metal affected for exposure of 6500 hours at $816^{\circ} \mathrm{C}(1500 \mathrm{~F})$ (Larson Miller No. 48) is, to a first approximation, comparable to 28 microns (0.0011 inches) average metal affected reported by Haynes for exposure of alloy 310 to 1008 hours at 982C (1800F) (Larson Miller No. 52). 

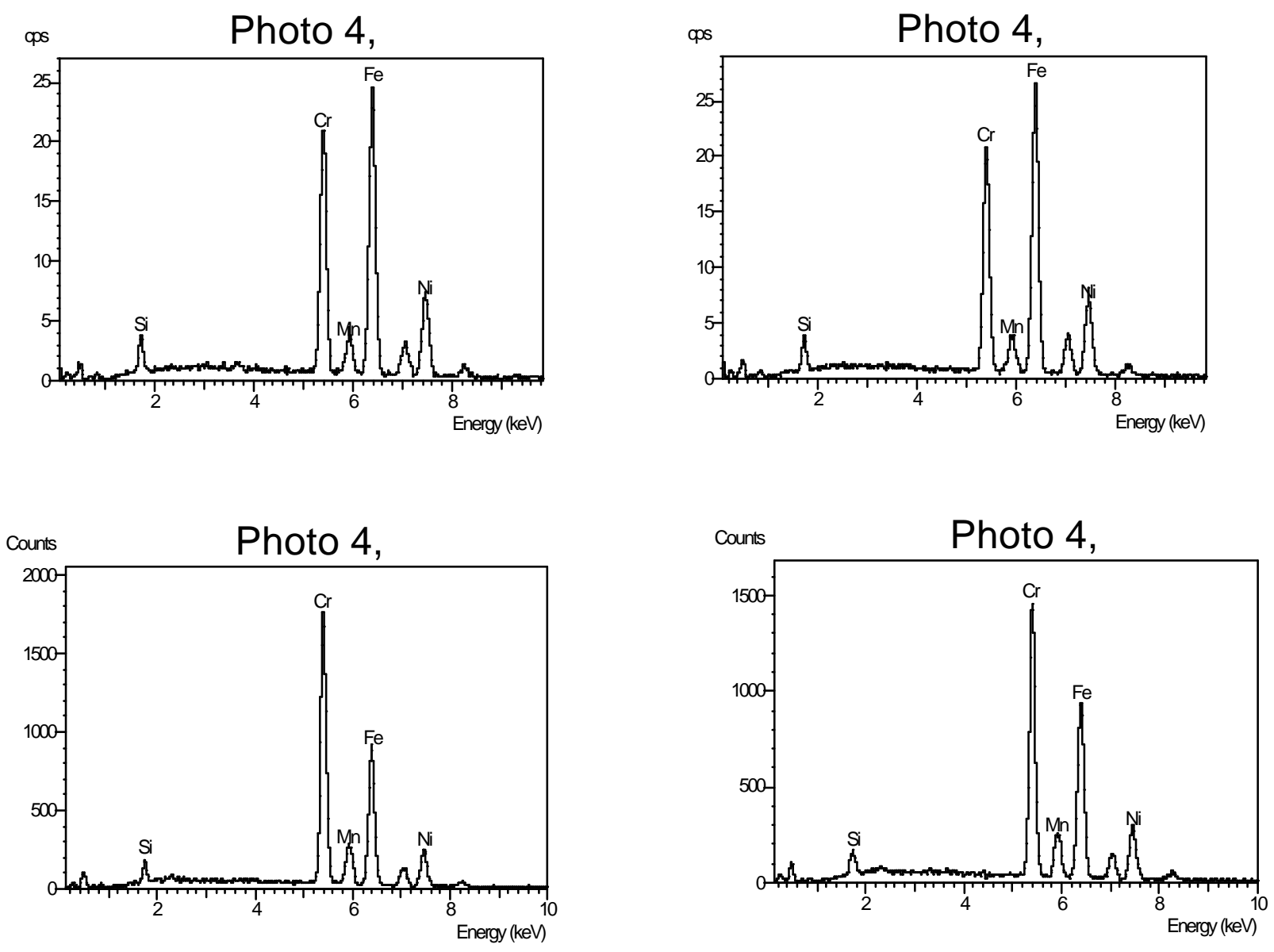

\begin{tabular}{|l|r|r|r|r|r|}
\hline & Wt\% Si & Wt\% Cr & $\mathbf{W t} \% \mathbf{M n}$ & $\mathbf{W t} \% \mathbf{~ F e}$ & $\mathbf{W t} \% \mathbf{~ N i}$ \\
\hline \hline Photo 4, spot 1 & 2.18 & 27.45 & 1.47 & 47.49 & 21.41 \\
\hline Photo 4, spot 2 & 2.21 & 25.58 & 1.60 & 49.23 & 21.38 \\
\hline Photo 4, spot 3 & 1.97 & 45.13 & 1.70 & 36.87 & 14.33 \\
\hline Photo 4, spot 4 & 1.82 & 40.40 & 2.46 & 38.63 & 16.69 \\
\hline
\end{tabular}

Figure 3.3.3-4 - EDAX Analysis of Matrix and Precipitate in Unexposed Alloy 310 


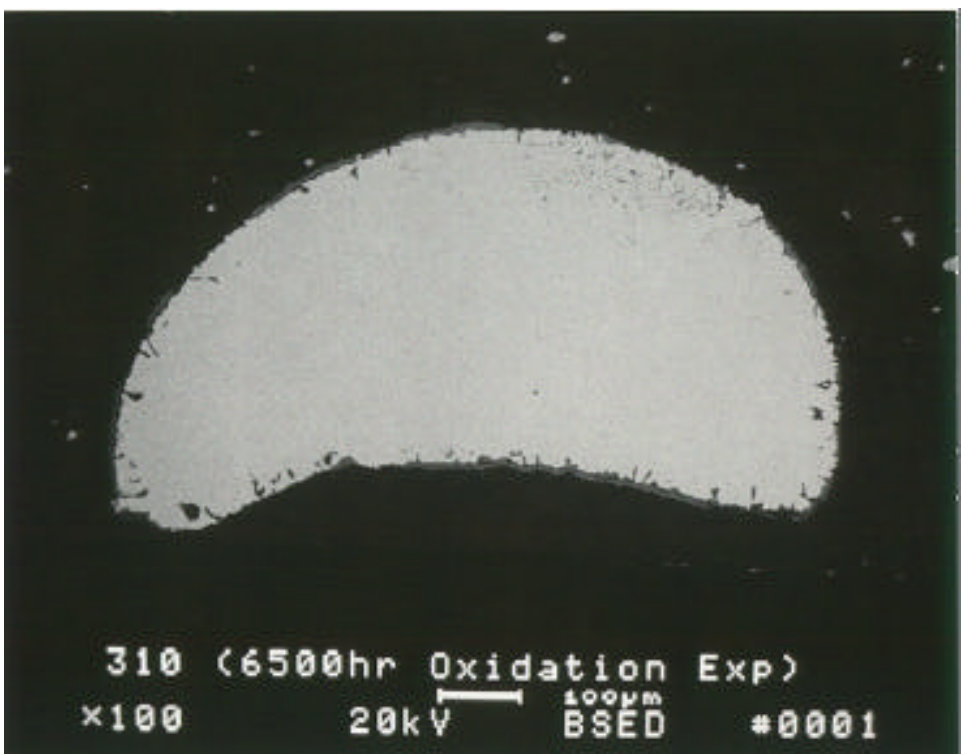

Figure 3.3.3-5 - SEM of Exposed Alloy 310 Fiber Cross Section

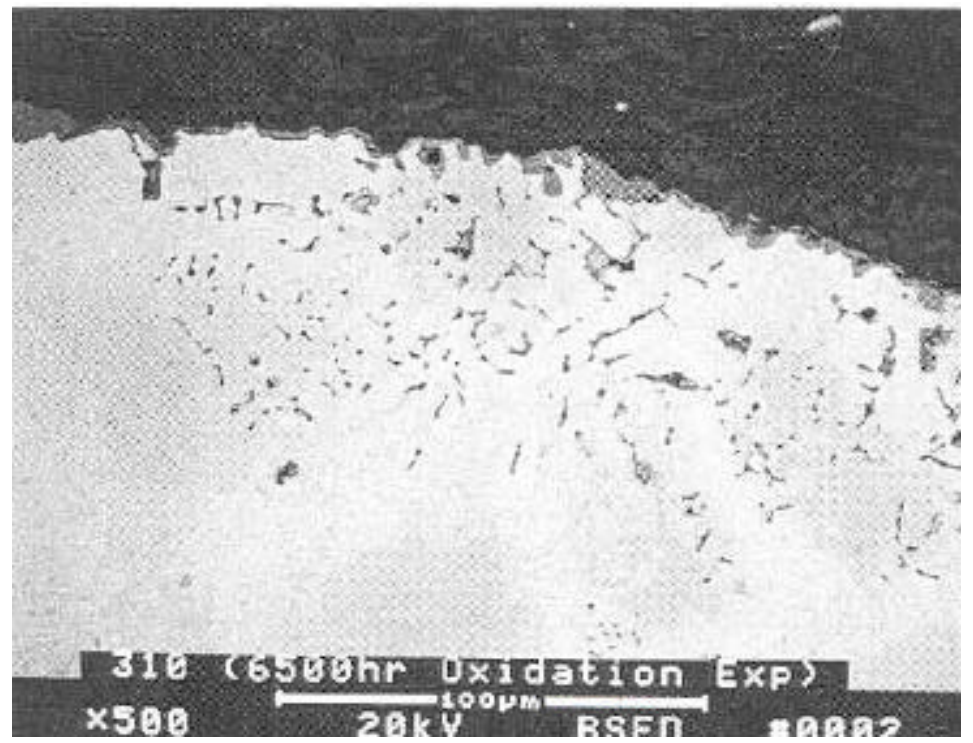

Figure 3.3.3-6 - SEM of Exposed Alloy 310 Fiber Cross Section 


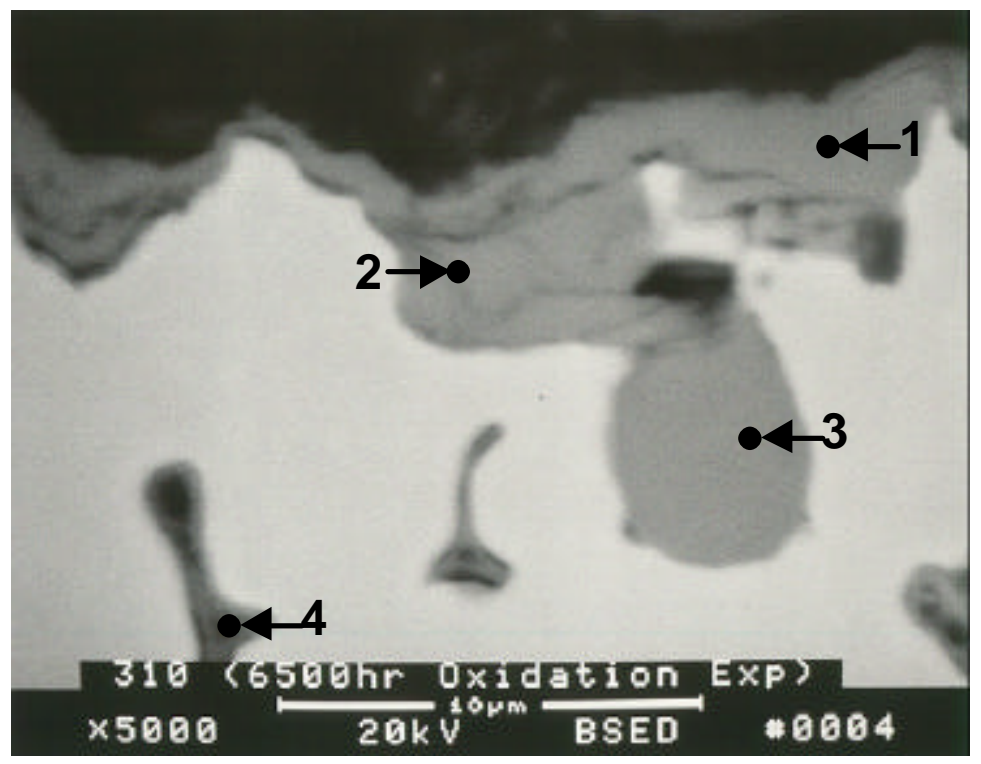

Figure 3.3.3-7 - Surface Oxide (spot 1), and Internal but Connected Oxides (spots 2, and 3) and Subsurface Oxides (spot 4) for Exposed Alloy 310 Fiber
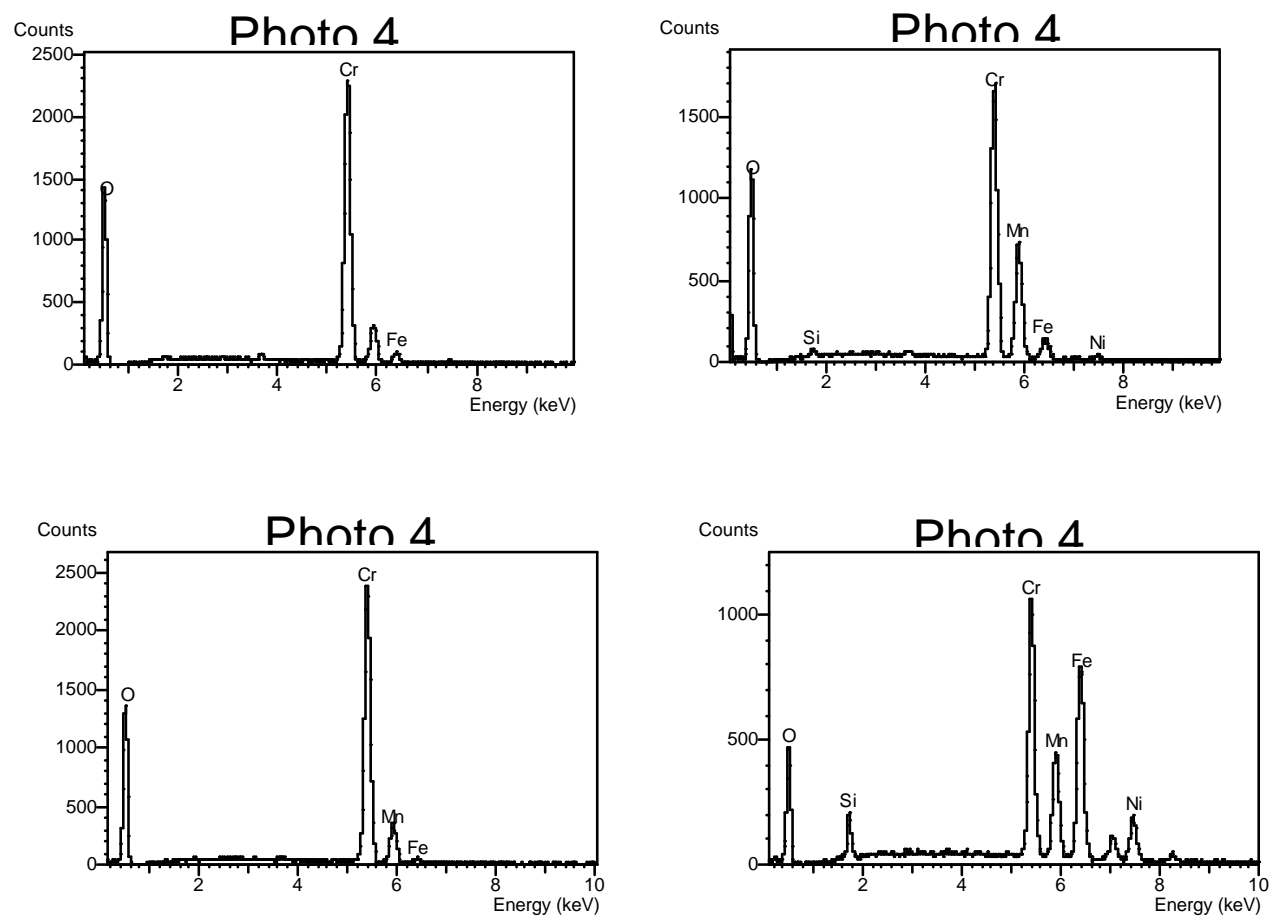

\begin{tabular}{|l|r|r|r|r|r|r|}
\hline & $\mathbf{W t} \% \mathbf{O}$ & $\mathbf{W t} \% \mathbf{~ S i}$ & $\mathbf{W t} \% \mathbf{~ r r}$ & $\mathbf{W t} \% \mathbf{M n}$ & $\mathbf{W t} \% \mathbf{~ F e}$ & $\mathbf{W t} \% \mathbf{~ N i}$ \\
\hline \hline Photo 4, spot 1 & 28.81 & & 65.39 & 1.27 & 3.51 & 1.02 \\
\hline Photo 4, spot 2 & 24.39 & 0.51 & 49.81 & 19.92 & 3.99 & 1.38 \\
\hline Photo 4, spot 3 & 28.01 & & 68.02 & 2.26 & 1.33 & 0.38 \\
\hline Photo 4, spot 4 & 10.23 & 2.68 & 28.73 & 11.84 & 34.80 & 11.73 \\
\hline
\end{tabular}

Figure 3.3.3-8 - EDAX Analysis of Exposed Alloy 310 Fiber 


\subsubsection{Results of Examination for 230 Fiber - Unexposed and Oxidizing}

Scanning electron micrographs (SEM) of cross sections of unexposed (new) alloy 230 fibers are shown in Figures 3.3.4-1 and 3.3.4-2. Energy Dispersive X-Ray Analysis (EDAX) of the matrix (area 1) and precipitate (spot 2) shown in Figure 3.3.4-3 are displayed in Figure 3.3.4-4.

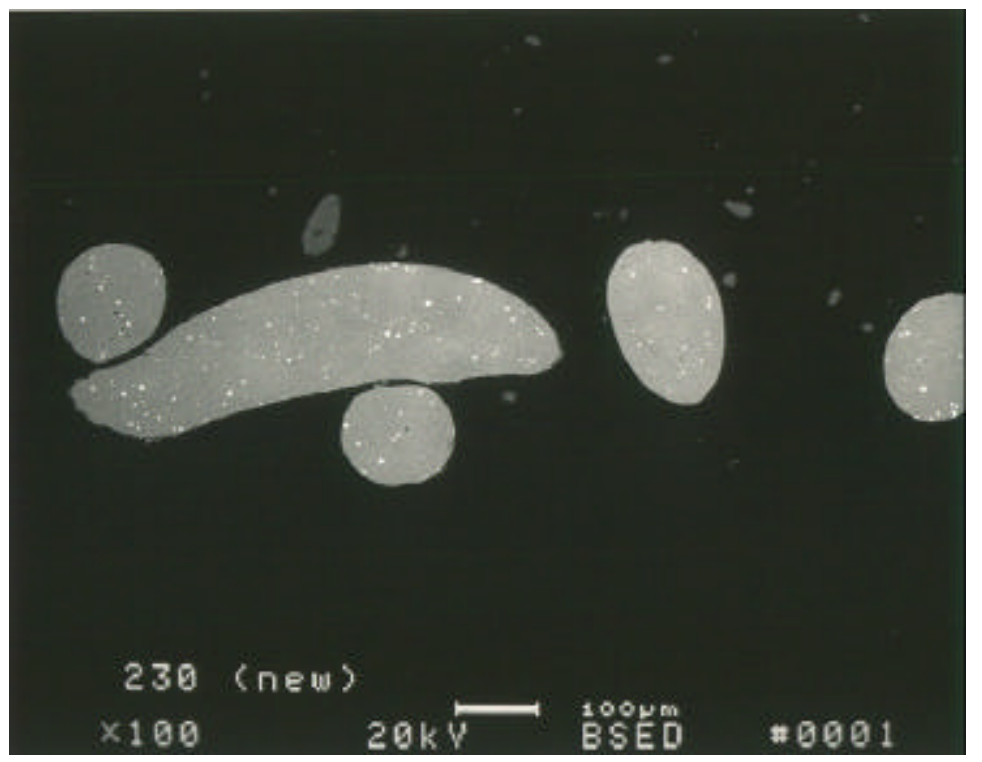

Figure 3.3.4-1 - SEM of Unexposed Alloy 230 Fiber Cross Sections

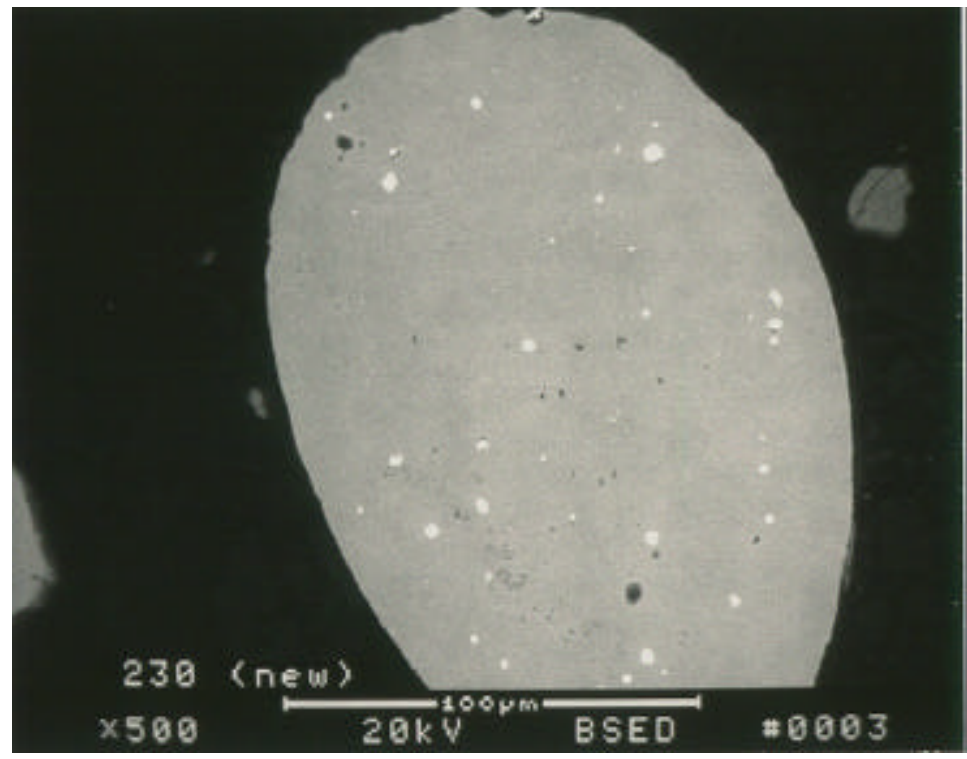

Figure 3.3.4-2 - SEM of Unexposed Alloy 230 Fiber Cross Sections 


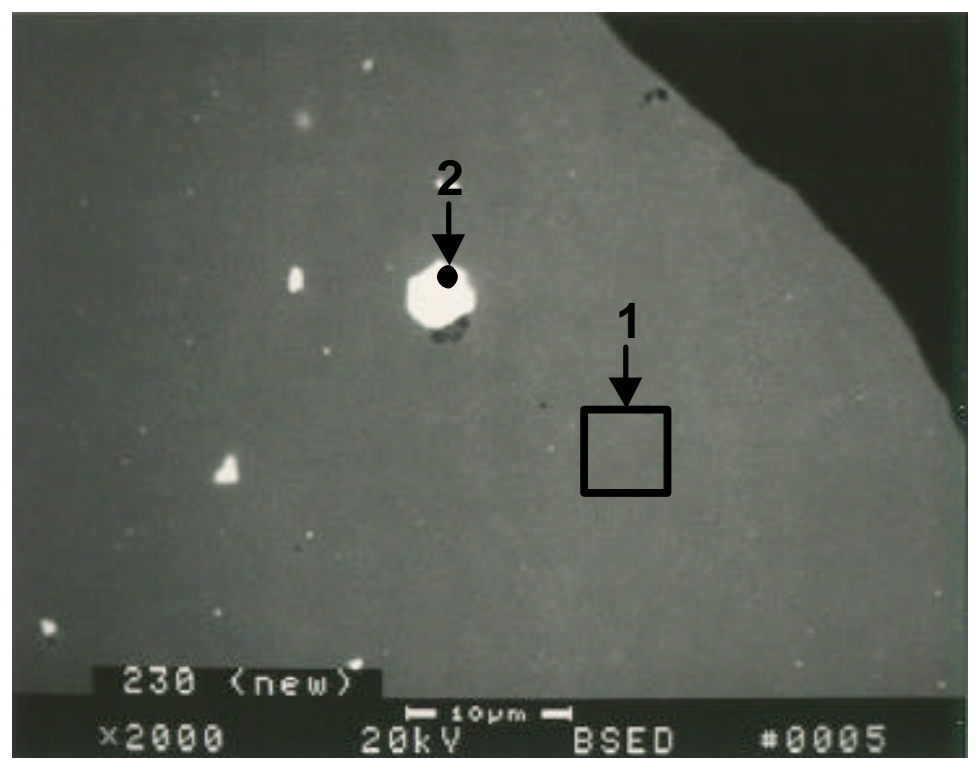

Figure 3.3.4-3 - Matrix (area 1) and Precipitate (spot 2) for Unexposed Alloy 230
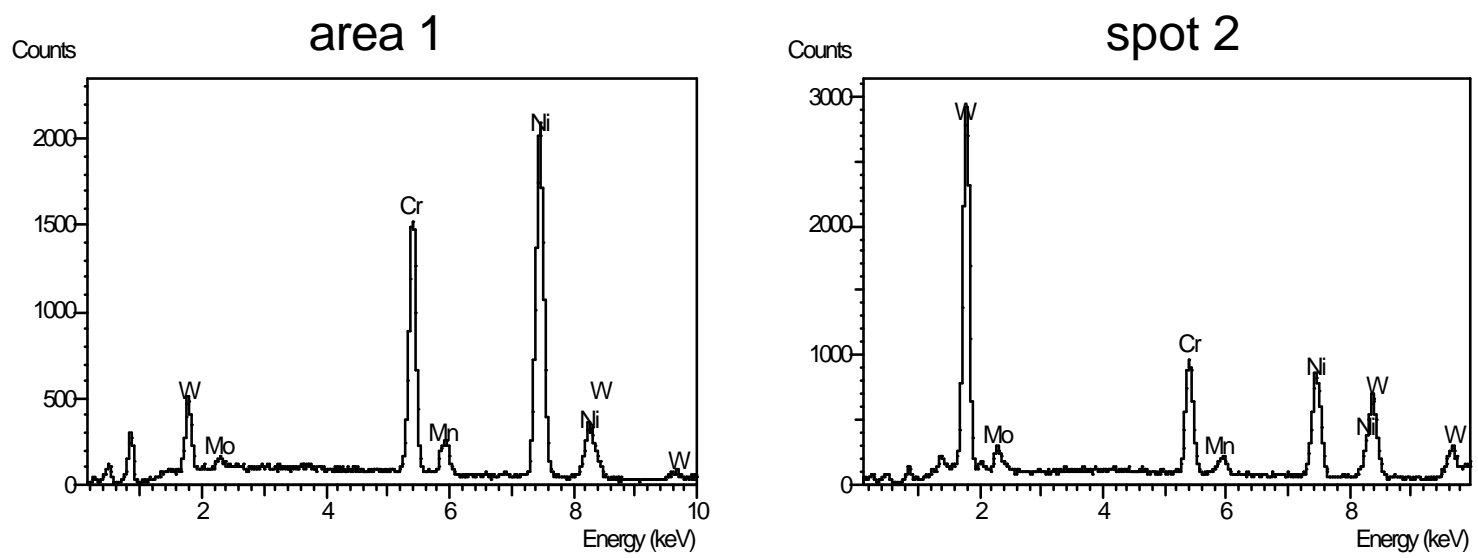

\begin{tabular}{|l|r|r|r|r|r|}
\hline & $\mathbf{W t} \% \mathbf{C r}$ & $\mathbf{W t} \% \mathbf{M n}$ & $\mathbf{W t} \% \mathbf{~ N i}$ & $\mathbf{W t} \% \mathbf{M o}$ & $\mathbf{W t} \% \mathbf{~ W}$ \\
\hline \hline area 1 & 22.34 & 0.31 & 65.28 & 1.24 & 10.83 \\
\hline spot 2 & 14.71 & 0.41 & 24.91 & 4.08 & 55.89 \\
\hline
\end{tabular}

Figure 3.3.4-4 - EDAX Analysis of Matrix and Precipitate in Unexposed Alloy 230

The matrix is typical of the alloy's nominal composition. The precipitate is evidently a tungsten carbide - which is typically found in alloy 230 . Such a precipitate has been found to be of $\mathrm{M}_{6} \mathrm{C}$ type and is referred to as primary to distinguish it from secondary precipitates, which follow from, elevated temperature exposure. 
Scanning Electron Micrographs of cross sections of alloy 230 wires after static oxidation exposure for 6500 hours at $816{ }^{\circ} \mathrm{C}$ (1500F) are shown in Figures 3.3.4-5 and 3.3.4-6. EDAX analysis of various spots shown in Figure 3.3.4-7 are displayed in Figure 3.3.4-8.

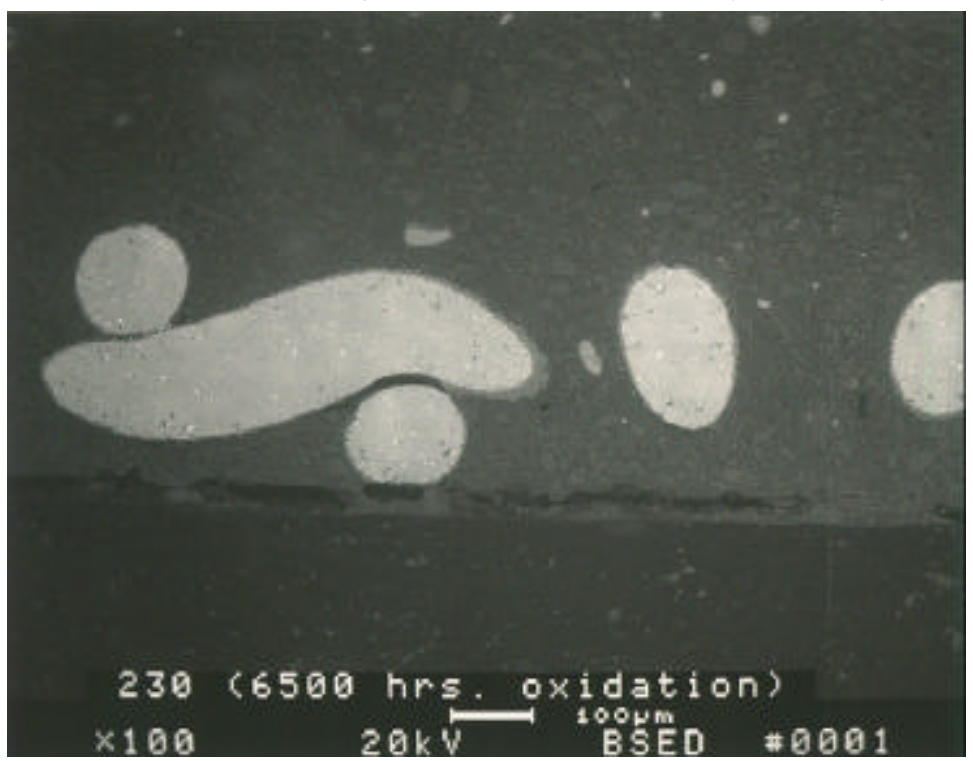

Figure 3.3.4-5 - SEM of Exposed Alloy 230 Fiber Cross Sections

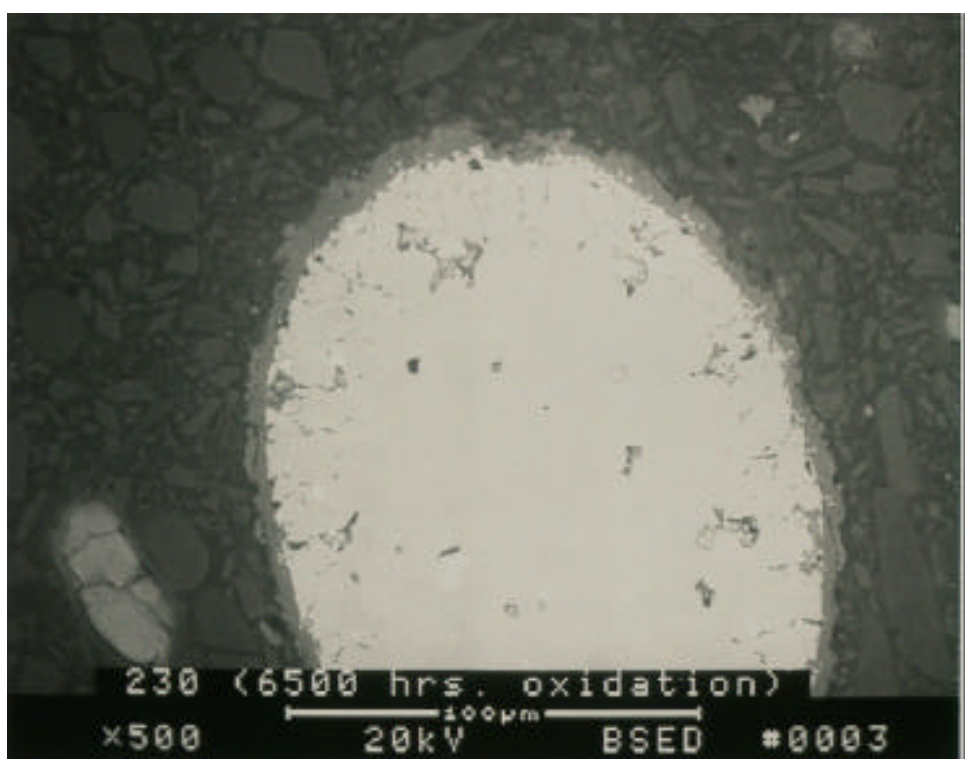

Figure 3.3.4-6 - SEM of Exposed Alloy 230 Fiber Cross Section 


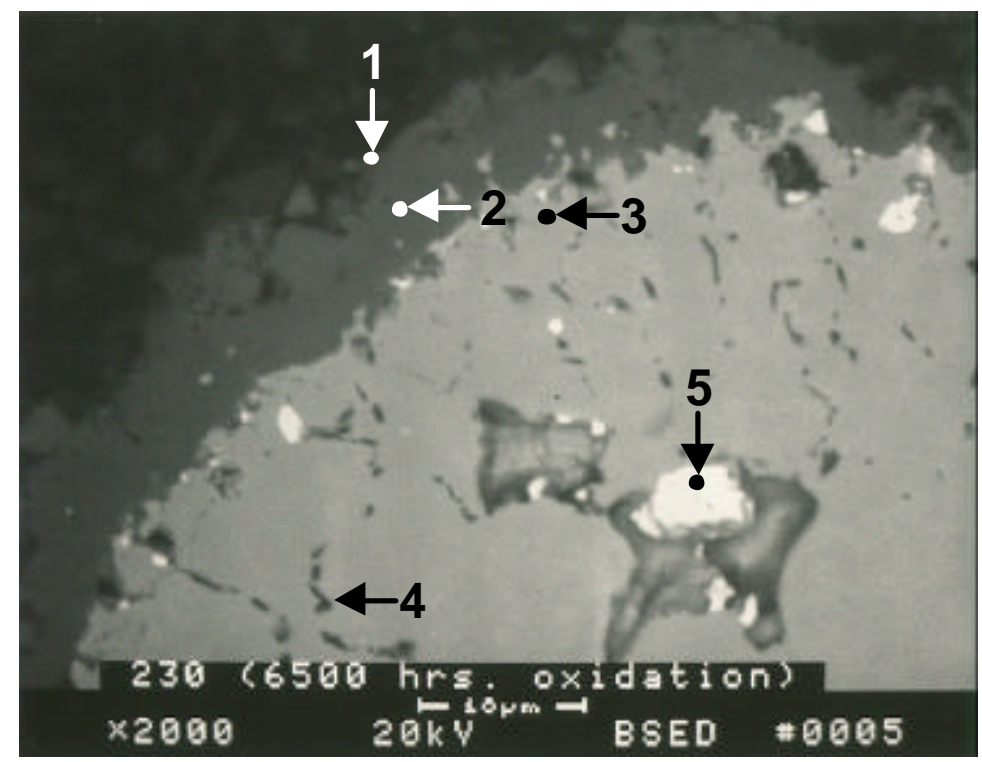

Figure 3.3.4-7 - Surface Oxide (spots 1 and 2), Matrix (spot 3), Internal Oxide (spot 4) and Precipitate (spot 5) for Exposed Alloy 230 Fiber

The surface oxide (spots 1 and 2 ) is evidently rich in chromium. The matrix (spot 3 ) is again typical of the basic alloy. Intemal oxide (spot 4) is found rich in aluminum. Spot 5 is again a tungsten carbide.

The thickness of the surface oxide is approximately 10 microns. Intemal oxidation of at least 30 additional microns extends the total amount of metal affected to approximately 40 microns. Recognizing that the wire is of the order of 140 microns ( 0.0055 inches) in diameter, about 60 percent of the fiber diameter and 80 percent of the fiber material have been affected by oxidation attack.

If we assume metal loss to be approximately equal to the thickness of the surface oxide, average metal affected may be defined as the surface oxide thickness plus one half of the internal oxidation. Average metal affected is then approximately 25 microns ( 0.001 inches). Our result of 25 microns average metal affected for exposure of 6500 hours at $816^{\circ} \mathrm{C}$ (1500F) (Larson Miller No. 48) is, to a first approximation, comparable to 18 microns (0.0007 inches) average metal affected reported by Haynes for exposure of alloy 230 to 1008 hours at 982C (1800F) (Larson Miller No. 52). 

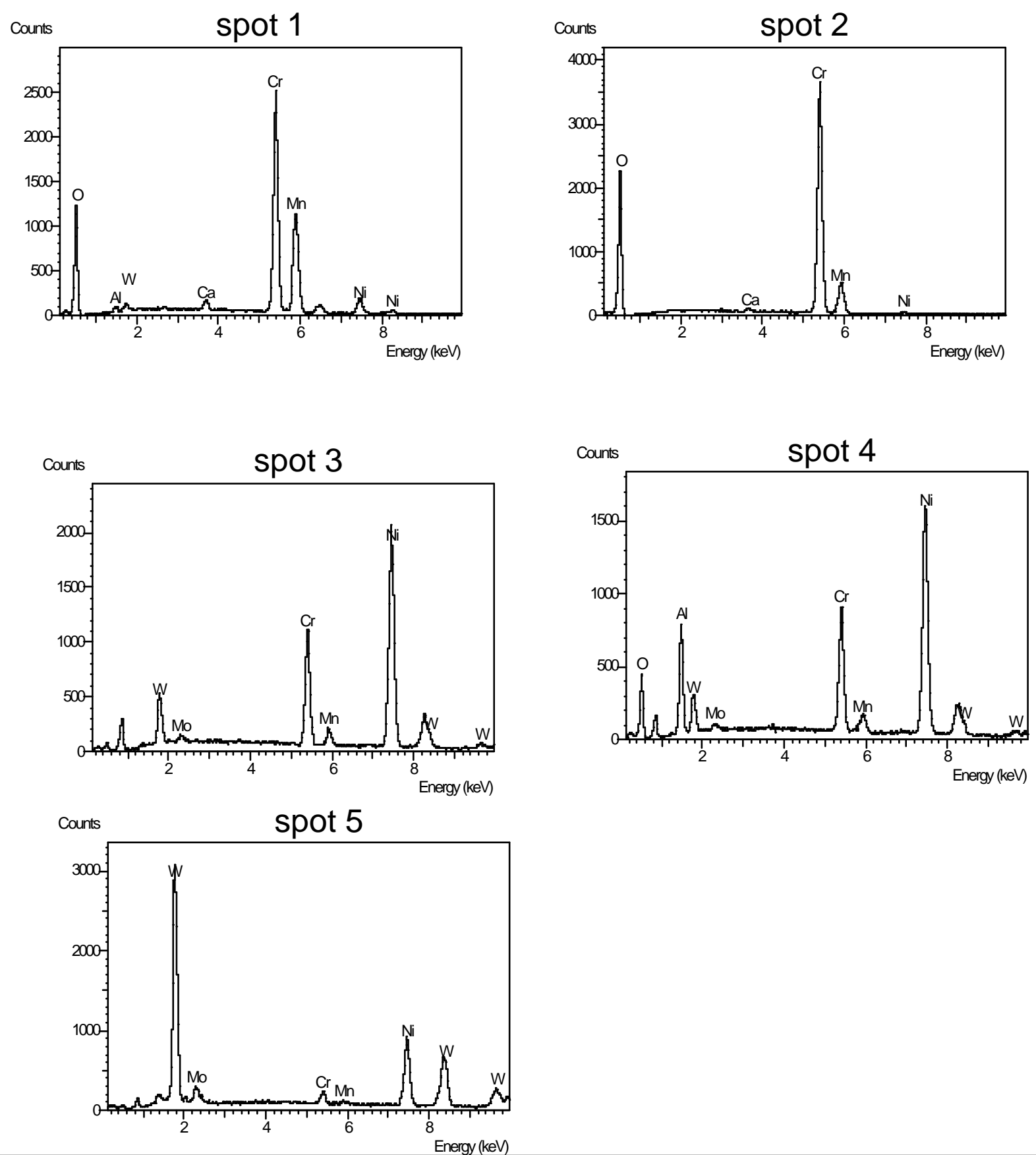

\begin{tabular}{|l|r|r|r|r|r|r|r|r|}
\hline & Wt\% O & Wt\% Al & Wt\% Ca & Wt\% Cr & Wt\% Mn & Wt\% Ni & Wt\% $\mathbf{~ M o ~}$ & Wt\% W \\
\hline \hline spot 1 & 23.89 & 0.51 & 0.90 & 46.54 & 19.53 & 7.23 & 0.29 & 1.10 \\
\hline spot 2 & 34.90 & & 0.28 & 62.97 & 0.72 & 1.15 & & \\
\hline spot 3 & & & & 17.24 & 0.29 & 68.80 & 1.42 & 12.25 \\
\hline spot 4 & 10.13 & 8.07 & & 14.79 & 0.05 & 58.45 & 1.02 & 7.48 \\
\hline spot 5 & & & & 3.04 & 0.12 & 28.75 & 5.02 & 63.02 \\
\hline
\end{tabular}

Figure 3.3.4-8 - EDAX Analysis of Exposed Alloy 230 Fiber 


\subsubsection{Results of Examination for 214 Fiber - Unexposed and Oxidizing}

Scanning electron micrographs (SEM) of cross sections of unexposed (new) alloy 214 fibers are shown in Figures 3.3.5-1 and 3.3.5-2. Energy Dispersive X-Ray Analysis (EDAX) of the matrix (area 1) and precipitate (spot 2) shown in Figure 3.3.5-3 are displayed in Figure 3.3.5-4.

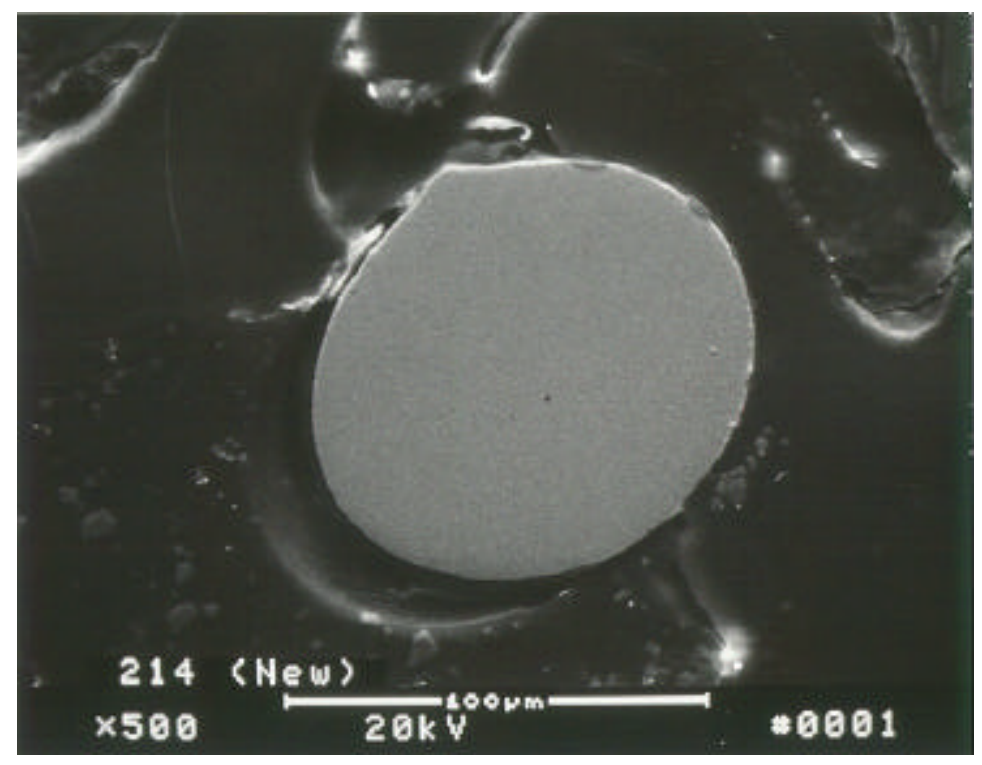

Figure 3.3.5-1 - SEM of Unexposed Alloy 214 Fiber Cross Section

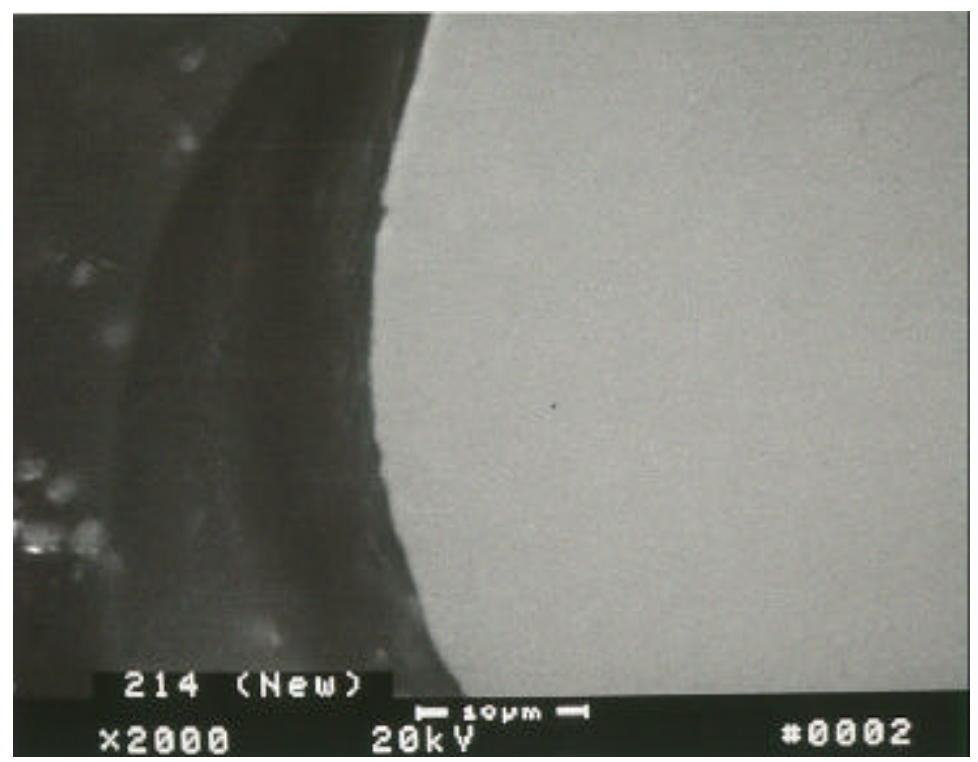

Figure 3.3.5-2 - SEM of Unexposed Alloy 214 Fiber Cross Section 


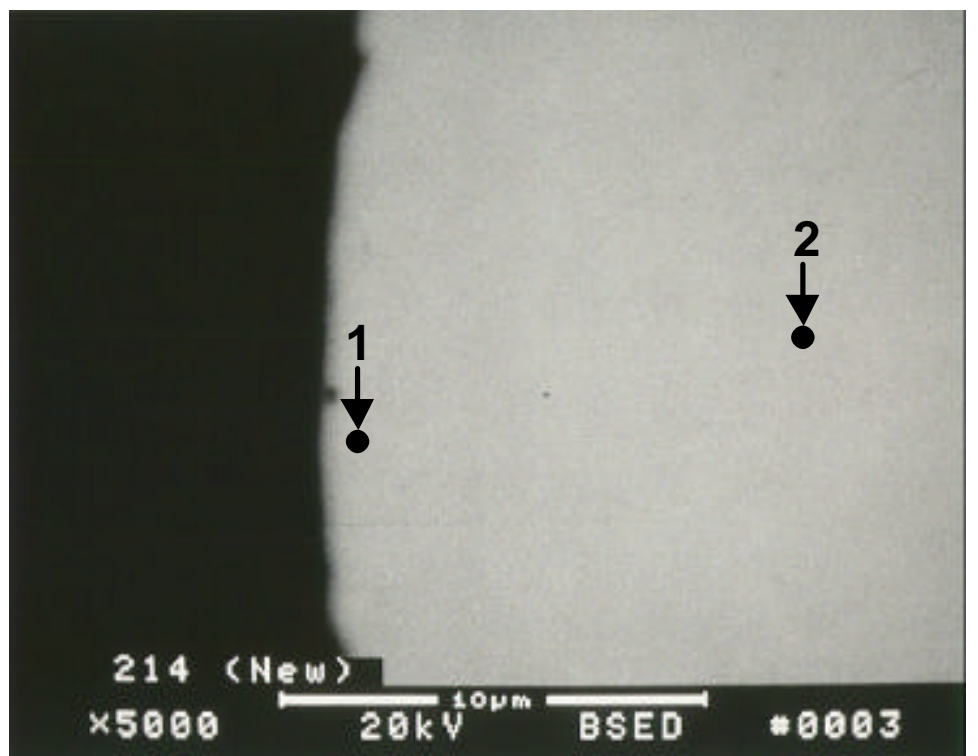

Figure 3.3.5-3 - Matrix - Near Surface (spot 1) and Matrix - Subsurface (spot 2) for Unexposed Alloy 214
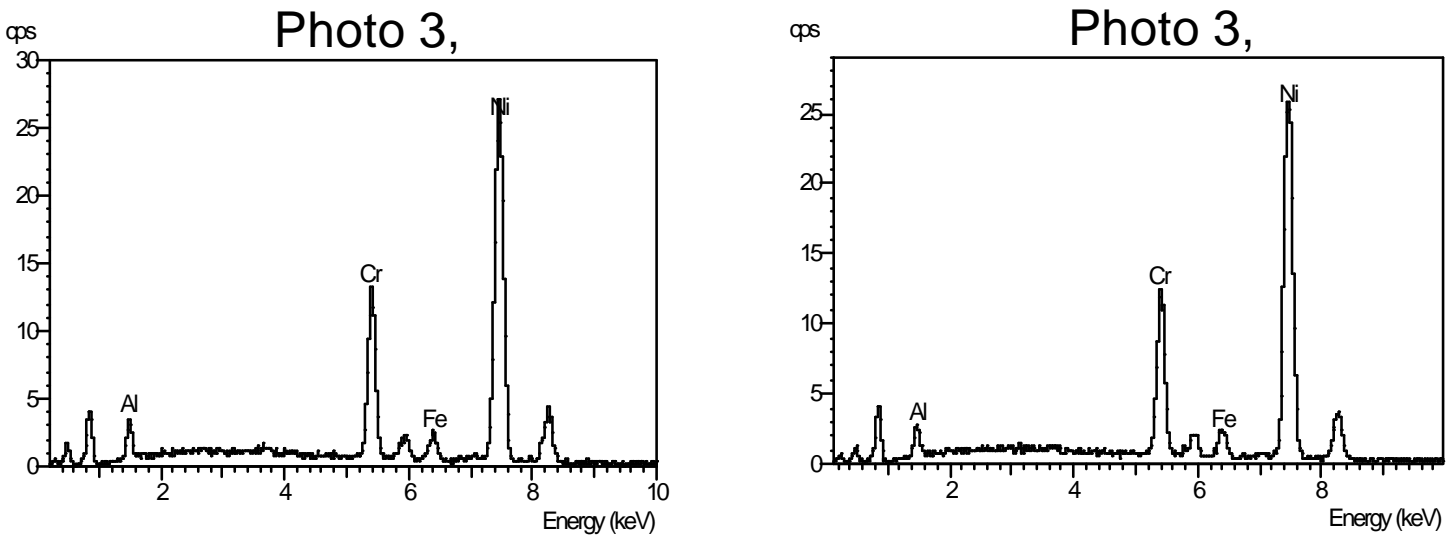

\begin{tabular}{|l|r|r|r|r|r|}
\hline & Wt\% Al & Wt\% Cr & Wt\% Mn & Wt\% Fe & Wt\% Ni \\
\hline \hline Photo 3, spot 1 & 2.83 & 16.23 & 0.28 & 3.42 & 77.23 \\
\hline Photo 3, spot 2 & 2.23 & 15.81 & 0.21 & 3.55 & 78.20 \\
\hline
\end{tabular}

Figure 3.3.5-4 - EDAX Analysis of Matrix in Unexposed Alloy 214 
The matrix is typical of the alloy's nominal composition.

Scanning Electron Micrographs of cross sections of alloy 230 wires after static oxidation exposure for 6500 hours at $81{ }^{\circ} \mathrm{C}(1500 \mathrm{~F})$ are shown in Figures 3.3.5-5 and 3.3.5-6. EDAX analysis of various spots shown in Figure 3.3.5-7 are displayed in Figure 3.3.5-8.

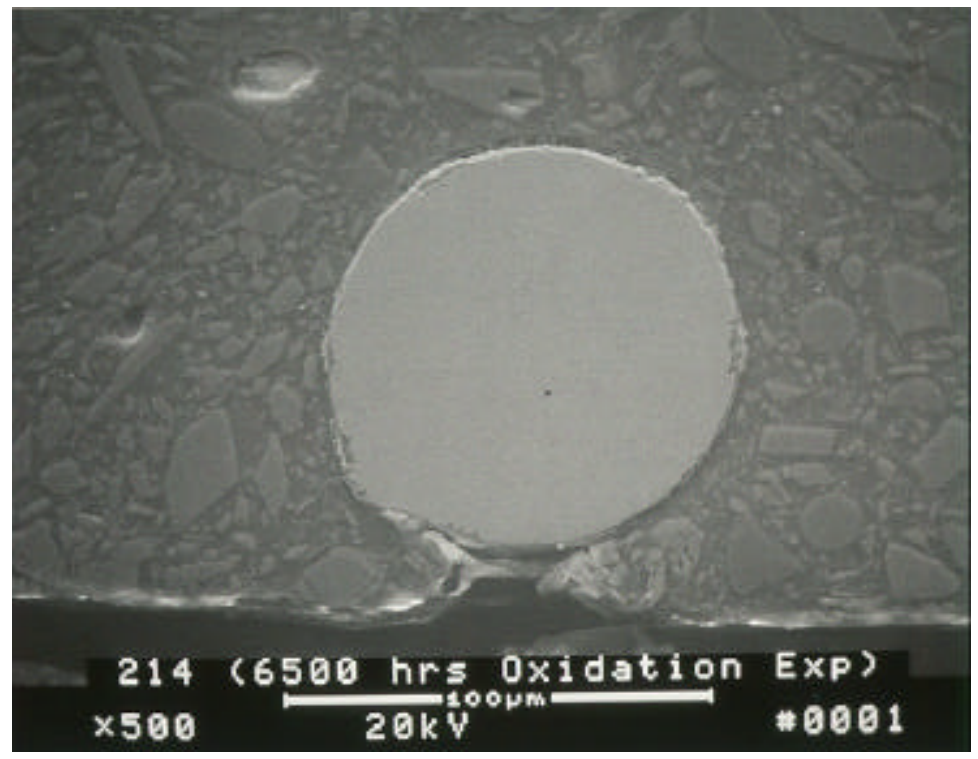

Figure 3.3.5-5 - SEM of Exposed Alloy 214 Fiber Cross Section

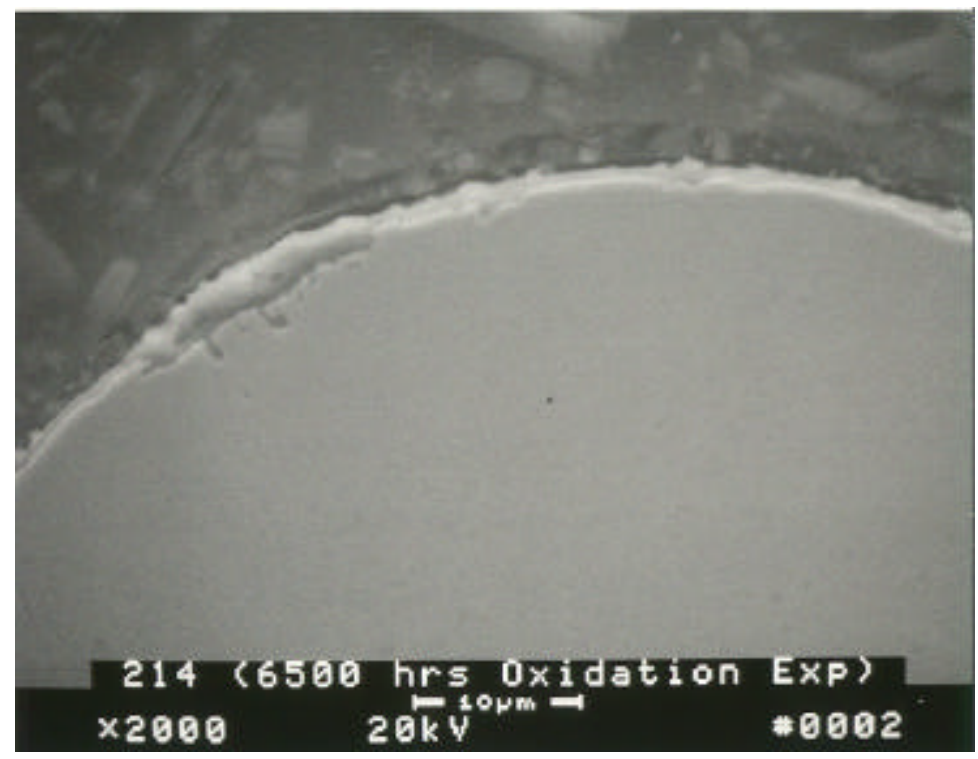

Figure 3.3.5-6 - SEM of Exposed Alloy 214 Fiber Cross Section 


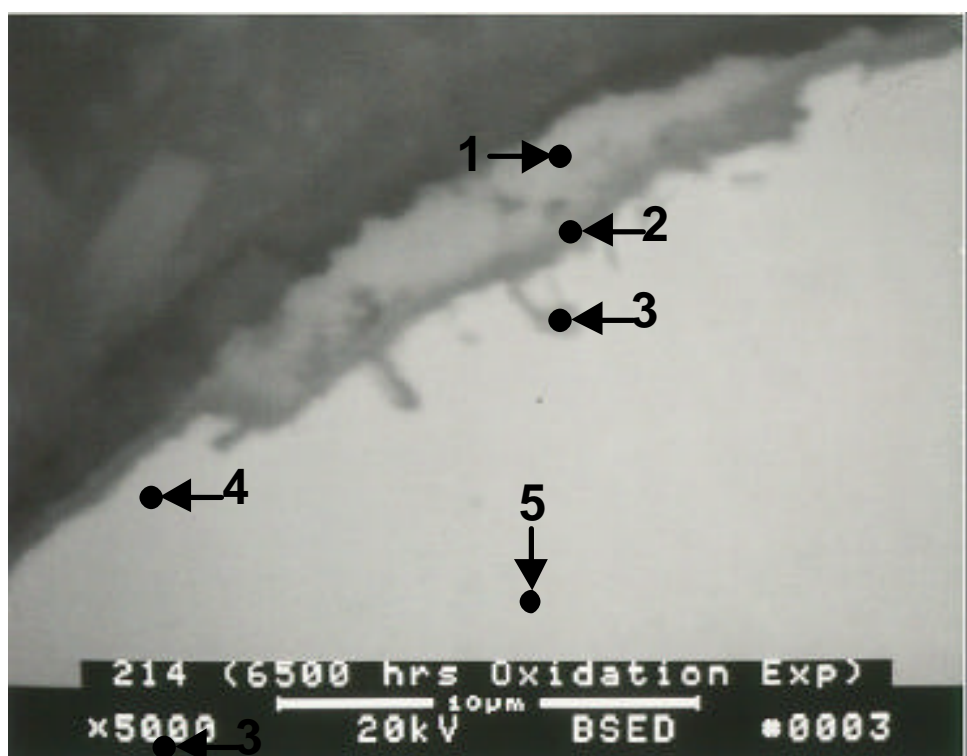

Figure 3.3.5-7 - Surface Oxide (spots 1 and 2), Precipitate (spot 3) and Matrix (spots 4 and 5) for Exposed Alloy 214 Fiber

The surface oxide (spots 1 and 2 ) is evidently rich in chromium or aluminum $\left(\mathrm{Al}_{2} \mathrm{O}_{3}\right)$. The precipitate (spot 3 ) is highly enriched in aluminum and is probably gamma prime $\left(\mathrm{Ni}_{3} \mathrm{Al}\right)$. The matrix (spots 4 and 5) is found to be typical of the alloy's nominal composition.

The thickness of the surface oxide is approximately 2 microns. Internal oxidation was difficult to assess but was approximately 2 additional microns, thereby extending the total amount of metal affected to approximately 4 microns. Recognizing that the wire is of the order of 100 microns ( 0.004 inches) in diameter, about 8 percent of the fiber diameter and 15 percent of the fiber material have been affected by oxidation attack.

If we assume metal loss to be approximately equal to the thickness of the surface oxide, average metal affected may be defined as the surface oxide thickness plus one half of the internal oxidation. Average metal affected is then approximately 3 microns (0.0001 inches). Our result of 3 microns average metal affected for exposure of 6500 hours at $816^{\circ} \mathrm{C}(1500 \mathrm{~F})$ (Larson Miller No. 48) is roughly comparable to 6 microns ( 0.0002 inches) average metal affected reported by Haynes for exposure of 1008 hours at 982C (1800F) (Larson Miller No. 52). 

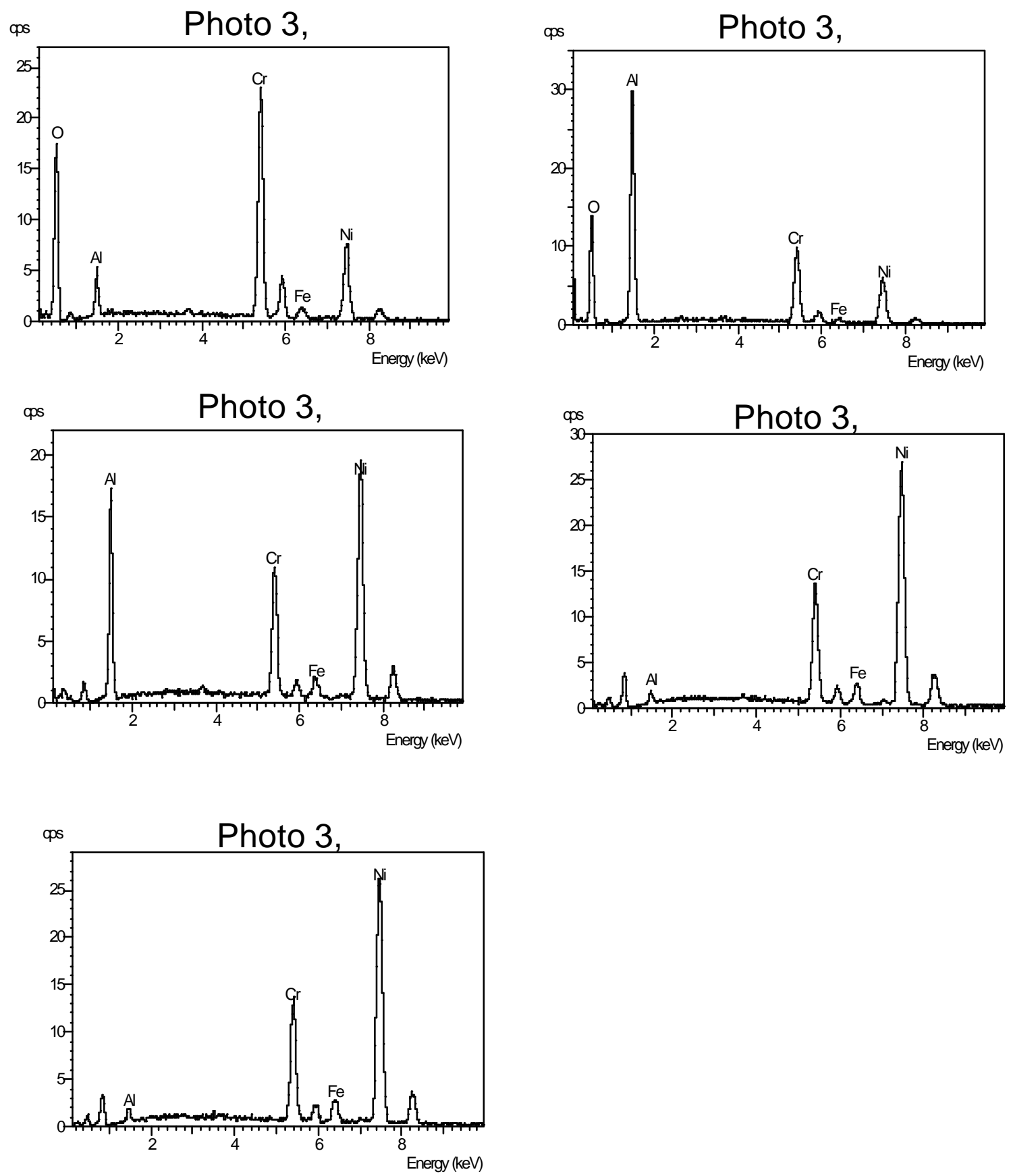

\begin{tabular}{|l|r|r|r|r|r|r|}
\hline & $\mathbf{W t} \% \mathbf{O}$ & $\mathbf{W t} \% \mathbf{A l}$ & $\mathbf{W t} \% \mathbf{C r}$ & $\mathbf{W t} \% \mathbf{M n}$ & $\mathbf{W t} \% \mathbf{~ F e}$ & $\mathbf{W t} \% \mathbf{~ N i}$ \\
\hline \hline Photo 3, spot 1 & 28.73 & 4.20 & 36.58 & 2.89 & 2.19 & 25.41 \\
\hline Photo 3, spot 2 & 28.92 & 27.81 & 18.83 & 0.24 & 1.38 & 22.82 \\
\hline Photo 3, spot 3 & & 17.75 & 15.87 & 0.24 & 3.03 & 63.11 \\
\hline Photo 3, spot 4 & & 1.21 & 16.64 & 0.52 & 4.02 & 77.60 \\
\hline Photo 3, spot 5 & & 1.29 & 17.26 & 0.30 & 4.05 & 77.10 \\
\hline
\end{tabular}

Figure 3.3.5-8 - EDAX Analysis of Exposed Alloy 214 Fiber 


\subsubsection{Results of Examination for FeCrAIY Fiber - Unexposed and Oxidizing}

Scanning electron micrographs (SEM) of a cross section of an unexposed (new) FeCrAlY alloy fiber are shown in Figures 3.3.6-1 and 3.3.6-2. Energy Dispersive X-Ray Analysis (EDAX) of the matrix are displayed in Figure 3.3.6-3.

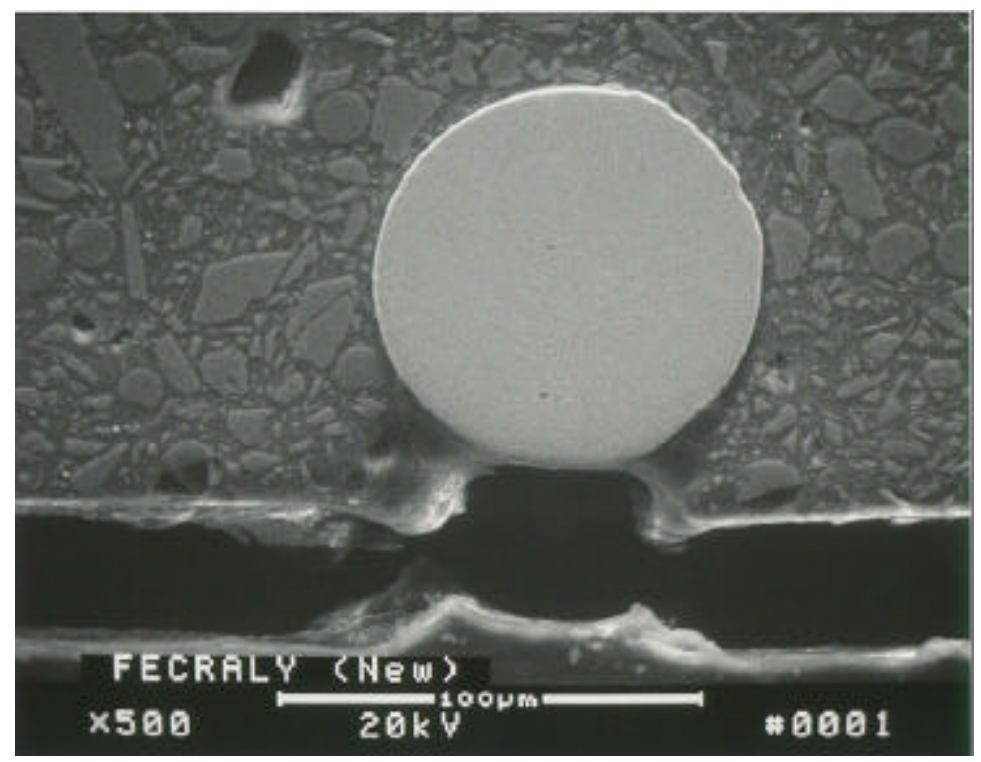

Figure 3.3.6-1 - SEM of Unexposed FeCrAIY Alloy Fiber Cross Section

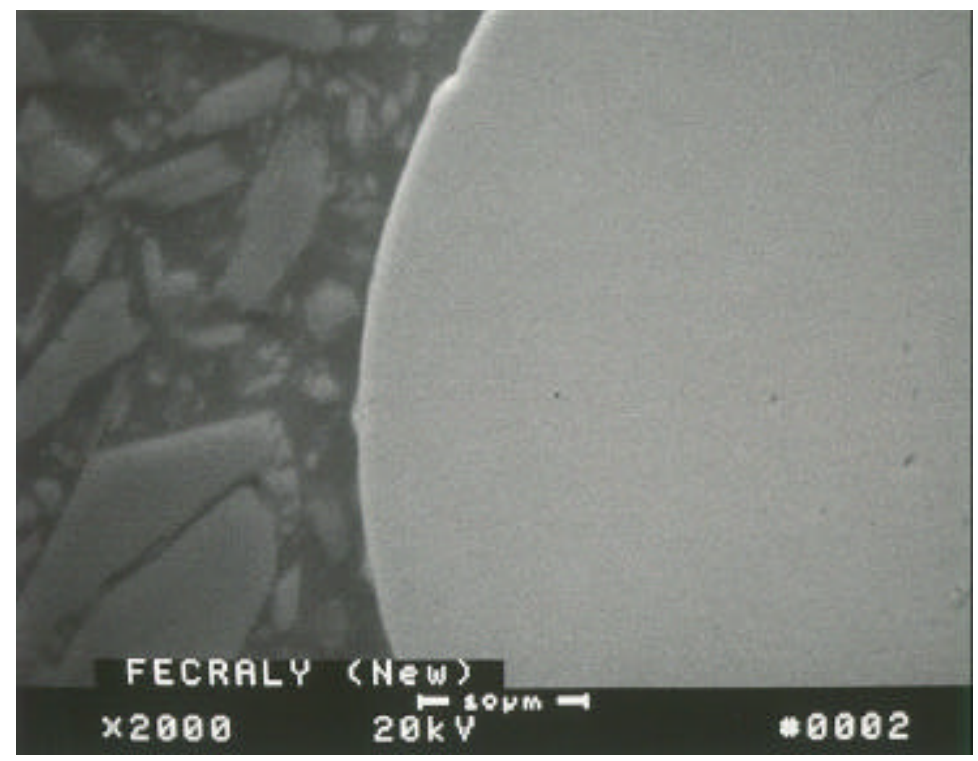

Figure 3.3.6-2 - SEM of Unexposed FeCrAIY Alloy Fiber Cross Section 

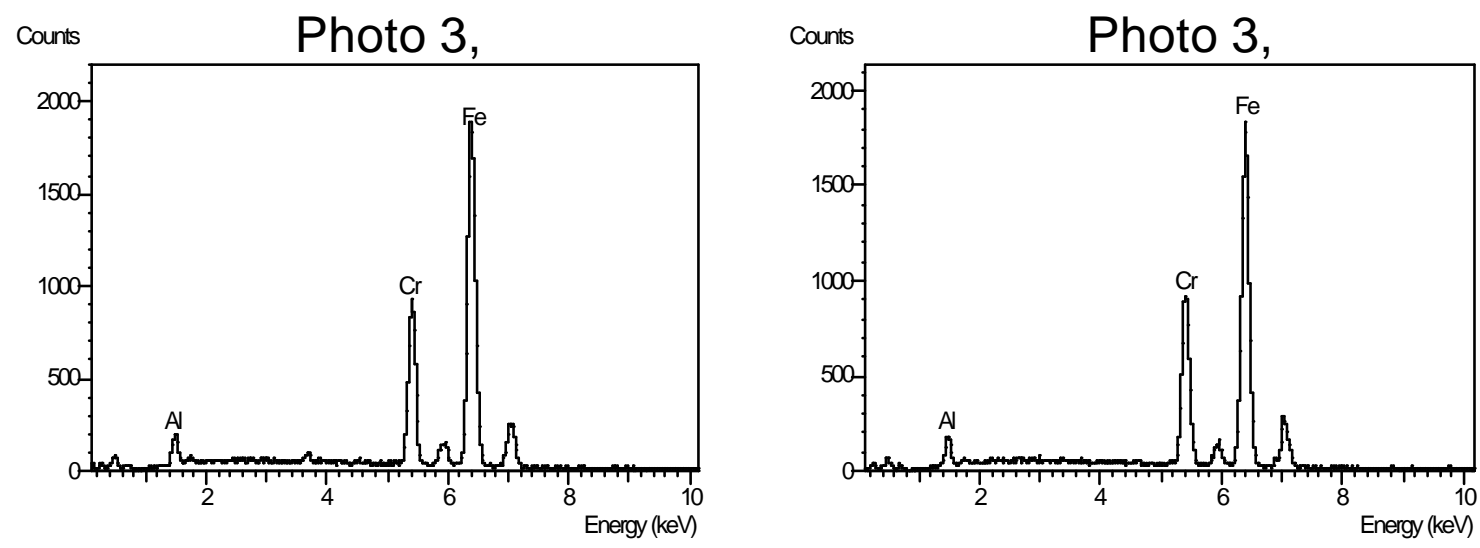

\begin{tabular}{|l|r|r|r|r|r|}
\hline & $\mathbf{W t} \% \mathbf{A l}$ & $\mathbf{W t} \% \mathbf{~ S i}$ & $\mathbf{W t} \% \mathbf{C r}$ & $\mathbf{W t} \% \mathbf{M n}$ & $\mathbf{W t} \% \mathbf{~ F e}$ \\
\hline \hline Photo 3, spot 1 & 2.69 & 0.34 & 22.52 & 0.02 & 74.42 \\
\hline Photo 3, spot 2 & 2.89 & 0.39 & 21.67 & 0.54 & 74.51 \\
\hline
\end{tabular}

Figure 3.3.6-3 - EDAX Analysis of Matrix in Unexposed FeCrAl Alloy

The matrix represents the alloy's nominal composition.

Scanning Electron Micrographs of a cross section of FeCrAlY alloy wire after static oxidation exposure for 6500 hours at $816^{\circ} \mathrm{C}\left(1500^{\circ} \mathrm{F}\right)$ are shown in Figures 3.3.6-4 and 3.3.6-5. EDAX analysis of various spots shown in Figure 3.3.6-6 are displayed in Figure 3.3.6-7.

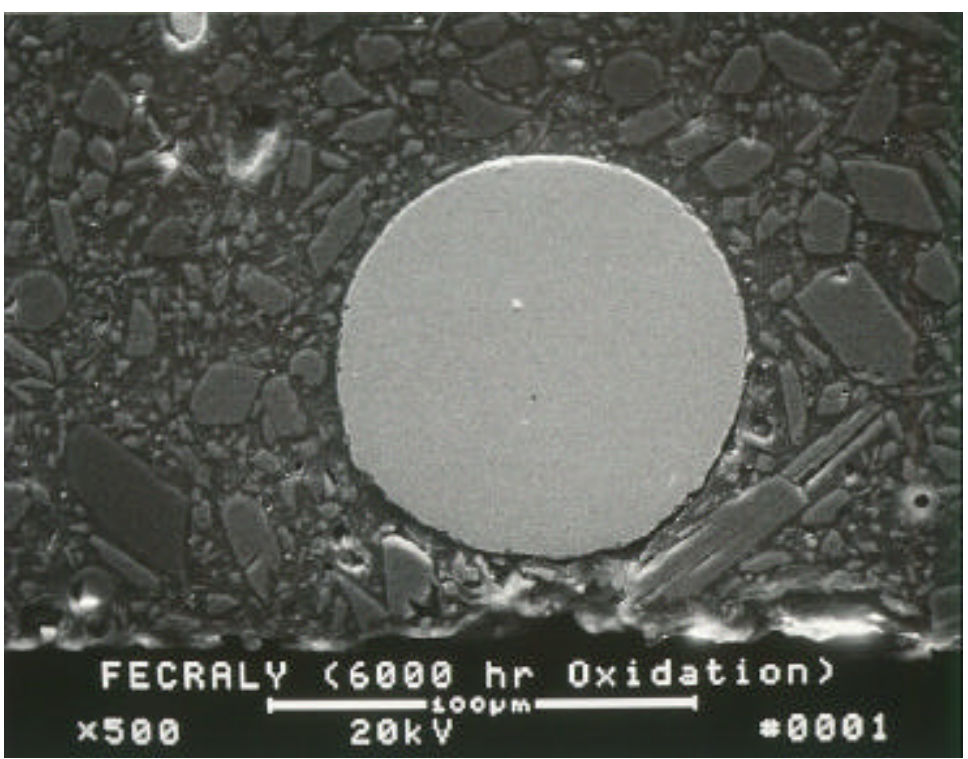

Figure 3.3.6-4 - SEM of Exposed FeCrAIY Alloy Fiber Cross Section 


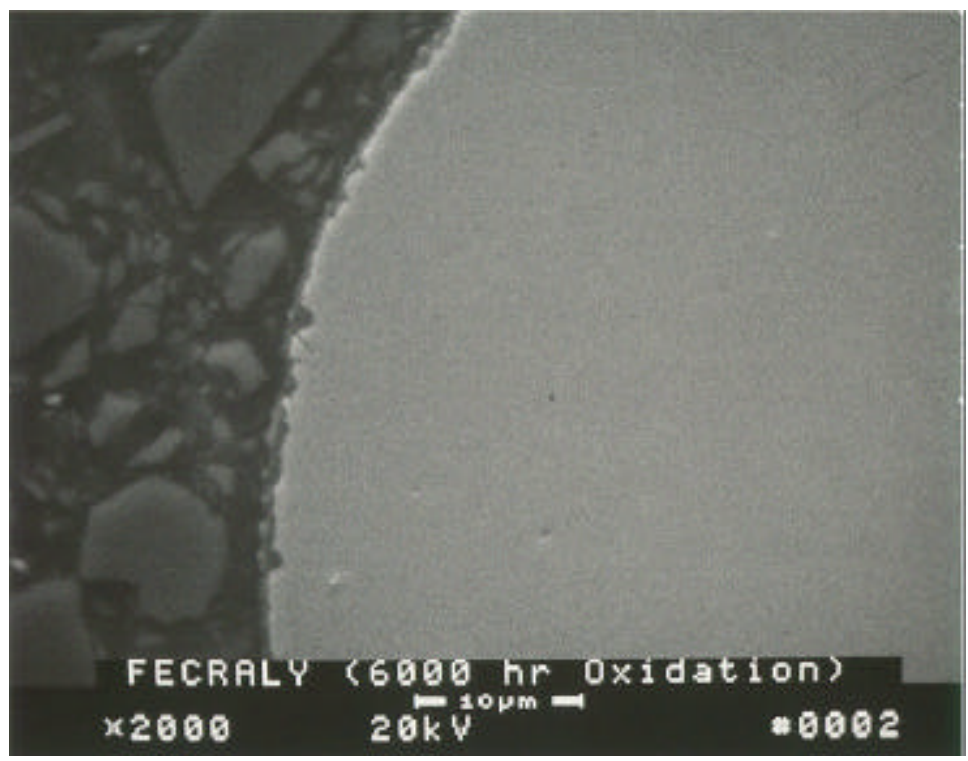

Figure 3.3.6-5 - SEM of Exposed FeCrAIY Alloy Fiber Cross Section

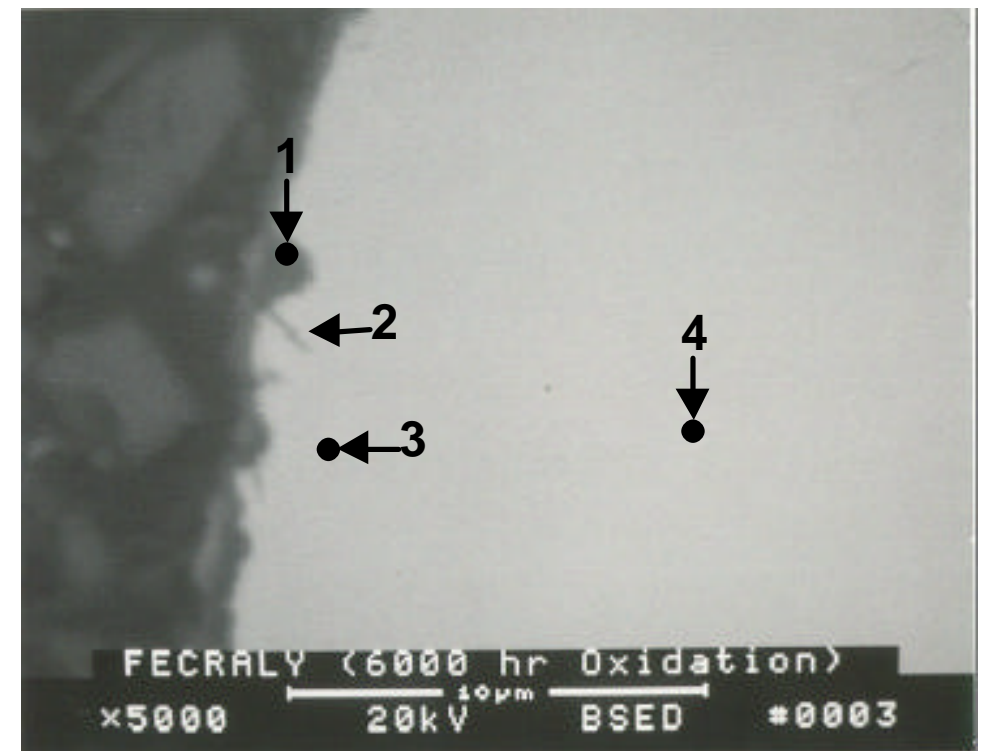

Figure 3.3.6-6 - Surface Oxide (spot 1), Internal Oxide (spot 2) and Matrix (spots 3 and 4) for Exposed FeCrAlY Alloy Fiber 

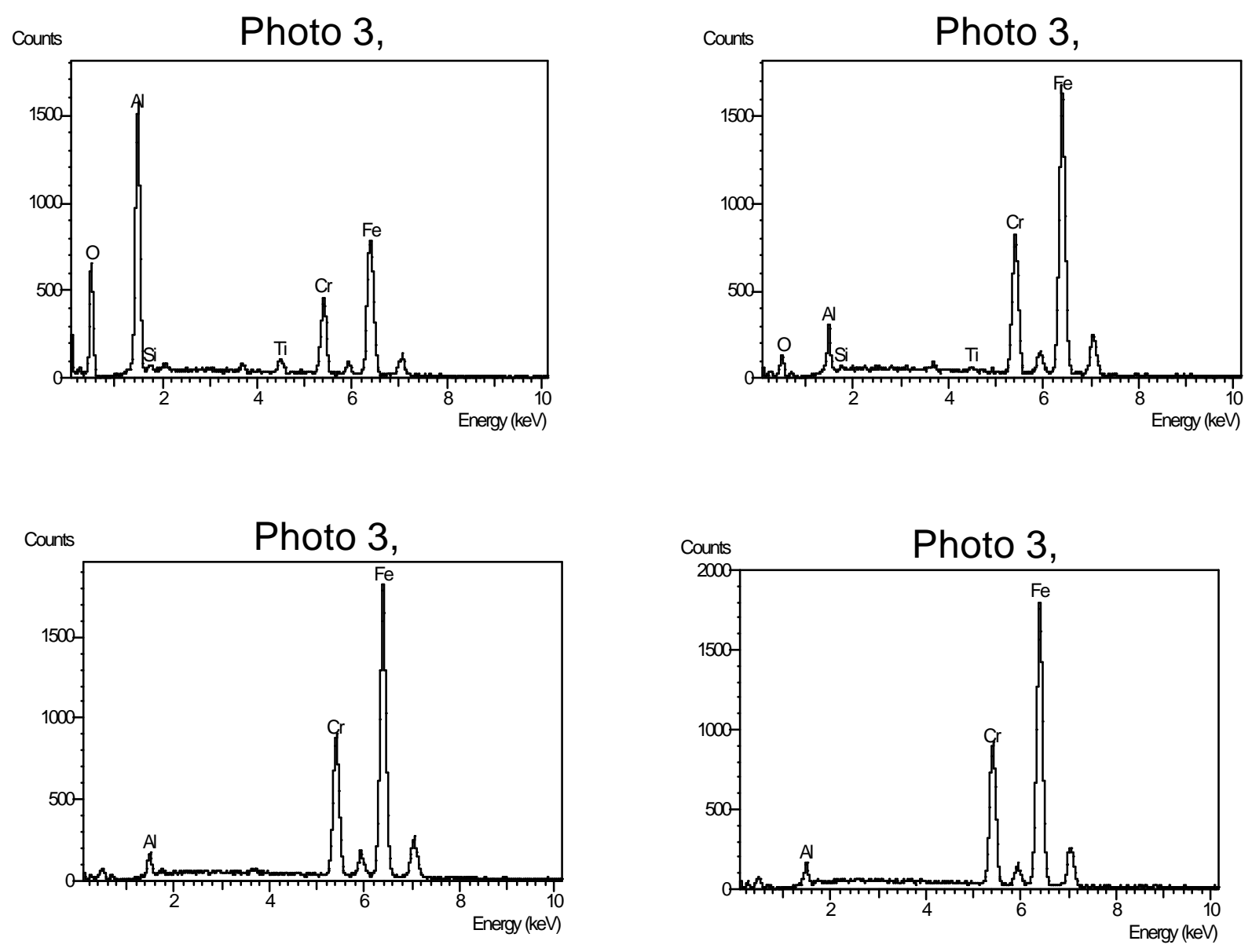

\begin{tabular}{|l|r|r|r|r|r|r|r|}
\hline & $\mathbf{W t} \% \mathbf{O}$ & $\mathbf{W t} \% \mathbf{~ A l}$ & $\mathbf{W t} \% \mathbf{~ S i}$ & $\mathbf{W t} \% \mathbf{~ T i}$ & $\mathbf{W t} \% \mathbf{C r}$ & $\mathbf{W t} \% \mathbf{~ M n}$ & $\mathbf{W t} \% \mathbf{F e}$ \\
\hline \hline Photo 3, spot 1 & 27.62 & 22.84 & 0.69 & 1.60 & 12.73 & 0.30 & 34.22 \\
\hline Photo 3, spot 2 & 5.65 & 4.36 & 0.35 & 0.45 & 19.77 & 0.69 & 68.73 \\
\hline Photo 3, spot 3 & & 2.52 & 0.40 & & 21.78 & 0.54 & 74.76 \\
\hline Photo 3, spot 4 & & 2.29 & 0.28 & & 22.69 & 0.50 & 74.23 \\
\hline
\end{tabular}

Figure 3.3.6-7 - EDAX Analysis of Exposed FeCrAIY Alloy Fiber

The surface oxide (spot 1 ) is highly enriched in aluminum and the subsurface oxide (spot 2) is somewhat enriched in aluminum relative to the matrix (spots 3 and 4).

The thickness of the surface oxide is approximately 2 microns. Intemal oxidation was not distinguished from the irregular depth of the surface oxide and is judged to be negligible. Therefore the total amount of metal affected was approximately 2 microns. Recognizing that the wire is of the order of 140 microns $\left(0.0056^{\prime \prime}\right)$ in diameter, about 3 percent of the fiber diameter and 6 percent of the fiber material have been affected by oxidation attack. 


\subsubsection{Results of Examination for 310 Fiber - Unexposed and Gasification}

Scanning electron micrographs (SEM) of a cross section of unexposed (new) alloy 310 fiber are shown in Figures 3.3.7-1 and 3.3.7-2.

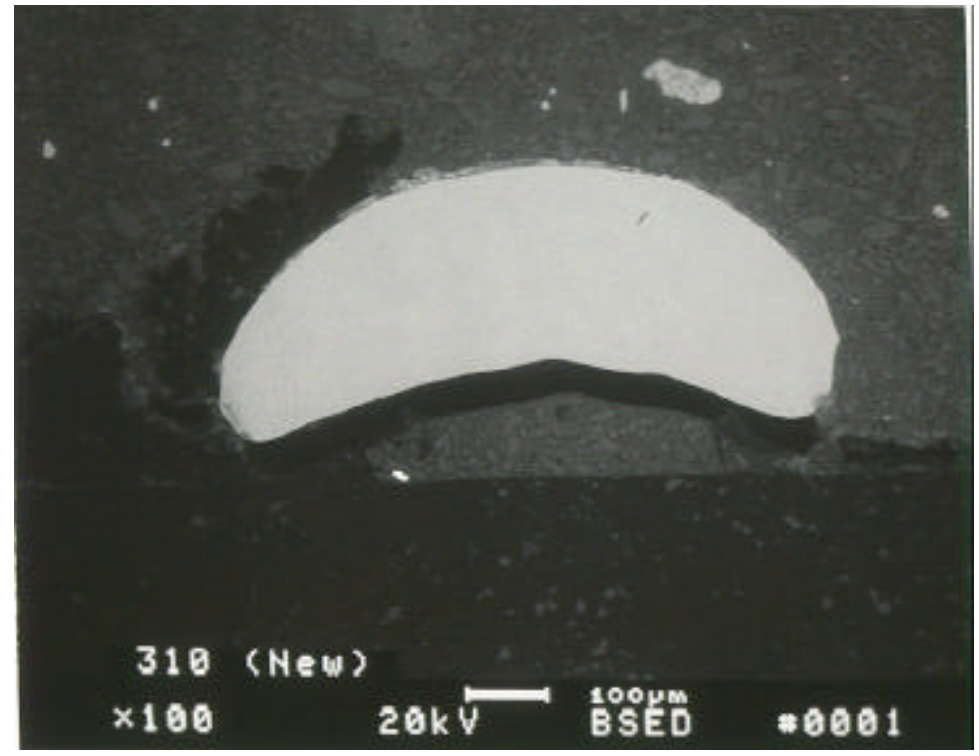

Figure 3.3.7-1 - SEM of Unexposed Alloy 310 Fiber Cross Section

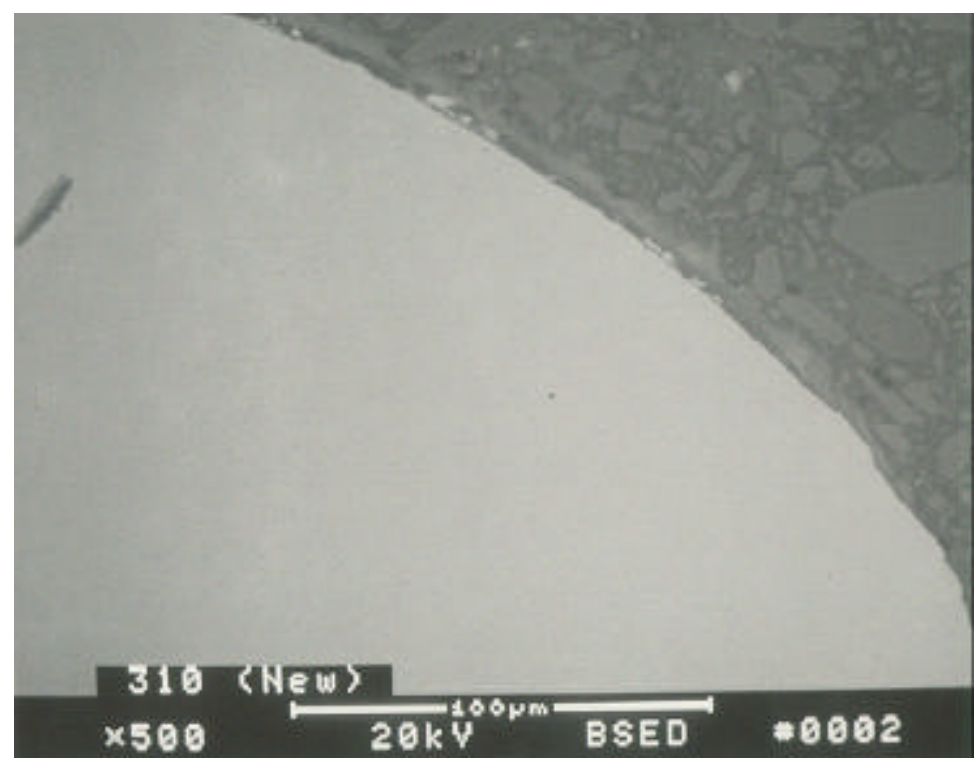

Figure 3.3.7-2 - SEM of Unexposed Alloy 310 Fiber Cross Sections 
A scanning electron micrograph of a cross section of alloy 310 wire after gasification exposure is shown in Figure 3.3.7-3. EDAX analysis of the two indicated surface and subsurface spots are shown in Figure 3.3.7-4.

The surface analysis (spot 1) and internal analysis (spot 2) are evidently similar to one another and typical of the basic alloy composition. No evidence of carburization, oxidation or other corrosive attack was apparent.

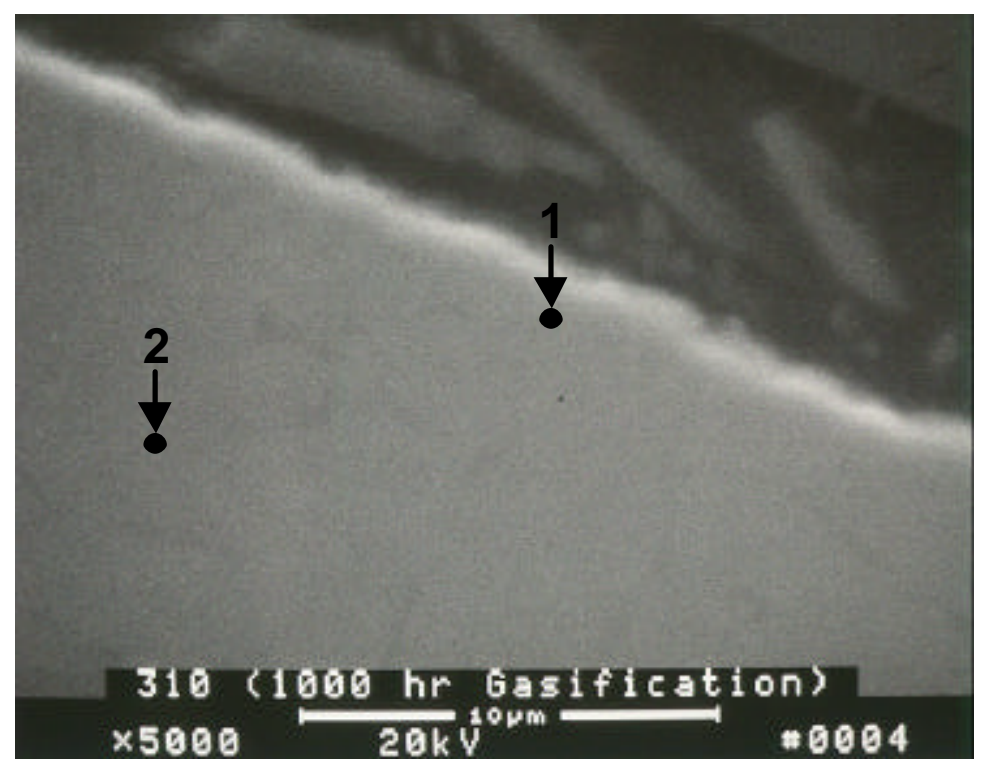

Figure 3.3.7-3 - SEM of Gasification Exposed Alloy 310 Fiber Cross Section
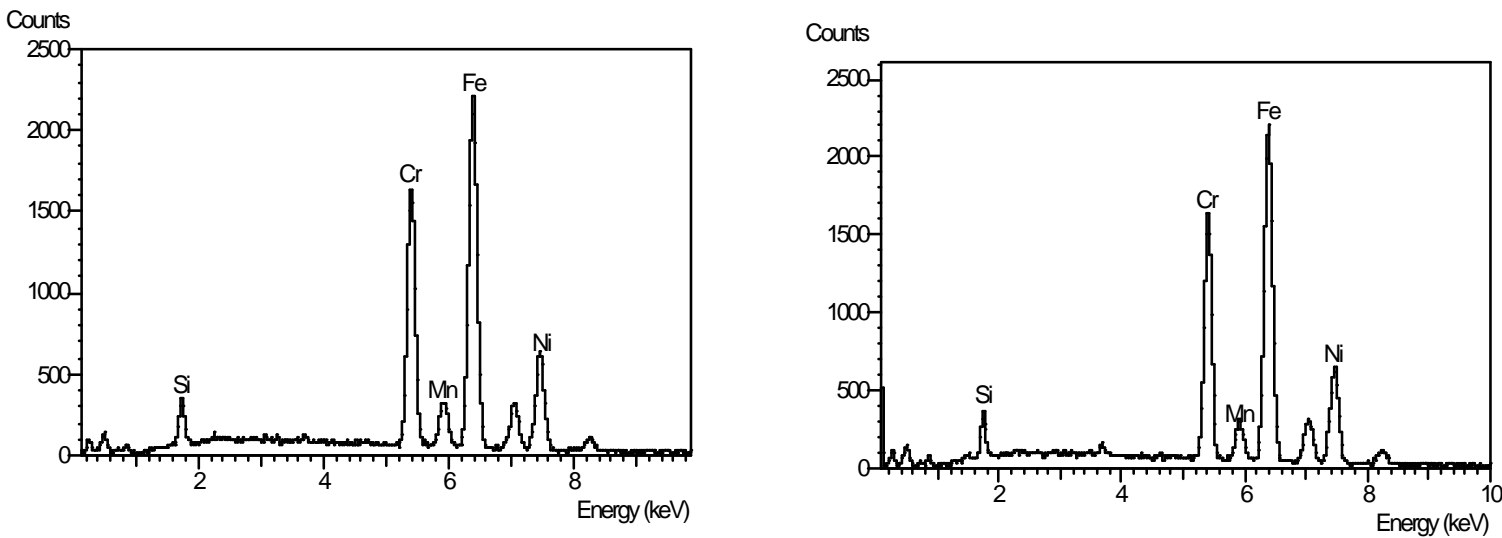

\begin{tabular}{|c|c|c|c|c|c|}
\hline & Wt\% Si & Wt\% Cr & Wt\% Mn & Wt\% Fe & Wt\% Ni \\
\hline \hline Photo 4, spot 1 & 2.26 & 24.28 & 1.82 & 49.80 & 21.83 \\
\hline Photo 4, spot 2 & 2.48 & 23.57 & 1.55 & 50.46 & 21.93 \\
\hline
\end{tabular}

Figure 3.3.7-4 - EDAX Analysis of Exposed Alloy 310 Fiber 


\subsubsection{Results of Examination for 160 Fiber - Unexposed and Gasification}

Scanning electron micrographs (SEM) of a cross section of unexposed (new) alloy 160 fiber are shown in Figures 3.3.8-1 and 3.3.8-2.

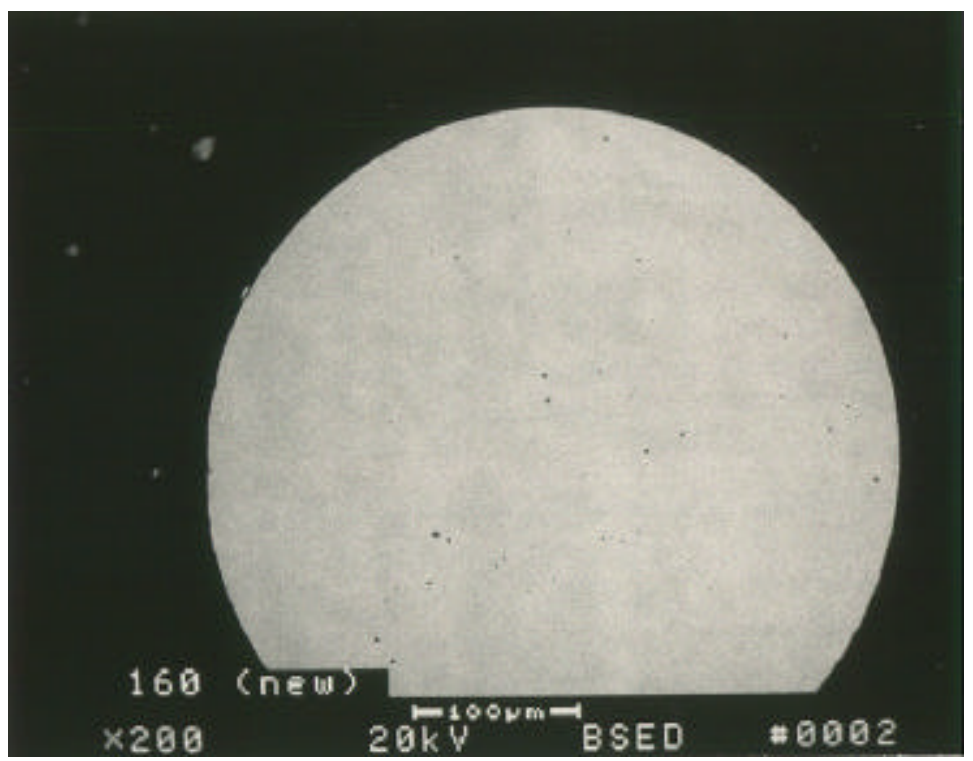

Figure 3.3.8-1 - SEM of Unexposed Alloy 160 Fiber Cross Section

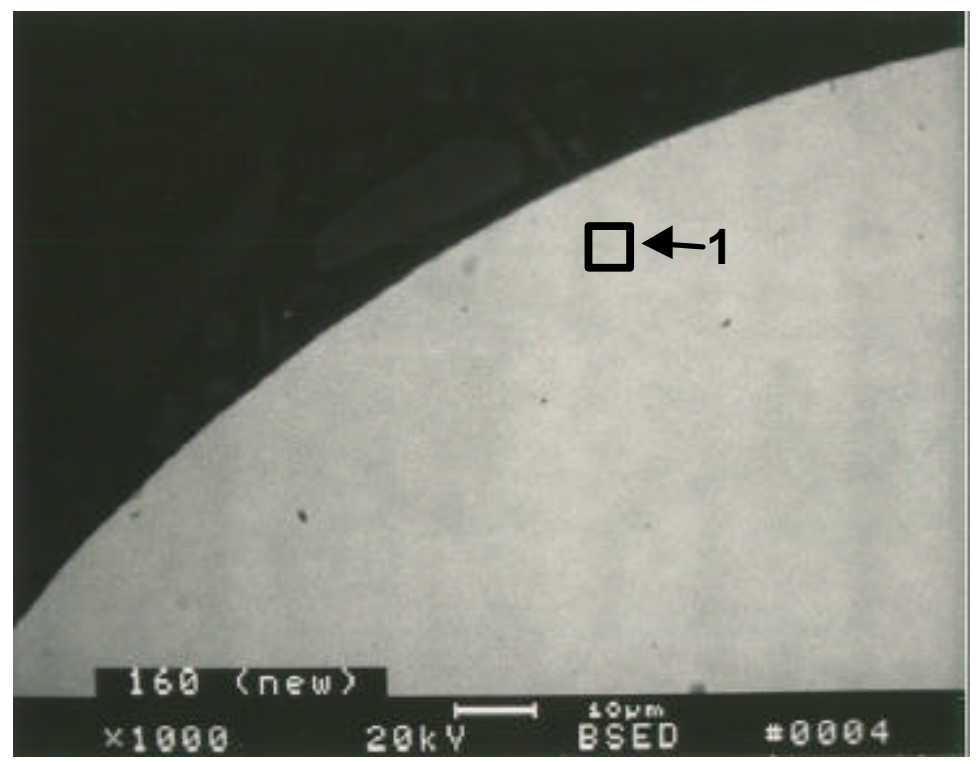

Figure 3.3.8-2 - SEM of Unexposed Alloy 160 Fiber Cross Section 
EDAX analysis of the indicated area 1 is shown in Figure 3.3.8-3. The analysis is typical of the basic alloy composition.

Scanning electron micrographs of cross sections of alloy 160 fiber after gasification exposure are shown in Figure 3.3.8-4 and 3.3.8-5. EDAX analysis of the two indicated surface and subsurface areas are shown in Figure 3.3.8-6.

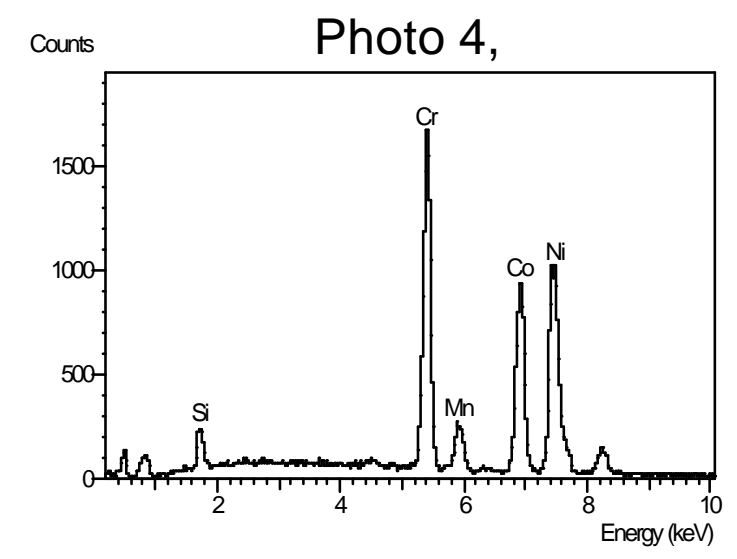

\begin{tabular}{|c|c|c|c|c|}
\hline $\mathbf{W t} \% \mathbf{~ S i}$ & $\mathbf{W t} \% \mathbf{C r}$ & $\mathbf{W t} \% \mathbf{M n}$ & $\mathbf{W t} \% \mathbf{C o}$ & $\mathbf{W t} \% \mathbf{~ N i}$ \\
\hline \hline 2.13 & 28.03 & 0.56 & 30.42 & 38.86 \\
\hline
\end{tabular}

Figure 3.3.8-3 - EDAX Analysis of Unexposed Alloy 160

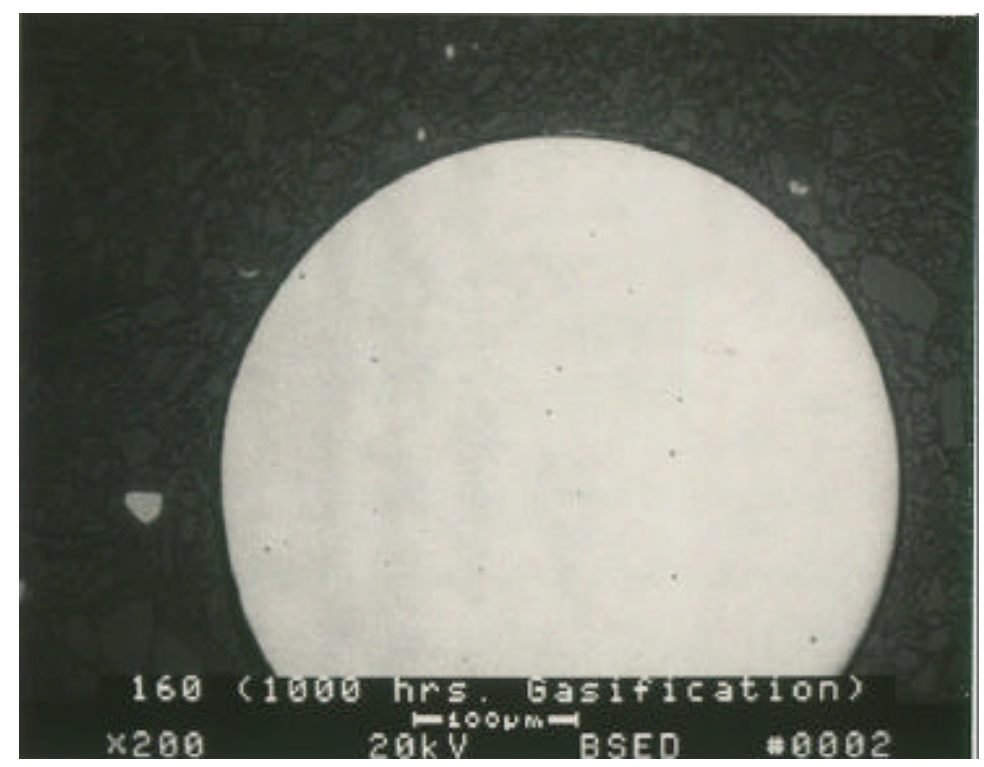

Figure 3.3.8-4 - SEM of Gasification Exposed Alloy 160 Fiber Cross Section 


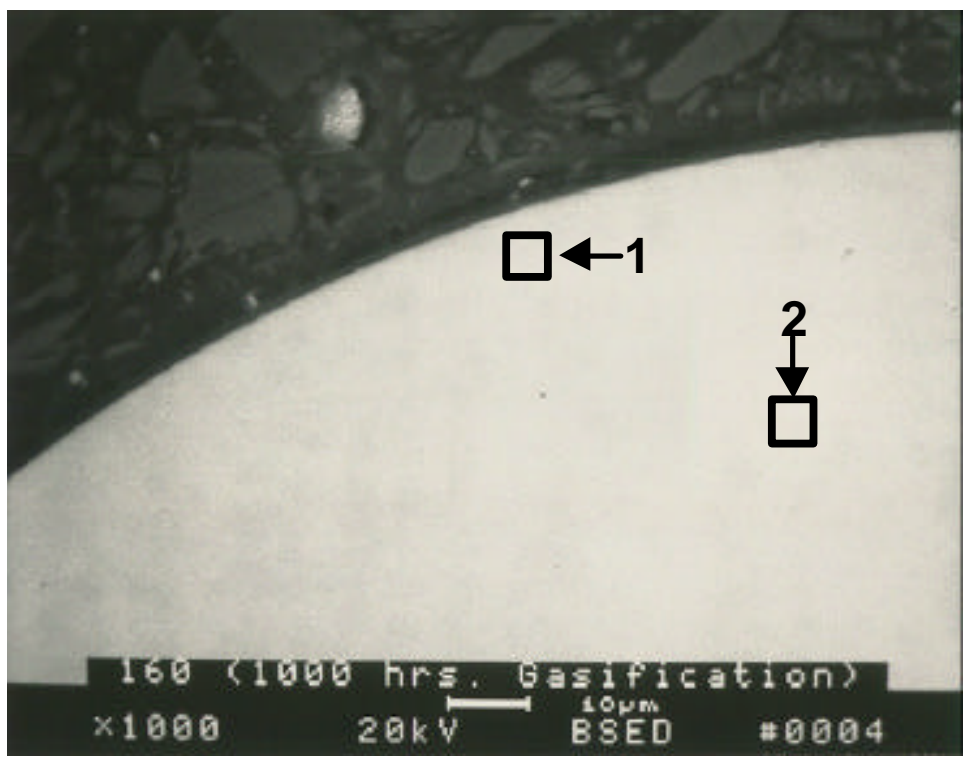

Figure 3.3.8-5 - SEM of Gasification Exposed Alloy 160 Fiber Cross Section
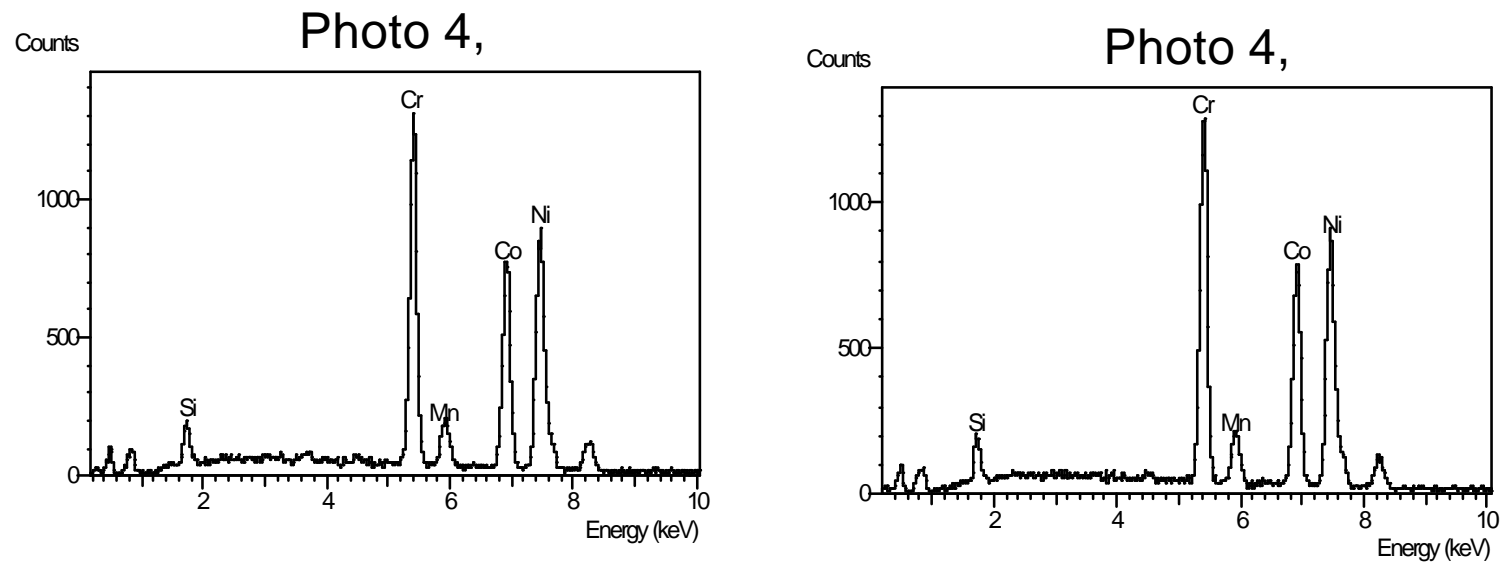

\begin{tabular}{|l|c|c|c|c|c|}
\hline & $\mathbf{W t} \% \mathbf{~ S i}$ & $\mathbf{W t} \% \mathbf{C r}$ & $\mathbf{W t} \% \mathbf{~ M n}$ & $\mathbf{W t} \% \mathbf{C o}$ & $\mathbf{W t} \% \mathbf{~ N i}$ \\
\hline \hline Photo 4, area 1 & 1.95 & 27.03 & 0.79 & 30.47 & 39.76 \\
\hline Photo 4, area 2 & 2.02 & 27.35 & 0.9 & 30.33 & 39.4 \\
\hline
\end{tabular}

Figure 3.3.8-6 - EDAX Analysis of Exposed Alloy 160 Fiber

The surface analysis (area 1) and intemal analysis (area 2) are evidently similar to one another and typical of the basic alloy composition. No evidence of carburization, oxidation or other corrosive attack was apparent. 


\subsubsection{Summary of Results}

A summary of average metal affected for various alloys exposed to oxidation and gasification conditions are summarized in Tables 3.3.9-1 and 3.3.9-2 respectively. Evidently alloys 214 and FeCrAlY are superior in oxidation resistance to alloys 310 and 230. For gasification conditions (typical of operation at the PSDF), both of the alloys examined, 160 and 310, showed resistance to high temperature reaction.

Table 3.3.9-1 - Summary of Oxidation Results

\begin{tabular}{|c|c|}
\hline Alloy & Average Metal Affected (microns) \\
\hline 310 & 20 \\
\hline 230 & 25 \\
\hline 214 & 3 \\
\hline FeCrAlY & 2 \\
\hline
\end{tabular}

Table 3.3.9-2 - Summary of Gasification Results

\begin{tabular}{|c|c|}
\hline Alloy & Average Metal Affected (microns) \\
\hline 310 & 0 \\
\hline 160 & 0 \\
\hline
\end{tabular}




\section{CONCLUSIONS}

Testing at NETL included inverted metal barrier filter, honeycomb barrier and fiber devices and provided the following conclusions:

1. Gaskets and fixturing for all SGDs were effective in preventing any by-pass leakage of fines.

2. The inverted metal barrier filter SGD blinded prematurely and permeability could not be recovered.

3. Honeycomb SGDs plugged completely upon exposure to fines.

4. Cracking of metal and ceramic honeycomb SGDs was attributed to manufacturing defects and fragile construction respectively.

5. The fine fiber SGD activated more quickly than the coarse fiber SGD upon exposure to fines.

Testing at STC included "catastrophic" and "nominal" filter failure conditions of both honeycomb and fiber SGDs and provided the following conclusions:

1. The metal honeycomb SGD was damaged in service - probably as a result of fuel burning.

2. The ceramic honeycomb SGD plugged effectively upon exposure to fines but damage in service confirmed fragile construction as noted in (4) above.

3. Fine fiber of $0.10 \mathrm{~mm}$ diameter is effective in preventing dust passage in a SGD while coarse fiber of $0.57 \mathrm{~mm}$ diameter is ineffective.

Optimization testing of improved ceramic honeycomb SGDs included silicon carbide units from two manufacturers and provided the following conclusions:

1. The units are durable up to service temperatures of $650^{\circ} \mathrm{C}$

2. The units plug rapidly upon exposure to fines and do not unplug upon backpulsing.

Exposures of fibers to oxidation and gasification conditions revealed:

1. Alloys 214 and FeCrAlY are superior in oxidation resistance to alloys 310 and 230.

2. Alloys 160 and 310 are both resistant to high temperature reaction in gasification conditions. 


\section{REFERENCES}

1. U.S. Patent No. 4,976,934 and work by R. D. Litt of Battelle indicating advantage of fine fiber over coarse fiber relative to particulate capture. 